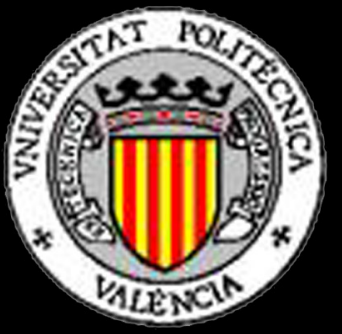

UNIVERSITAT

POLITÈCNICA

DE VALÈNCIA

Departamento de Biotecnología

"Análisis funcional del gen $E p 5 C$ y su implicación en los mecanismos de defensa en plantas".

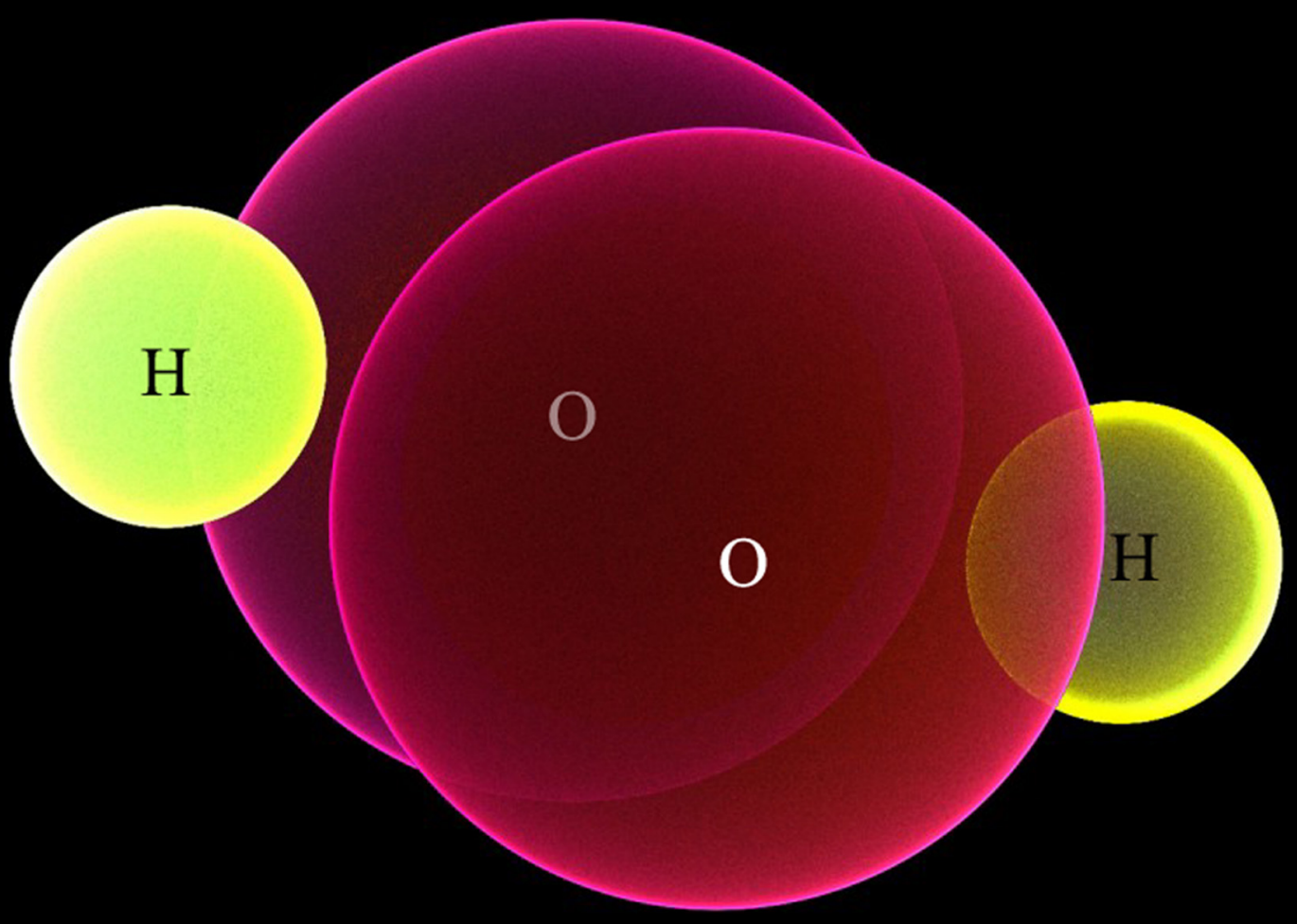

Alberto Coego González

Valencia, 2006 



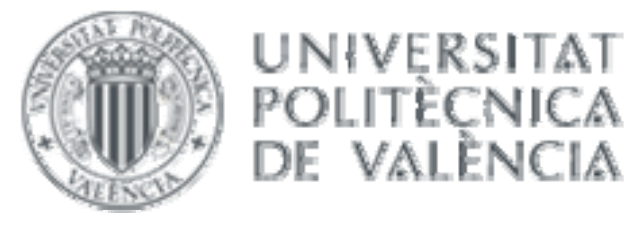

Departamento de Biotecnología

\title{
“Análisis funcional del gen Ep5C y su implicación en los mecanismos de defensa en plantas”
}

\author{
Alberto Coego González \\ TESIS DOCTORAL
}

Director:

Dr. Pablo Vera Vera

Valencia, 2006 

Universidad Politécnica de Valencia

Consejo Superior de Investigaciones Cientificas

INSTITUTO DE BIOLOGIA MOLECULAR Y CELULAR DE PLANTAS

Avenida de los Naranjos, s/n

Tel 34 (9) 63877730 - Fax 34 (9) 63877859

46022 Valencia España

Dr. D. Pablo Vera Vera, Catedrático de Bioquímica y Biología Molecular de la Universidad Politécnica de Valencia

\section{CERTIFICA:}

Que la presente memoria titulada "Análisis funcional del gen Ep5C y su implicación en los mecanismos de defensa en plantas" ha sido realizada por Alberto Coego González bajo mi dirección, y constituye su Memoria de Tesis para optar al grado de Doctor Ingeniero Agrónomo.

Para que así conste a todos los efectos oportunos, firma el presente certificado en Valencia, a dieciséis de junio de dos mil seis.

Fdo. Pablo Vera Vera 

A mis padres Gladys y Joaquin, a mi esposa Margarita, y a mis hijos Alejandro y Daniel. 



\section{Agradecimientos}

Durante todos estos años de trabajo en el laboratorio, he tenido la oportunidad de conocer y compartir con un número grande de personas a las cuales desearía agradecerles todo el apoyo que me han brindado desde mi llegada a este país y principalmente al IBMCP y sobre todo a quienes han contribuido a la culminación exitosa de este trabajo de investigación.

Sin lugar a dudas, a quien más debo agradecer es a mi director de tesis, el Doctor Pablo Vera por haberme dado la oportunidad de trabajar en su grupo y sobre todo por ser no solo un jefe, sino por darme también su apoyo en todos los momentos.

No podría dejar de mencionar en este momento a Esther Mayda, José Gadea, Enric Bellés, Lucia Jordá, Gema Ancillo, Concha Domingo, Dolores, Mireia Bordás, Mari Carmen Marquez, María Emilia Medina, Helena Olivares, Joaquin Fayos, Ismael Rodrigo, José María Bellés, Mónica Diez, Susana quienes desde un inicio me brindaron todo su apoyo y compañerismo tanto dentro como fuera del laboratorio y sin los cuales mi proceso de adaptación a este país hubiera resultado más difícil.

Merece un agradecimiento especial, mi gran amiga María José Gil Morrió, con quien he compartido todos estos años de trabajo y con la cual me unen muchos lazos de amistad y cariño. De igual manera mis más sinceras gracias a Puri y a Ernesto, ambos han sido muy importantes en mi vida desde que llegue a Valencia y con los cuales he compartido muchos ratos lindos. También hago extensivo este agradecimiento a Susi por todo el apoyo que me ha brindado y me sigue brindando hasta la fecha.

A José Luis y a Astrid tampoco podría dejar de mencionar, pues ambos han compartido todo mi trabajo desde mis comienzos, siendo 
participes del día a día en el laboratorio, tanto a nivel personal como profesional.

Para terminar una dedicación muy especial a la nueva generación incorporada en el grupo, en primer lugar y de manera muy especial a Vicentin por toda su ayuda y por brindarme siempre su amistad, a María José Castelló por soportarme, a mis colegas de las cervecitas de los viernes sobre todo Emilio, Jorge, Silvia y Brande, así como también a Albor, Elsa, Pablote y la gran Lorena. También quisiera incluir en este listado a Ana y María José Hernández, los dos últimos fichajes de Pablo Vera, que a pesar de haber compartido muy poco con ellas, me han ofrecido todo su apoyo.

A Brigitte Mauch Mani y a Victor Flors por haber colaborado en todos los experimentos con hongos fitopátogenos.

En fin deseo agradecer a todos aquellos que de una forma u otra han aportado su granito de arena en este trabajo. A todos muchas gracias por los momentos pasados.

Como no todo es trabajo en esta vida, no podría dejar de mencionar a mi Margarita y mucho menos a mis dos retoños, Ale y Dani. Tampoco podría olvidar a mis padres, y a mis amigos Hector, Eduardo, Pedro y Marcelo, todos ellos han sufrido las penas y glorias de toda esta etapa y sin los cuales no hubiera sido posible llegar al final.

A todo el personal de apoyo del invernadero y del IBMCP, a todos muchas gracias. 


\section{RESUMEN}

La mancha bacteriana causada por el patógeno Pseudomonas syringae $p v$. tomato ( $P$. s. tomato) es una de las enfermedades más devastadoras del cultivo del tomate. En este trabajo se demuestra que la sola inhibición de la expresión del gen Ep5C, que codifica una peroxidasa catiónica extracelular, es suficiente para conferir una marcada resistencia a P.s. tomato. Esta inhibición encontrada en las plantas de tomate produce una resistencia que no requiere la activación de las rutas de defensa descritas hasta ahora, controladas por el ácido salicílico y el ácido jasmónico. Así, la inhibición de este gen constituye una nueva herramienta genética para obtener plantas transgénicas resistentes a esta enfermedad. La temprana inducción del gen Ep5C está mediada por el $\mathrm{H}_{2} \mathrm{O}_{2}$, una especie reactiva de oxígeno generada durante el curso de $u$ interacciones planta-patógeno. Los mecanismos que controlan la resistencia de las plantas a patógenos necrotrofos constituye uno de los aspectos menos estudiados en la actualidad. La búsqueda de nuevos componentes genéticos que participan en la cascada de señalización de las plantas frente a patógenos constituye uno de los retos de la biología molecular moderna. En este trabajo llevamos a cabo un escrutinio, utilizando plantas transgénicas de Arabidopsis thaliana portadoras del gen de la $\beta$-glucoronidasa (GUS) como gen marcador bajo el control del promotor del gen Ep5C, en busca de mutantes alterados en la expresión de dicho gen. En el presente trabajo presentamos la identificación y caracterización de uno de los mutantes, en concreto el mutante ocp3 (overexpressor of cationic peroxidase 3), el cual presenta expresión constitutiva del gen GUS. Las plantas ocp3 muestran una elevada acumulación de $\mathrm{H}_{2} \mathrm{O}_{2}$, y se caracterizan por presentar expresión constitutiva de GST1 y PDF1.2, 
dos genes marcadores de la respuesta defensiva, pero sin embargo no muestra expresión de $P R-1$, un gen marcador dependiente de la ruta del ácido salicílico (SA). La característica más sobresaliente de las plantas ocp3 es sin duda su marcada resistencia a patógenos necrotrofos (Botrytis cinerea y Plectosphaerella cucumerina). Sin embargo la resistencia a patógenos biotrofos (Hyaloperonospora parasitica y Pseudomonas syringae pv. tomato DC3000) permanece inalterable en comparación con las plantas controles. La expresión de $P R-1$ en las plantas ocp3 tras la infección con Pseudomonas syringae pv. tomato DC3000 demuestra que efectivamente ocp3 no tiene afectada la ruta del SA. Los estudios de epistasia realizados con diferentes dobles mutantes entre ocp3 y pad4, nahG, npr1, ein2 jin1 o coi1 revelaron que la resistencia mostrada por ocp3 a patógenos necrotrofos es totalmente dependiente de la percepción del ácido jasmónico (JA) a través de COI1 e independiente de SA o etileno (ET)

El gen OCP3 codifica un factor de transcripción del tipo homebox que se expresa de manera constitutiva en plantas sanas pero que se reprime en respuesta a la infección por patógenos necrotrofos. Los resultados obtenidos en este trabajo sugieren que OCP3 constituye un factor importante en la ruta dependiente de COI 1 que media la resistencia a hongos necrotrofos. 


\section{RESUM}

La màcula bacteriana causada pel patògen Psedomonas syringae $p v$. tomato $(P$. s. tomato) és una de les malalties més devastadores del cultiu de la tomaca. En aquest treball es demostra que només la inhibició de l'expresssió del gen Ep5C, que codifica una peroxidasa catiònica extracel.lular, és prou per a conferir una marcada resistència a $P$. s. tomato. Aquesta inhibició a les plantes de tomaca produeix una resistència que no requereix l'activació de les rutes de defensa descrites fins ara, controlades per l'àcid salisílic i l'àcid jasmònic. Així, la inhibició d'aquest gen contitueix una nova ferramenta genètica per a obtindre plantes transgèniques resistents a aquesta enfermetat. La ràpida inducció del gen $E p 5 C$ està mediada per I' $\mathrm{H}_{2} \mathrm{O}_{2}$, una espècie reactiva d' oxigen generada durant el curs d' interaccions planta-patògen. Els mecanismes que controlen la resistència de les plantes front a patògens necròtrofs constitueix un dels aspectes menys estudiats en l'actualitat. La recerca de nous components genètics que paticipen en la ruta de senyalització de les plantes front a patògens constitueix un dels reptes de la biología molecular moderna. En aquest treball portarem a terme un escrutini, utilitzant plantes transgèniques d'A. thaliana portadores del gen de la $\beta$-glucoronidasa (GUS) com a gen marcador baix el control del promotor del gen Ep5C, per a la recerca de mutants alterats en l'expressió d'aquest gen. En aquest estudi presentem la identificació i caracterització d'un dels mutants, en concret el mutant ocp3 (overexpressor of cationic peroxidase 3) el qual presenta expressió constitutiva del gen GUS. Les plantes ocp3 mostren una alta acumulació d' $\mathrm{H}_{2} \mathrm{O}_{2}$, i es caracteritzen per presentar expressió constitutiva de GST1 i PDF1.2, dos gens marcadors de la resposta defensiva, però no obstant no mostra expressió de $P R-1$, un gen marcador dependent de la ruta de l'àcid salisílic (SA). La característica 
més destacada de les plantes ocp3 és sense dubte la seua marcada resistència a patògens necròtrofs (Botrytis cinerea i Plectosphaerella cucumerina). No obstant, la resistència a patògens biòtrofs

(Hyaloperonospora parasitica i Psedomonas syringae pv. tomato DC3000) permaneix sense alteració si comparem amb les plantes control. L'expressió de PR-1 en les plantes ocp3 després de la infecció amb Psedomonas syringae pv. tomato DC3000 demostra que ocp3 no té afectada la ruta del SA. Els estudis d'epistàsia realitzats amb diferents dobles mutants entre ocp3 i pad4, nahG, npr1, ein2 jin1 o coi1 revelaren que la resistència presentada per ocp3 a patògens necròtrofs és totalment dependent de la percepció de l'àcid jasmònic (JA) per mitjà de COI1 e independent de SA o etilé (ET).

El gen OCP3 codifica un factor de transcripció del tipus homeobox que s'expressa de manera constitutiva en plantes sanes però es reprimeix en resposta a la infecció per patògens necròtrofs. Els resultats obtinguts en aquest treball sugereixen que OCP3 constitueix un factor important en la ruta dependent de COI 1 implicada en la resistència a fongs necròtrofs. 


\begin{abstract}
Bacterial speck caused by pathogen Pseudomonas syringae $p v$. tomato ( $P$. s. tomato) is a devastating disease of tomato plants. Here we show that inhibition of Ep5C gene expression, which encodes a secreted cationic peroxidase, is sufficient to confer resistance against $P$. $S$. tomato. The inhibition of Ep5C protein accumulation in antisense tomato plants established resistance that was not accompanied by the preactivation of known defense pathways. Therefore, Ep5C inhibition represent a novel form of disease resistance based on a loss of a gene function which is required in the plant for successful infection by a compatible bacterial pathogen. Ep5C expression is rapidly induced by $\mathrm{H}_{2} \mathrm{O}_{2}$, a reactive oxygen intermediate normally generated during the course of a plant-pathogen interaction. The mechanisms controlling plant resistance to necrotrophic fungal pathogens are poorly understood. To identify novel plant components operating in pathogen-induced signalling cascades, we initiated a large-scale screen using Arabidopsis plants carrying the $\beta$-glucoronidase reporter gene under the control of the $\mathrm{H}_{2} \mathrm{O}_{2}$-responsive Ep5C promoter. Here we report the identification and characterization of a mutant, ocp3 (for overexpressor of cationic peroxidase 3 ) in which the reporter construct is constitutively expressed. Healthy ocp3 show increased accumulation of $\mathrm{H}_{2} \mathrm{O}_{2}$ and express constitutively the GST1 and PDF1.2 marker genes, but not the salicylic acid (SA)-dependent pathogenesis-related $P R-1$ gene. Strikingly, the ocp3 mutant shows enhanced resistance to the necrotrophic pathogens Botrytis cinerea and Plectosphaerella cucumerina . Conversely, resistance to virulent forms of the biotrophic oomycete Hyaloperonospora parasitica and the bacterial pathogen Pseudomonas syringae pv. tomato DC3000 remains unaffected in ocp3 plants when
\end{abstract}


compared to wild-type plants. Consistently whit this, ocp3 plants are not affected in SA metabolism and express normal levels of $P R$ genes after pathogen attack. To analyze signal transduction pathways where ocp3 operates, epistasis analyses between ocp3 and pad4, nahG, npr1, ein2 jin1 or coi1 were performed. These studies revealed that the resistance signalling to necrotrophic infection in ocp3 is fully dependent on the appropriate perception of jasmonic acid (JA) through COI1 and independent of the SA or ethylene (ET) signalling pathways.

The OCP3 gene encodes a homeodomain transcription factor that is constitutively expressed in healthy plants but repressed in response to infection by necrotrophic fungis. Together, these results suggest that OCP3 is an important factor for the COI1-dependent resistance of plants to infection by necrotrophic pathogens. 
Índice.

I. Introducción

1. Aspectos generales acerca de la interacción planta-patógeno. .....1

2. Etapas de señalización de la respuesta defensiva en plantas. .......4

2.1. Respuestas locales..........................................................................

2.1.1. Alteraciones en el flujo de iones y en los estados de fosforilación. . 4

2.1.2. Especies de Oxígenos Reactivas (ROS) .....................................8

2.1.3. Producción de Óxido Nítrico (NO) ...........................................14

2.1.4. Alteraciones de la pared celular............................................16

2.1.5. Respuesta Hipersensible (HR)........................................17

2.1.6. Producción de compuestos de bajo peso molecular con función

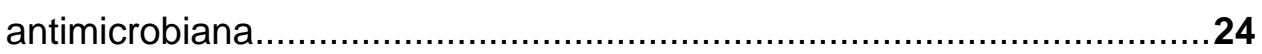

2.1.7. Activación de genes de defensa...............................................26

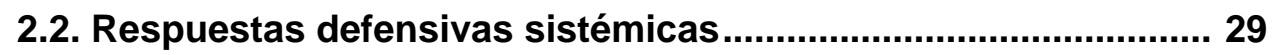

2.2.1. Respuestas sistémicas dependientes de SA: Resistencia Sistémica Adquirida (SAR). .....................................................29

2.2.1. Respuestas sistémicas dependientes de JA/ET: Resistencia sistémica Inducida (ISR) ............................................................ 31

3. Principales rutas de señalización defensiva.................................34

3.1. Ruta del Ácido Salićlico (SA) ................................................... 36

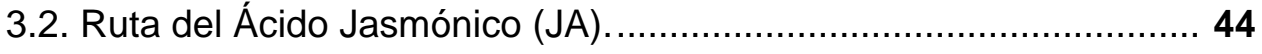

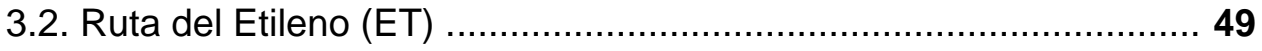

4. Interconexión entre las rutas defensivas...................................54 
$\underline{\text { Indice }}$

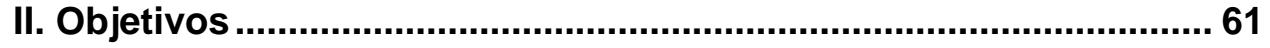

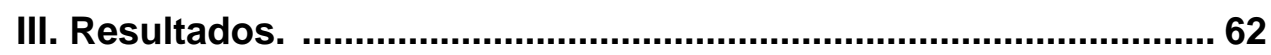

3a. Capitulo 1: The $\mathrm{H}_{2} \mathrm{O}_{2}$-regulated Ep5C gene encodes a peroxidase required for bacterial speck susceptibility in tomato. 63 3b . Capitulo 2: An Arabidopsis Homeodomain Transcription Factor, OVEREXPRESSOR OF CATIONIC PEROXIDASE 3, Mediates Resistance to Infection by Necrotrophic Pathogen.... 74

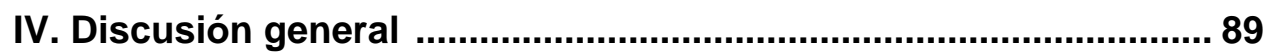

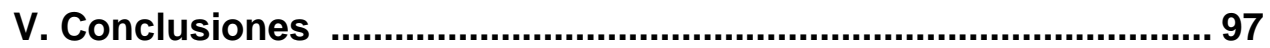

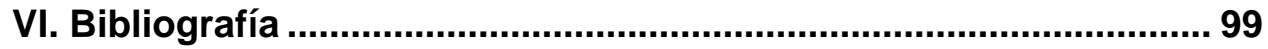


I. Introducción. 



\section{Introducción.}

\section{Aspectos generales acerca de la interacción planta-} patógeno.

Como parte del proceso evolutivo las plantas han desarrollado múltiples mecanismos que les han permitido adaptarse a diferentes entornos ambientales, y dentro de estos destacan aquellos que les permiten defenderse del ataque de patógenos. Algunos de estos mecanismos son constitutivos, es decir, se encuentran establecidos en la planta antes de la llegada del patógeno. Así, la existencia en las plantas de una serie de barreras defensivas de tipo estructural, tales como la propia pared celular o la cutícula, dificultan la entrada de diferentes agentes invasores, impidiendo el acceso del patógeno al citoplasma celular y por tanto a los nutrientes, siendo este mecanismo particularmente relevante en el caso de patógenos biotrofos (MauchMani y Slusarenko, 1993). Existen otros mecanismos de defensa más sofisticados consistentes en ciertos cambios bioquímicos (síntesis de diferentes compuestos) que se activan de forma específica tras la percepción de un patógeno y que proporcionan protección no sólo en el sitio de infección, sino también en los tejidos dístales (Shah et al., 1999). Dentro de estos compuestos sintetizados de novo encontramos a las fitoalexinas, las fitoancipinas, las proteínas relacionadas con la patogenicidad (PRs), algunos péptidos antibióticos y determinadas especies de oxígeno reactivas. Muchos de estos compuestos proporcionan a la planta una defensa efectiva de amplio espectro (Yoder et al., 1993; Jackson y Taylor, 1996; Yoder et al., 2001). El conjunto de estos mecanismos constituye la base de la inmunidad natural de las plantas a un gran número de patógenos. Este fenómeno 


\section{$\underline{\text { Introducción }}$}

de inmunidad natural, que permite responder y hacer frente a una infección, viene determinada en muchos casos por determinantes genéticos tanto por parte de la planta (genes de resistencia " $R$ ") como del patógeno (genes de avirulencia "Avr") (Staskawicz et al., 1995). La interacción específica de ambos productos génicos es la responsable de la activación de la respuesta defensiva, tal y como propuso Flor en 1971 al establecer las bases teóricas para la hipótesis de la interacción "gen a gen". Cuando se produce este reconocimiento específico entre los productos de los genes de resistencia $R$ y los resultantes de la expresión de los genes de avirulencia Avr se activa una cascada de señalización que finalmente dará lugar al rápido colapso o muerte celular de aquellas células y tejidos situados en el sitio de inoculación, impidiéndose de este modo la posterior propagación del agente infeccioso. Este mecanismo, que se conoce como respuesta hipersensible o HR (Agrios, 1988; Mathieu, 1991; Goodman y Novacky, 1994; Dangl et al., 1996), constituye uno de los mecanismos inducibles más sofisticados que han desarrollado las plantas para detener el avance de un patógeno. La HR, por tanto, es un mecanismo genéticamente programado de respuesta rápida y que trae consigo la activación a nivel local de un gran número de genes que provocan el colapso y muerte de las células más cercanas al sitio de entrada del patógeno. La activación transcripcional de numerosos genes durante el desarrollo de la HR es esencial para la detención y progresión de la infección patogénica. Este fenómeno de muerte celular programada que acontece en el lugar de entrada del patógeno provoca la aparición posterior de una resistencia sistémica no específica o resistencia sistémica adquirida "SAR" (Ryals et al., 1996) a lo largo de toda la planta. La SAR se caracteriza por ser de duración larga (desde días hasta meses dependiendo del patógeno) y por su inespecificidad al 
proporcionar resistencia a un amplio espectro de patógenos. Esta protección acontece en los tejidos distales a los puntos de infección inicial y resulta funcional frente a posibles infecciones secundarias causadas por un amplio espectro de patógenos (Ryals et al., 1996; Delaney, 2000). La SAR se caracteriza por la acumulación de la molécula señal ácido salicílico (SA) y por la activación de la expresión selectiva y coordinada de un grupo característico de genes de defensa (genes SAR) que estarán directamente implicados en el establecimiento y mantenimiento de dicha resistencia (Dong, 1998; Glazebrook, 1999; Glazebrook, 2001).

En el caso de que no se produzca la interacción "gen a gen", bien por la falta de un gen $R$, o de un gen Avr, o simplemente por ineficiencia en dicho reconocimiento, la interacción se dice que es compatible y el patógeno escapa a la respuesta defensiva, invadiendo la totalidad del órgano afectado o en el peor de los casos la planta entera (Staskawicz et al., 1995). En el caso contrario de que exista este reconocimiento "gen a gen" se dice que la interacción planta-patógeno es incompatible y consecuentemente se activa la respuesta HR y la enfermedad no tiene lugar.

Como comentábamos anteriormente el reconocimiento del patógeno por parte de la planta resulta en el inicio de un complejo proceso de señalización y transducción de señales a nivel celular. Estos cambios comienzan a producirse de manera local en la zona donde se ha producido la invasión del patógeno y más tarde se extienden de manera sistémica por toda la planta. Este complejo mecanismo de respuesta de la planta tiene lugar en dos etapas bien diferenciadas. 


\section{Etapas de señalización de la respuesta defensiva en plantas.}

\subsection{Respuestas locales.}

\subsubsection{Alteración en el flujo de iones y en los estados de} fosforilación.

A los pocos minutos de la percepción de la presencia del agente invasor comienzan a producirse en la célula vegetal alteraciones a nivel de la membrana plasmática. Esta respuesta provoca cambios en la actividad de la bomba $\mathrm{H}^{+}$-ATPasa (modificaciones covalentes del tipo fosforilación-desfosforilación), mediados por proteínas quinasas y fosfatasas (Scheel, 1998), que traen consigo una alteración del potencial de membrana, con el consiguiente cambio en el flujo de distintos iones $\left(\mathrm{H}^{+}, \mathrm{K}^{+}, \mathrm{Cl}^{-}\right.$y $\left.\mathrm{Ca}^{2+}\right)$ a través de la membrana plasmática (Dangl et al., 1996; Scheel, 1998). Estas modificaciones producidas en el cambio de iones conducen a la entrada de $\mathrm{Ca}^{2+}$ desde los espacios extracelulares y la salida de $\mathrm{K}^{+} \mathrm{y} \mathrm{Cl}^{-}$al exterior celular. Como consecuencia de esta alteración en la permeabilidad de la membrana plasmática se activan una serie de mecanismos que generan diferentes señales, que conducen en último término a la inducción de la expresión de múltiples genes de defensa (Jones et al., 2000 y Grant y Loake, 2000). Sin embargo, estos cambios en la expresión diferencial de genes dependen en gran medida del tipo de elicitor. En un principio, el término elicitor se utilizó para denominar moléculas capaces de inducir la producción de fitolaexinas, pero en la actualidad se utiliza normalmente para compuestos que activan la defensa de las plantas (Ebel y Cosio, 1994; Hahn, 1996; Nürnberger, 1999). En sentido mas amplio, el 
concepto de elicitor incluye tanto sustancias de origen patogénico (elicitores exógenos) como moléculas de las plantas liberadas por la acción de los patógenos (elicitores endógenos) (Ebel y Cosio, 1994; Boller, 1995). Se ha propuesto que ciertos elicitores (productos de genes Avr) causan una activación de la bomba de $\mathrm{H}^{+}$, acidificando el medio e hiperpolarizando la membrana (Blumwald et al., 1998). Tratamientos realizados en suspensiones celulares de tomate portadoras del gen Cf5 con el elicitor AvrCf5, indujeron una fosforilación diferencial de proteínas de la membrana plasmática y en particular de una $\mathrm{H}^{+}$-ATPasa (Vera-Estrella et al., 1994). Este mecanismo de modificación de la actividad $\mathrm{H}^{+}$-ATPasa mediante fosforilacióndesfosforilación, conduce a la producción de un estallido oxidativo en el que se producen especies de oxígeno reactivas (ROS) tales como el ión superóxido y el peróxido de hidrógeno (Lamb y Dixon, 1997; Jabs et al., 1997; Scheel, 1998; Alvarez et al., 1998).

Dentro de los iones acumulados en el citosol, el $\mathrm{Ca}^{2+}$ parece ser uno de los más sobresalientes. Un incremento transitorio en los niveles de $\mathrm{Ca}^{2+}$ intracelular parece estar mediando la producción de especies de oxígeno reactivas, consecuencia de la activación de una quinasa dependiente de $\mathrm{Ca}^{2+}$ implicada en la fosforilación de componentes del complejo NADPH oxidasa. Por otra parte se postula que el $\mathrm{Ca}^{2+}$ podría estar implicado en la deposición de lignina y de callosa (un polímero de 1,3- $\beta$ glucano) en el plasmodesmo, constituyendo así una barrera física que impide la penetración de algunos hongos. Además se ha descrito que estos polímeros de lignina y callosa bloquean el movimiento célula a célula de ciertos virus y la síntesis de fitoalexinas (Blumwald et al., 1998.

Existen numerosas evidencias que indican que tanto las quinasas como las fosfatasas desempeñan un papel esencial, no sólo en los 
primeros instantes del reconocimiento entre el huésped y el patógeno, sino también en los eventos posteriores que tienen lugar durante la cascada de señalización que conducirá a la activación de la respuesta defensiva de la planta (Yang et al., 1997). El aislamiento y caracterización del gen Pto de tomate, el cual codifica una serina/treonina quinasa (Martin et al., 1993; Martin, 1999), y de Xa21 de arroz, que codifica un receptor transmembrana rico en leucina y con un dominio quinasa (Song et al., 1995), así como los experimentos farmacológicos realizados con inhibidores de la fosforilación de proteínas también demuestran el papel que juegan estas modificaciones covalentes post-traduccionales en la activación de los mecanismos de respuestas tempranas (Ligterink et al., 1997 Scheel, 1998; Zhang y Klessig, 1998; Romeis et al., 1999).

Muchos de los elicitores capaces de activar el programa defensivo están constitutivamente presentes en la pared celular del patógeno como componentes estructurales, por ejemplo glucanos y fragmentos de quitina, la proteína flagelina y determinados lipopolisacáridos (LPS). Algunos elicitores son claves al funcionar como determinantes de la virulencia del patógeno, por ejemplo harpins y productos de genes avr. La función de otros elicitores sigue siendo desconocida. Por otra parte, los principales elicitores de ciertas interacciones planta-patógeno parecen derivar de la degradación de las paredes celulares de la planta huésped y su liberación es provocada por enzimas del patógeno. Estas enzimas, que son frecuentemente consideradas también como factores de virulencia y que además proporcionan nutrientes al patógeno atacante, liberan fragmentos pécticos (oligogalacturónidos, OGAs) que pueden actuar como elicitores endógenos (Ebel y Cosio, 1994; Shibuya y Minami, 2001). 
No sorprende, por tanto, que la naturaleza y estructura química de los elicitores sea muy variada, incluyendo oligosacáridos, péptidos, proteínas y lípidos. El hecho de que entre esta amplia gama de compuestos no exista ningún motivo estructural común, sugiere que las plantas tienen una capacidad, también amplia, de reconocimiento de estructuras moleculares extrañas, como señales inductoras de sus defensas.

La mayor parte de los elicitores descritos hasta ahora son componentes o productos de hongos o bacterias, pero también se han descrito elicitores presentes en virus o producidos por insectos. Los insectos masticadores producen heridas que activan respuestas defensivas, y además producen otros elicitores más específicos de la defensa vegetal. Los elicitores derivados de insectos mejor caracterizados son formas conjugadas de ácidos grasos con aminoácidos (FACs) de la oruga de Manduca sexta. La herida, junto con los FACs, induce la producción de compuestos volátiles que activan genes de defensa, aunque también actúan como una defensa indirecta para atraer depredadores de orugas (Kessler y Baldwin, 2002).

Sustancias tipo elicitores están implicadas también en el establecimiento de interacciones simbióticas, como por ejemplo en el caso de leguminosa-Rhizobium (Cullimore et al., 2001). La bacteria produce señales químicas o factores de nodulación (Nod) responsables del reconocimiento de la bacteria por la planta y de la subsiguiente nodulación.

Como se describió anteriormente, hay una serie de componentes denominados elicitores generales que están presentes en muchos patógenos y son reconocidos por una amplia variedad de plantas. Recientes avances en la caracterización de respuestas a uno de estos 


\section{$\underline{\text { Introducción }}$}

elicitores, la flagelina, ha contribuido decisivamente al conocimiento de la inmunidad vegetal (Felix et al., 1999; Meindl et al., 2000; Asai et al., 2002). La flagelina representa la unidad estructural proteica del filamento del flagelo de las eubacterias. Las flagelinas de un conjunto de bacterias Gram-negativas tienen actividad elicitora, excepto aquéllas de organismos altamente especializados tipo Rhizobium meliloti y Agrobacterium tumefaciens (Felix et al., 1999). Se demostró con Pseudomonas syringae (Felix et al., 1999) que la flagelina induce la alcalinización del medio, producción de etileno en cultivos de células de tomate, deposición de callosa y activación de genes de defensa en Arabidopsis (Gomez-Gomez et al., 1999). Estos conjuntos de moléculas, denominados patrones moleculares asociados a patógenos (PAMPs), tras ser reconocidas por los correspondientes receptores, activan la respuesta inmune y la correspondiente producción de compuestos antimicrobianos. Por tanto, parece ser que el sistema inmune de las plantas guarda cierta analogía con el sistema inmune innato de los animales, aunque su naturaleza sea distinta, pueden ser activados por moléculas elicitoras semejantes (Nürnberger y Brunner, 2002).

\subsubsection{Especies de Oxígeno Reactivas (ROS).}

El reconocimiento de un patógeno potencial da lugar a varias respuestas tempranas que incluyen, además del flujo rápido de iones a través de la membrana plasmática, una alteración del metabolismo del oxígeno que produce especies de oxígeno reactivas (ROS). Las ROS son por tanto consideradas como moléculas señalizadoras de la repuesta defensiva de las plantas ante el ataque de patógenos. La 
sobreproducción y acumulación de ROS constituye uno de los procesos más rápidos que tienen lugar tras el reconocimiento del patógeno. $A$ dicho fenómeno se le conoce con el nombre de explosión oxidativa o "oxidative burst" (Doke et al., 1983; Apostol et al., 1989; Tenhaken et al., 1995; Xing et al., 1997; Lamb y Dixon, 1997). Estudios realizados con suspensiones celulares (Apostol et al., 1989) permitieron cuantificar por primera vez la cinética del proceso de producción de ROS. Sin embargo, su existencia había sido descrita con anterioridad en ensayos realizados con tubérculos de papa infectados con Phytopthora infestans, donde se observó un incremento en los niveles de ión superóxido (Doke et al., 1996). Desde entonces esta respuesta se ha venido observando en un gran número de interacciones patogénicas tanto de naturaleza bacteriana y fúngica como vírica (Sutherland, 1991).

La generación de ROS, y en particular la generación de $\mathrm{H}_{2} \mathrm{O}_{2}$ en la célula infectada, tiene un comportamiento bifásico bien diferenciado. La primera fase se inicia a los pocos minutos del reconocimiento del patógeno; este reconocimiento provoca un estallido oxidativo débil y transitorio, que no tiene un efecto directo sobre la viabilidad celular (Levine et al., 1994; Baker et al., 1995; Draper et al., 1997). La segunda fase ocurre entre la primera y la tercera hora después de haberse producido dicho reconocimiento, es un estallido oxidativo mucho más intenso y prolongado y es crítico para el establecimiento de la resistencia y la activación de una respuesta hipersensible (Levine et al., 1994; Lamb et al., 1997; Feys y Parker, 2000). Ambas fases parecen estar reguladas de forma independiente. Se cree que esa primera fase podría constituir un sistema inespecífico de alerta rápida ante una situación general de estrés, mientras que la segunda fase se activaría específicamente ante reacciones de tipo incompatible, contribuyendo a la muerte celular característica de una HR y/o provocando la 


\section{$\underline{\text { Introducción }}$}

señalización y activación de los posteriores mecanismos de defensa (Baker y Orlandi, 1995).

El mecanismo por el cual ocurre este rápido incremento en los niveles de ROS no está del todo esclarecido. Por analogía con los modelos de animales, se ha propuesto que se trata de un fenómeno que acontece a los pocos minutos de detectarse la presencia del patógeno y estaría regulado por la activación rápida del complejo enzimático NADPH oxidasa. Dicho complejo está formado por varias subunidades proteicas que se asocian a la membrana plasmática y que transfieren electrones desde el interior de la membrana al oxígeno molecular en el exterior. Ello resultaría en la producción de ión superóxido que posteriormente se dismutaría a peróxido de hidrógeno generando la posterior aparición transitoria de otras especies de oxígeno activas (Doke et al., 1996; Lamb et al., 1997; Ogawa et al., 1997; Del Río et al., 1998; Potikha et al., 1999; Pei et al., 2000; Grant et al., 2000). Además, en las plantas existen otros compartimentos celulares, tales como las mitocondrias, los cloroplastos y los peroxisomas, en los que también tiene lugar la generación de ROS (Seo et al., 2000; Dat et al., 2000; Corpas et al., 2001).

En células animales se sabe que el complejo NADPH oxidasa está compuesto por dos polipéptidos asociados a la membrana (gp91-phox y gp22-phox) que se activan cuando otras tres proteínas del citosol (p47-phox, p67-phox y rac) se unen a los componentes de la membrana (Jones, 1994; Henderson y Chappel, 1996). En plantas se han identificado algunas proteínas homólogas a las del complejo NADPH oxidasa de animales (Desikan et al., 1996; Xing et al., 1997; Potikha et al., 1999) y algunos de los genes ya han sido clonados y secuenciados (Keller et al., 1998; Torres et al., 1998) y en la actualidad están siendo estudiados de forma intensa. Asimismo, se sabe de la existencia de una 
proteína denominada Rac que interviene activamente en los programas de muerte celular (Kawasaki et al., 1999) y que gp91-phox podría estar regulada por los niveles de $\mathrm{Ca}^{2+}$ (Keller et al., 1998).

El ión superóxido $\left(\mathrm{O}_{2}{ }^{-}\right)$producido extracelularmente por el complejo NADPH oxidasa es rápidamente dismutado, ya sea de forma no enzimática o mediante la acción de la superóxido dismutasa (SOD), a peróxido de hidrógeno $\left(\mathrm{H}_{2} \mathrm{O}_{2}\right)$, que por sus características propias puede atravesar la membrana biológica y señalizar muchos procesos intracelulares. El $\mathrm{H}_{2} \mathrm{O}_{2}$ además, también puede ser producido durante la respuesta defensiva por oxalato oxidasas (Zhang et al.,1995) y peroxidasas de la matriz extracelular (Bolwell et al., 1995). El incremento en los niveles de acumulación de ROS parece estar asociado a varios de los procesos que acompañan a la respuesta defensiva. Existen numerosos estudios en los cuales se ha descrito que el $\mathrm{H}_{2} \mathrm{O}_{2}$ podría estar implicado en el refuerzo de la pared celular (contribuyendo al entrecruzamiento de ciertas proteínas ricas en prolinas e hidroxiprolinas) y en el entrecruzamiento y polimerización de monómeros de lignina mediado por peroxidasas o simplemente participando en la activación de la expresión de genes protectores (como la GST, enzima encargado de detoxificar hidroperóxidos lipídicos) y la activación de la muerte celular programada en la respuesta hipersensible (HR) por la acción conjunta con el óxido nítrico y del $\mathrm{O}_{2}^{-}$(Delledonne et al., 1998). Además en varias ocaciones se ha postulado que un aumento en los niveles de ROS podría tener un efecto antimicrobiano directo (Wu et al., 1995; Peng y Kuc, 1992).

La reactividad del $\mathrm{H}_{2} \mathrm{O}_{2}$ y el $\mathrm{O}_{2}^{-}$es relativamente moderada, sin embargo el daño celular producido por las ROS se debe a la conversión de estas dos especies en otras más reactivas, tales como los radicales hidroperóxidos $\left(\mathrm{HO}_{2}^{-}\right)$y los radicales hidróxilos $\left(\mathrm{OH}^{-}\right)$. Dichas especies 


\section{$\underline{\text { Introducción }}$}

son capaces de convertir ácidos grasos de la membrana, como el linolénico, linoléico y araquidónico, en peróxidos lipídicos, con el consiguiente daño a la correcta funcionalidad de la membrana que esto supone. Asimismo, también pueden dañar proteínas y ácidos nucleicos, afectando gravemente al correcto funcionamiento de la célula vegetal (Levine et al., 1994).

Además de la activación del complejo NADPH oxidasa se han propuesto otros sistemas para la producción de ROS. Entre ellos podemos destacar la presencia de algunas peroxidasas de pared que actúan como NADH oxidasas (Peng y Kuc, 1992); de lipoxigenasas (Chamulitrat et al., 1991) y de una oxalato oxidasa que produce $\mathrm{H}_{2} \mathrm{O}_{2}$ a partir de ácido oxálico y cuyos niveles de expresión aumentan en condiciones patogénicas (Zhang et al., 1995), o también por inhibición de las enzimas encargadas de eliminar dichos productos en condiciones normales (Chen et al., 1993; Durner y Klessig, 1995).

El mecanismo de defensa basado en la liberación rápida de ROS no está limitado a reacciones patogénicas incompatibles. Como hemos visto, el primer aumento de $\mathrm{H}_{2} \mathrm{O}_{2}$ se produce también ante reacciones compatibles y, como se había demostrado con anterioridad, ante estímulos de tipo mecánico (Yahraus et al., 1995). Además se han descrito aumentos en los niveles de ROS al exponer las plantas a diferentes tipos de situaciones estresantes, como exposición a la luz UV, herbicidas, heridas, ozono, sequía o fluctuaciones de temperatura (Scandalios, 1992; Mittler y Zilinskas, 1994; Prasad et al., 1994). Todo ello sugiere que la producción de ROS por las plantas no es algo específico de reacciones patogénicas sino que constituye quizás un sistema general de alarma que sirve a la planta para poner en marcha su complejo mecanismo de rutas defensivas que prevengan de cualquier tipo de estrés. 
Independientemente de cual sea el mecanismo por el que se genera el $\mathrm{H}_{2} \mathrm{O}_{2}$, el resultado es su acumulación en el apoplasto, y dado que es capaz de atravesar por difusión la membrana plasmática, su acumulación final en el interior de la célula. Muchas son las funciones que se le atribuyen al aumento de $\mathrm{H}_{2} \mathrm{O}_{2}$. En primer lugar se le atribuye una actividad antimicrobiana directa (Levine et al., 1994; Baker y Orlandi, 1995). Durante la fagocitosis de bacterias por los neutrófilos, la acumulación de $\mathrm{H}_{2} \mathrm{O}_{2}$ en una vesícula permite alcanzar concentraciones que resultan tener un efecto antimicrobiano. Sin embargo, como las células vegetales son incapaces de formar dichas estructuras, las concentraciones de $\mathrm{H}_{2} \mathrm{O}_{2}$ que se alcanzan no son tan elevadas y su papel como agente antimicrobiano directo dependería de la susceptibilidad de cada patógeno. Algunos estudios realizados con cultivos celulares han permitido cuantificar la concentración de $\mathrm{H}_{2} \mathrm{O}_{2}$ que se libera al medio extracelular durante una interacción planta-patógeno. La cuantía de estos niveles parece estar oscilando entre 0,05 mM (Nürnberger et al., 1994) y 1.2 mM (Legendre et al., 1993), niveles que parecen ser suficientes para inhibir el crecimiento de algunos fitopatógenos (Wu et al., 1995; Peng y Kuc, 1992). Sin embargo, todavía falta por demostrar de manera directa el papel del $\mathrm{H}_{2} \mathrm{O}_{2}$ como antimicrobiano directo durante las infecciones patogénicas en plantas.

Recientemente se ha descrito que el $\mathrm{H}_{2} \mathrm{O}_{2}$ media o participa en el mecanismo de apertura y cierre de los estomas a través de la activación de canales de calcio, lo cual limitaría también la entrada de ciertos patógenos (Pei et al., 2000). Además se cree que pueda ser un potente activador de ciertas MAP quinasas (e.g. WIPK), que son proteínas que se inducen en respuesta al ataque por patógenos (Bolwell, 1999). Por otra parte, el $\mathrm{H}_{2} \mathrm{O}_{2}$ induce la actividad de la enzima ácido benzoico 2- 


\section{$\underline{\text { Introducción }}$}

hidroxilasa (BA 2-H) la cual está involucrada en la biosíntesis del ácido salicílico (SA).

\subsubsection{Producción de óxido nítrico (NO).}

El NO también es una de las especies de nitrógeno reactivas que participa como molécula señalizadora en varios de los procesos relacionados con la respuesta defensiva. También se ha descrito el papel del NO en la activación del proceso de muerte celular asociado a la HR (Romero-Puertas et al., 2004; Zeier et al., 2004). En mamíferos se conoce que juega un papel fundamental como regulador de varios procesos biológicos que están involucrados en la respuesta inmune a nivel del sistema nervioso y del sistema vascular. De los experimentos realizados en modelos animales se conoce que el NO está también relacionado con los procesos inflamatorios y con los programas de muerte celular programada (Stamler, 1994; Schmidt, 1994; Mayer y Hemmes, 1997; Wendehenne et al., 2001). El NO conduce a la generación de peroxinitritos (ONOO '), potentes agentes oxidantes que se forman por la combinación del $\mathrm{NO}$ con el $\mathrm{O}_{2}{ }^{-}$. Este peroxinitrito formado durante la respuesta inflamatoria causa una gran cantidad de efectos tóxicos, incluyendo la peroxidación de lípidos y la muerte celular (Radi et al., 1991; Stamler et al., 1992; Stamler, 1994). La generación de NO y su participación como molécula reguladora no está limitada a las células animales, sino que la síntesis y acumulación de este compuesto ha sido descrita también en las plantas, en donde el NO desempeña un papel fundamental en diversas funciones fisiológicas que comprenden desde el desarrollo hasta la respuesta de defensa (Dangl, 1998; Durner y Klessig, 1999; Beligni y Lamattina, 2000). 
En plantas, el reconocimiento de un patógeno avirulento también va acompañado de la síntesis de NO (Durner y Klessig, 1999). Se ha demostrado que el NO tiene la capacidad de potenciar la muerte celular producida por el incremento de los niveles de ROS debido a que se une a los grupos hemo de ciertas proteínas (catalasas y ascorbato peroxidasa) inhibiendo de esta forma su actividad detoxificadora de $\mathrm{H}_{2} \mathrm{O}_{2}$. Finalmente se ha propuesto que la participación de $\mathrm{NO}$ en el proceso de muerte celular se produce como consecuencia de su capacidad para inhibir la actividad de enzimas implicadas en la detoxificación de ROS, tales como la aconitasa citosólica que actúa en la regulación del metabolismo del hierro (Navarre et al., 2000). El exceso de hierro libre potenciaría el efecto tóxico que ejercen las especies activas de oxígeno, a través de su participación en la reacción de Fenton, en la que se generan radicales de alta toxicidad, tales como el radical hidróxilo (Stamler et al., 1994; Navarre et al., 2000).

Aún no está claro si el NO o sus derivados tienen un efecto tóxico directo sobre los patógenos, aunque se ha visto que el NO así como el peroxinitrito (ONOO) inhiben el crecimiento "in vitro" de cepas de Pseudomonas syringae pv phaseolicola, y que este efecto se previene por urato, un secuestrador del peroxinitrito (Alamillo y García, 2001). Experimentos realizados con inhibidores de la síntesis de NO refuerzan la idea del papel sinérgico que juega éste con los ROS en la activación de un amplio repertorio de proteínas relacionadas con la respuesta defensiva de las plantas (Delledonne et al., 1998; Durner et al., 1998). Recientemente también se ha demostrado en plantas que el NO y los ROS pueden generar peroxinitritos, los cuales participan también de forma activa en los programas de muerte celular y, por tanto, inhibiendo el avance del patógeno (Durner et al., 1999). 


\subsubsection{Alteraciones de la pared celular.}

El $\mathrm{H}_{2} \mathrm{O}_{2}$ generado en la superficie celular como consecuencia de la explosión oxidativa es el responsable del entrecruzamiento oxidativo mediado por peroxidasas entre los componentes estructurales de la pared (posiblemente mediante enlaces isoditirosina inter e intramoleculares). Un incremento en los niveles de $\mathrm{H}_{2} \mathrm{O}_{2}$ contribuye a reforzar la estructura de la pared celular mediada por la acción de peroxidasas. Estas modificaciones hacen que la pared se vuelva más refractaria a la digestión por enzimas líticos microbianos y sirva para frenar la entrada del patógeno cuando aún las defensas de la planta dependientes de la activación de la maquinaria transcripcional no han actuado (Bradley et al.,1992; Brisson et al., 1994). Asimismo, la posterior síntesis y secreción de nuevos polímeros tales como callosa, lignina y proteínas de pared (ejemplo glicoproteínas ricas en prolina, HRGP) favorece la formación de nuevos entrecruzamientos con los elementos preexistentes dando lugar a un refuerzo adicional de la pared (Hammond-Kosack y Jones, 1996; Kawano, 2003).

Como se ha comentado, muchas proteínas estructurales de la pared celular de las plantas, HRGP (Glicoproteínas ricas en hidroxiprolinas) y GRP (Glicoproteinas ricas en prolinas) entre otras, son activadas a diferentes niveles ante una infección. También la inducción de determinadas enzimas implicados en el metabolismo de la pared celular (callosa sintasa, cinamil alcohol deshidrogenasa o peroxidasas), tienen como función fortalecer o dar rigidez a la pared celular con el fin de detener el avance del patógeno (Bowles, 1990; Showalter, 1993; Domingo et al., 1994). 
Existen otras proteínas extracelulares denominadas proteínas inhibidoras de poligalacturonasas (PGIPS) que también contribuyen a la respuesta defensiva de las plantas a nivel de la pared celular. Estas proteínas contienen un motivo LRR que inhibe a ciertas poligalacturonasas (PGs) presentes en una subclase específica de patógenos necrotróficos cuya función es degradar la pared celular de la planta. Las PGIPs posiblemente participen retardando la función de las PGs, y como resultado se produce un incremento en los niveles de poligalactúronidos con cadenas de más de ocho unidades, los cuales constituyen otra de las señales adicionales que activan mecanismos de defensa pues inducen la producción de ciertas PRs (quitinasas, glucanasas, inhibidores de proteasas) y algunas fitoalexinas (Orozco et al., 2001).

\subsubsection{Respuesta Hipersensible (HR).}

Como se ha comentado, tras el reconocimiento entre los productos de los genes $R$ de resistencia de la planta y Avr de los factores de avirulencia del patógeno se desencadena la rápida activación de la respuesta defensiva de la planta. Este modelo denominado gen a gen, fue propuesto por Flor (1971) y ha sido confirmado posteriormente en numerosas interacciones planta-patógeno (Innes, 1998). Generalmente tanto los alelos $R$ como los Avr son dominantes, y cuando se establece el reconocimiento la planta es resistente y el patógeno avirulento. Ello conduce a una interacción denominada incompatible. Con cualquiera otra combinación génica la interacción resultará compatible, la planta será susceptible y el 


\section{$\underline{\text { Introducción }}$}

patógeno virulento. En una interacción compatible, el patógeno inicia la infección, en la que puede multiplicarse y progresar sistémicamente por todos los tejidos provocando el desarrollo de la enfermedad. Sin embargo, en el caso de una interacción incompatible el patógeno no logra progresar, debido a que la planta reacciona restringiendo la dispersión del mismo (Keen, 1990; van Kan et al., 1992). Este proceso de infección de la planta por un patógeno produce una muerte celular localizada en el sitio de infección. Esta rápida respuesta se denomina respuesta hipersensible (HR) y acontece de forma macroscópica 12-48 horas después de la infección, pudiéndose observar que las células próximas a los haces vasculares presentan una mayor hipersensibilidad al desarrollo de este tipo de muerte que el resto de células del mesófilo. Este fenómeno podría prevenir la posible expansión de los patógenos, impidiéndoles penetrar en el sistema vascular y extenderse así por toda la planta (Pennell y Lamb, 1997). Del mismo modo, se ha observado que la inoculación con un patógeno activa también la muerte de algunas células en hojas distales que no han sido inoculadas, este efecto se conoce como microHR (Álvarez et al., 1998) y no puede apreciarse macroscópicamente. En ausencia de la elicitación de la HR, gran parte de la respuesta defensiva no tiene lugar y por lo tanto se extiende la infección desencadenando el desarrollo de la enfermedad.

En los últimos años, se ha abordado la clonación de numerosos genes de avirulencia a partir de diversos patógenos, así como genes de resistencia procedentes de diversas especies vegetales. La clonación de los genes $R$ revela la existencia de un número limitado de motivos estructurales (Hammond-Kosac y Parker, 2003). Estos motivos incluyen dominios posiblemente implicados en el reconocimiento o en la interacción con los factores de avirulencia y dominios de señalización. 
Resultados recientes han mejorado significativamente el conocimiento de los mecanismos de la percepción de elicitores y el desarrollo de la resistencia a las enfermedades. En este sentido, es interesante resaltar, que en muchas interacciones planta-patógeno y en particular aquellas específicas en que el agente patogénico es una bacteria, el reconocimiento de productos del gen $A v r$ por el gen $R$ parece tener lugar intracelularmente (Nürnberger, 1999; Bonas y Lahaye, 2002). En ellas están frecuentemente implicadas proteínas con dominios NB-LRR (nucleotide binding-leucine rich repeat) y extremos amino terminales variables. Las proteínas NB-LRR tienen dominios estructurales comunes con proteínas animales implicadas en los procesos de inmunidad innata (Moffett et al., 2002). El dominio LRR muy posiblemente está involucrado en interacciones entre proteínas, mientras que el dominio NB estaría más directamente relacionado con señalización.

No todas las proteínas $\mathrm{R}$ son intracelulares, algunas parecen actuar como receptores de la superficie celular. Los genes $\mathrm{R}$ del tipo NB-LRR a su vez se dividen en dos grupos según la presencia de dominios adicionales en el extremo amino-terminal. El primer grupo presenta un dominio TIR (toll/interleukin-1 receptor) que tiene homología con dominios presentes en Drosophila y mamíferos, respectivamente. El segundo grupo de proteína NB-LRR presenta un dominio CC (coiled coil). Menos comunes son los genes $R$ de tipo quinasa, tipo $C f-x$ y tipo Xa-21. Otro ejemplo lo constituye en gen Rrs1 de Arabidopsis que presenta un dominio adicional en la zona carboxilo-terminal de la clase WRKY que confiere resistencia contra la bacteria Ralstonia solanacearum (Deslandes et al., 2002). Las proteínas WRKY son factores de transcripción que se unen a elementos W (TTGACCC/T) 


\section{$\underline{\text { Introducción }}$}

presentes en multitud de promotores inducibles por patógenos (Eulgem et al., 2000).

En virtud del modelo gen a gen, que propone una interacción directa entre el factor de avirulencia y el producto del gen de resistencia, se deduce que los genes $R$ codificarían los receptores con capacidad de reconocer los ligandos específicos codificados por los correspondientes genes Avr. Debido a que la interacción directa entre proteínas $\mathrm{R}$ y Avr solo ha sido demostrada para un par de interacciones (Jia et al., 2000; Deslandes et al., 2003), actualmente la hipótesis del guardián centinela está adquiriendo mayor relevancia (Mackey et al., 2002; Mackey et al., 2003; Axtel y Staskawicz, 2003; Shao., 2003). Esta hipótesis contempla distintas posibilidades de cómo los productos de los genes $R$ detectan los factores de avirulencia del patógeno (Belkhadir et al., 2004). Un ejemplo lo constituye la interacción indirecta entre el gen de avirulencia AvrPphB de Pseudomonas syringae y el gen $R$ de Arabidopsis RPS5. AvrPphB codifica una cisteín proteasa cuya diana es muy probablemente la proteína quinasa PBS1 y no RPS5. Sin embargo, la unión entre AvrPphB y PBS1 es necesaria para la resistencia mediada por RPS5. Además, la unión de PBS1 con AvrPphB5 debe mediar la degradación de RPS5 que desencadena la señalización (Shao et al., 2003). Los receptores de la superficie de las células vegetales son componentes clave que perciben estímulos extracelulares procedentes del medio, incluyendo tanto elicitores generales como específicos. Estos contienen sitios de unión de alta afinidad de distinta naturaleza, tales como oligosacáridos, glicopéptidos y péptidos (Cosio et al., 1990; Cheong y Hahn, 1991; Basse et al., 1993; Nürnberger et al., 1994; Ito et al., 1997; Umemoto et al., 1997; Mithöfer et al., 2000)

Otro ejemplo de resistencia mediada por los genes $R$ lo constituye el gen RAR1 (necesario para la función del gen $R$ Mla-12 de 
cebada que confiere resistencia frente a Erysiphe graminis $f s p$ hordei) y SGT1 (suppressor of G2 allele of SKP1). Ambos genes son reguladores de la resistencia mediada por genes $R$ en Arabidopsis, tabaco y cebada (Azevedo et al., 2002; Liu et al., 2002; Muskett et al., 2002; Tor et al., 2002). En Arabidopsis los genes EDS1 y NDR1 son también indispensables para la función de dos tipos de genes $R$ (Aarts et al., 1998). El mutante eds1 (enhanced disease susceptibility1) suprime la resistencia de genes $R$ de la clase TIR-NB-LRR (Falk et al., 1999) mientras los mutantes ndr1 (non-race-specific disease resistance1) suprimen la resistencia mediada por los genes $R$ del tipo CC-NB-LRR (Century et al., 1997).

A través de aproximaciones moleculares se ha conseguido identificar algunos posibles tipos de receptores en plantas. Atendiendo a sus características estructurales se han clasificado en diferentes categorías: 1) proteín quinasas tipo receptor (RLKs), 2) receptores histidín quinasas y 3 ) receptores con diferente número de dominios transmembrana (Walker, 1994; Satterlee y Sussman, 1998; Grignon, 1999). Algunos de los receptores mejor caracterizados, aunque no están directamente implicados en la percepción de patógenos, son el receptor de etileno ETR1 y el receptor de citoquinina CRE1. Ambos son receptores histidín quinasa (Bleecker y Kende, 2000; Inoue et al., 2001).

Las RLKs son de especial interés en la percepción de patógenos. Hay al menos 340 genes que codifican supuestas RLKs en el genoma de Arabidopsis (The Arabidopsis Genome Initiative, 2000). Las RLKs están caracterizadas por un dominio extracelular que está implicado probablemente en la percepción de la señal, un dominio transmembrana y un dominio quinasa citoplásmico, que puede iniciar una cascada de transducción de señal en el interior de la célula. Todas las RLKs de plantas identificadas son serina-treonina quinasas $y$, de acuerdo con las 


\section{$\underline{\text { Introducción }}$}

características estructurales del dominio extracelular, se han clasificado en diferentes categorías (Shiu y Bleecker, 2001).

La diversidad de las RLKs, y el gran número de ellas presentes en el genoma de Arabidopsis, sugiere que pueden estar implicadas en la percepción de una gran diversidad de estímulos, tales como los elicitores producidos tanto durante interacciones simbióticas (Endre et al., 2002; Stracke et al., 2002), como en las interacciones que rinden enfermedad. Algunas RLKs han sido identificadas como productos de genes, por ejemplo Xa21 (una RLK del tipo LRR) de arroz (Oryza sativa) que confiere resistencia a Xanthomonas oryzae pv. oryzae (Song et al., 1995b) y RLK10 de trigo (Triticum aestivum) que confiere resistencia al hongo de la roya parda Puccinia recondita (Feuillet et al., 1997). Varios genes $R$ parecen codificar proteínas citoplasmáticas relacionadas con RLKs, tales como el producto del gen Pto $R$ implicado en la resistencia contra P. syringae (Shiu y Bleecker, 2001).

Además de los productos del gen $R$, otras RLKs han sido asociadas con respuestas defensivas de las plantas frente a patógenos. En estos casos, la asociación se ha establecido tomando como base el patrón de expresión que presentan ciertas RLKs en plantas infectadas con patógenos o tratadas con elicitores o con moléculas señal relacionadas con las respuestas defensivas, tales como el SA. Por ejemplo, la RLK3 de Arabidopsis es inducida por estrés oxidativo, por el ataque patogénico y por SA (Czernic et al., 1999; Farmer et al., 1999); el factor SFR1 (RLK con un dominio $S$ homologo a SLG "Self incompatibility-locus glycoproteins") de Brassica oleracea es inducido por herida e infección bacteriana (Pastuglia et al., 1997), y las StPRKs (receptor-quinasas de patata) son inducidas por enzimas que degradan la pared celular de Erwinia carotovora y por oligogalacturónidos cortos (Montesano et al., 2001). Las StPRKs constituyen un nuevo grupo de 
RLKs con un motivo bimodular de cisteína en el dominio extracelular (Montesano et al., 2001). Otro grupo de quinasas de receptores relacionados con patógenos es la familia WAK (quinasas asociadas a la pared) que es inducida por patógenos y SA, de la cual se piensa que puede interaccionar con la pectina de la pared celular (He et al., 1999; Shiu y Bleecker, 2001).

Las características estructurales de algunas RLKs sugieren una función elicitora del receptor. Así algunas RLKs contienen dominios extracelulares similares a secuencias presentes en las proteínas relacionadas con la patogénesis (PRs) de plantas. Ejemplos de esta clase son la PR5K, proteína tipo PR5 (taumatina) de Arabidopsis, (Wang et al., 1996) y CHRK1, tipo quitinasa de tabaco (Kim et al., 2000) la cual contiene motivos tipo lectinas que podrían estar implicados en el reconocimiento de oligosacáridos de quitina derivados de patógenos.

El sistema receptor general patogénico mejor caracterizado para un elicitor general es el receptor de flagelina (Gomez-Gomez et al., 2000, Gomez-Gomez et al., 2002). En una búsqueda de mutantes de Arabidopsis insensibles a flagelina, estos autores encontraron el gen FLS2. Se demostró que este gen codifica una RLK transmembrana con un dominio LRR, estructuralmente semejante a Xa21. Las regiones LRR participan frecuentemente en interacciones proteína-proteína y se han descrito datos experimentales que sugieren que el dominio LRR de FLS2 interacciona realmente con un dominio conservado de flagelina eubacteriana (Bauer et al., 2001). Es importante resaltar que FLS2 es estructuralmente semejante al receptor Toll de Drosophila y a los TLRs de mamíferos (receptores tipo Toll). Ambos receptores tipo LRR están implicados en la mediación de la respuesta inmune en animales. Ello sugiere que tanto plantas como animales parecen tener receptores relacionados con el mismo elicitor, la flagelina. Estudios recientes 


\section{$\underline{\text { Introducción }}$}

utilizando la expresión transitoria en protoplastos de Arabidopsis condujeron a la identificación de una cascada de MAP quinasas y de factores de transcripción WRKY que actúan posteriormente a FLS2 (Asai et al., 2002). La similitud de este sistema de señalización con el de los animales sugiere, también, un origen evolutivo común de la respuesta inmune en plantas y animales.

\subsubsection{Producción de compuestos de bajo peso} molecular con función antimicrobiana.

Como respuesta a la infección se produce la inducción de la síntesis de algunos compuestos (fitoalexinas, fitoancipinas, etc) con una marcadada actividad antimicrobiana "in vitro". Dependiendo de la especie vegetal, las plantas sintetizan un grupo característico de fitoalexinas, las cuales provienen del metabolismo secundario y muy frecuentemente constituyen derivados de fenilpropanoides, terpenoides o poliacetilenos. Este grupo de compuestos de estructuras químicas muy diversas se pueden encontrar de forma constitutiva en las plantas (fitoancipinas) o bien pueden acumularse alrededor del sitio de entrada del patógeno (fitoalexinas) y en respuesta a un amplio número de elicitores (Smith, 1996). Ambos grupos de compuestos son potentes antifúngicos, presentan actividad bactericida y están ampliamente distribuidos en el reino vegetal (Osbourn, 1999). A pesar de su probada actividad antimicrobiana "in vitro", queda por determinar aún cuál es realmente el alcance de su función "in vivo". Dentro de las fitoancipinas se incluyen las saponinas, los glucósidos cianogénicos y los glucosinolatos, los cuales se producen como precursores inactivos que 
se convierten en compuestos activos en respuesta al daño tisular o al ataque por parte de un patógeno como consecuencia de la acción de enzimas hidrolíticas de la planta que son liberadas cuando se ve afectada la integridad celular. Recientemente se ha descrito que el principal glucosinolato presente en hojas de Arabidopsis thaliana es el 4-metilsulfibutil isotiocianato (ITC). Este compuesto soluble en agua no se produce en el mutante gms-1, que tiene alterada la síntesis de algunos glucosinolatos (Tierens et al., 2001; Tierens et al., 2002) y que presenta por tanto una mayor sensibilidad a patógenos como Alternaria brassicicola, Botritys cinerea, y Peronospora parasitica, lo cual sugiere el papel que desempeñan estos compuestos en defensa.

Las fitoalexinas por su parte se sintetizan a partir de precursores remotos, son compuestos derivados de indoles y con un alto contenido de azufre. Tienen también una gran actividad antimicrobiana (Glazebrook et al., 1997). La fitoalexina más conocida es la camalexina, que se acumula en la zona infectada durante la respuesta hipersensible (Tsuji et al., 1992). El estudio de mutantes de Arabidopsis thaliana deficientes en la acumulación de la fitoalexina camalexina, tales como pad1, pad2 y pad3 (phytoalexin accumulation deficient) (Glazebrook y Ausubel, 1994; Zhou et al., 1999), muestran que pese a no estar afectada la respuesta defensiva de estos mutantes frente a estirpes avirulentas de Pseudomonas syringae, sí que mostraban una clara hipersusceptibilidad a la infección por patógenos virulentos como el hongo Alternaria brassicicola (Thomma et al., 1999; Glazebrook et al., 1994). Esto favorecería la interpretación del papel funcional de las fitoalexinas para reducir la severidad de infecciones secundarias o el crecimiento de patógenos virulentos. 


\subsubsection{Activación de genes de defensa.}

Concominante a la puesta en marcha de la respuesta hipersensible (HR), se disparan en las cercanías del sitio de entrada del patógeno una gran cantidad de procesos defensivos destinados a frenar el avance de la infección.

La complejidad de los sistemas de transducción de señales requeridos para activar de forma coordinada la respuesta defensiva a este nivel es tal que resulta difícil entender el orden, la finalidad y la función que desempeñan cada una las moléculas que están tomando parte en este tipo de respuesta. Se han propuesto diferentes modelos con el fin de facilitar el estudio de estos mecanismos, sin embargo aún quedan muchos aspectos por esclarecer. La búsqueda de mutantes alterados en algunas de las rutas propuestas sigue siendo la herramienta más acertada para el entendimiento de los diferentes y complejos procesos involucrados en la respuesta defensiva de las plantas. Otro de los problemas que posee el estudio de este tipo de respuesta es el comportamiento que muestran algunos genes, ya que existen casos de genes que se activan sólo a nivel local como defensa inmediata o temprana y otros que muestran expresión a nivel local y también tienen un papel en defensa sistémica (SAR), dificultando de este modo la distinción entre respuestas locales y respuestas sistémicas.

Se han encontrado en plantas otras proteínas que poseen un papel antimicrobiano directo. A este grupo de proteínas pertenecen algunos inhibidores de proteasas y amilasas (Ryan, 1990), las lectinas o tioninas (García-Olmedo et al., 1992), que son proteínas con cierta acción tóxica, y algunas enzimas implicadas en la síntesis de fenilpropanoides, como la fenilalanina amonio liasa o la chalcona 
sintasa (Bowles, 1990). Acompañando a estos mecanismos de defensa, también actúan otros de protección celular específicos, constitutivos o inducibles, como es el caso de algunos enzimas (catalasas, superóxidos dismutasas, peroxidasas, etc) que minimizan las consecuencias del estrés oxidativo que se produce durante una infección (Bowler et al., 1989; Scandalios, 1992).

De entre todo este conjunto cabe destacar la acumulación de proteínas $P R$. Este término incluye aquellas proteínas cuya expresión se ve inducida de novo bajo condiciones patogénicas (Linthorst et al., 1991; Van Loon y Van Sttrien, 1999). Como situación patogénica no sólo se incluye HR y SAR, sino también la respuesta al ataque producido por insectos, nemátodos o herbívoros. Aunque algunas PRs comparten características bioquímicas, como son su bajo peso molecular, su estabilidad a $\mathrm{pH}$ bajo, su resistencia a proteasas o su localización subcelular, vacuolar o extracitoplásmatica, son sus características de inducción las que permiten considerar a una proteína como miembro de este grupo. Existe una clasificación que las agrupa en diferentes familias dependiendo de las características particulares de cada una de ellas (van Loon et al., 1999). Algunas proteínas $P R$ han sido caracterizadas funcionalmente in vitro como antifúngicas y antimicrobianas. Otras presentan actividades quitinasas o glucanasas (Collinge et al., 1993; Domingo et al., 1994), sin embargo aún queda por precisar la función biológica y bioquímica de muchas de estas proteínas. La demostración de la actividad antimicrobiana que presentan algunas $P R s$, junto con el hecho de tratarse de unos genes cuya expresión se induce durante las respuestas HR y SAR, favorece la interpretación de que estas proteínas son en parte responsables del mantenimiento de la resistencia en la planta (Lawton et al., 1993). De hecho, la coexpresión constitutiva de dos o más proteínas $P R$ supone un efecto sinérgico en el 


\section{$\underline{\text { Introducción }}$}

control de la infección (Zhu et al., 1994), confirmándose que la actividad coordinada de genes $P R$ es clave para conseguir el estado general de resistencia que se produce ante determinadas infecciones patogénicas.

Estudios realizados a nivel de isoformas específicas han revelado que si bien algunas PRs desempeñan un papel en defensa, otras homólogas a ellas están expresándose de manera constitutiva o jugando un papel en procesos fundamentales del metabolismo. Un ejemplo de esto lo constituye el gen $\mathrm{RCH} 10$ que codifica una quitinasa de arroz que se expresa de forma constitutiva en raíces y varios órganos florales, y que se induce en hojas de tabaco transgénico en respuesta a herida (Zhu et al., 1994). También el gen PR-10a de patata descrito por Constabel et al.,1993, muestra inducción en plantas transgénicas de patata tras el tratamiento con Phytophthora infestans en tubérculos y peciolos, pero está además activado de manera constitutiva en estigmas. Por último existe una isoforma ácida de la PR1 de tomate que también muestra expresión constitutiva en diferentes órganos y no parece inducirse ante estímulos patogénicos clásicos como infección por patógenos necrosantes, ácido salicílico o etileno (Tornero et al., 1997).

Otro grupo de PRs, activadas durante la respuesta defensiva, funcionan como proteasas (Vera y Conejero, 1989; Schaller y Ryan, 1996; Tornero et al., 1996), hidrolizando proteínas secretadas por el patógeno, o bien actuando en procesos de modificación de proteínas de la planta implicadas en la activación de las defensas (Tornero et al., 1997). En la actualidad sirven como marcadores moleculares de la respuesta defensiva (Hunt y Ryals, 1996). 


\subsection{Respuestas defensivas sistémicas.}

\subsubsection{Respuestas sistémicas dependientes de SA:} Resistencia Sistémica Adquirida (SAR).

Después de la infección por parte de un patógeno necrosante, o tras la aparición de una HR en la planta huésped, se activa una respuesta defensiva general contra un amplio espectro de patógenos. Esta forma de resistencia inducida se conoce con el término Resistencia Sistémica Adquirida (SAR) (Ross, 1961; Ryals et al., 1996). Esta respuesta se caracteriza por proporcionar una resistencia sistémica duradera e inespecífica frente a un amplio espectro de patógenos (Sticher et al., 1997), incluyendo aquellos que normalmente son virulentos, y por llevar asociada la inducción de la expresión de genes SAR característicos, tanto a nivel local como sistémicamente (Ward et al., 1991). El tiempo necesario para el establecimiento de SAR depende de la planta y del organismo inductor. El conjunto mayoritario de proteínas defensivas sintetizadas en las plantas durante dicha respuesta SAR pertenece a la familia de las proteínas $P R$. De interés es resaltar que sólo los genes que codifican proteínas PR ácidas (PR-1, $P R-2, P R-5)$ responden fuertemente a SA o cualquiera de sus análogos y se expresan tanto local como sistémicamente después de una infección. Por el contrario, los genes que codifican las isoformas básicas se inducen localmente alrededor de la HR. Esto nos indica que las proteínas $P R$ básicas no estarían implicadas en la respuesta SAR (Brederode et al., 1991).

Aunque el ácido salicílico (SA) no es la única molécula señalizadora que se trasloca sistémicamente dando lugar a la inducción de SAR (Bi et al., 1995), su presencia en los tejidos distales es 


\section{$\underline{\text { Introducción }}$}

necesaria para que se establezca la cascada de señalización que da lugar a la activación de la respuesta SAR y se dé la expresión de genes SAR (Vernooij et al., 1994). La adición exógena de SA tanto a hojas de plantas de tabaco como de Arabidopsis thaliana induce la expresión de un conjunto de genes SAR y por consiguiente una mayor resistencia de las plantas a patógenos. La identificación de dos compuestos sintéticos análogos al SA, el ácido 2,6-dicloroisonicotínico "INA" (Métraux et al., 1991; Ward et al., 1991) y el S-metil éster del ácido-1,2,3-benzotiodiazol7-carbotiótico "BTH" (Görlach et al., 1996) refuerza el papel que juega el SA en la inducción de SAR.

La inducción de resistencia en partes de la planta distales al sitio de inoculación incial sugiere la existencia de una señal que se desplazaría sistémicamente dando lugar al establecimiento de SAR (Bi et al., 1995). En un inicio se propuso al SA como dicha señal, sin embargo ciertos experimentos han demostrado que no es la señal sistémica, aunque su presencia en tejidos distales es absolutamente necesaria para la implatación de SAR (Vernooij et al., 1994). El mutante dir1 (defective in induced resistance1) se caracteriza por su incapacidad para montar una respuesta SAR (Maldonado et al., 2002). Dado que DIR1 codifica una proteína apoplástica de transferencia lipídica que se localiza en el floema, se plantea la posibilidad de que moléculas de naturaleza lipídica podrían ser las responsables de la señalización sistémica. Además la proteína de unión al SA, SABP2, es una lipasa cuya actividad es estimulada por la unión al SA que podría generar una señal de naturaleza lipídica también involucrada en la respuesta SAR (Kumar y Klessig, 2003). Resultados más recientes indican que SABP2 posee actividad esterasa de metilsalicilato lo que representa una actividad crítica a la hora de regular la interconversión entre una forma 
potencialmente inactiva en activación de SAR como el metilsalicilato una forma activa como el SA libre (Forouhar et al., 2005).

En la actualidad, la identificación de mutantes en Arabidopsis que presentan las respuestas defensivas constitutivamente activadas, tales como acd2, Isd, cpr1 (constitutive expresser of $\underline{P R}$ genes; Bowling et al.1994) o cim3 (constitutive immunity mutants; Ryals et al., 1996),; Weymann et al., 1995), o bien aquellos que muestran defectos en la inducción de las defensas, tales como npr1 (non expresser of $\underline{P R}$ genes; Cao et al., 1994), nim1 (non inducible immunity; Delaney et al., 1995), sai1 (salicylic acid insensitive; Shah et al., 1997), ndr1 (non race specific disease resistance; Century et al., 1995), pad4 (phytoalexin accumulation deficient) (Glazebrook et al., 1994) o eds (enhanced disease susceptibility; Parker et al., 1996; Rogers y Ausubel, 1997), o aquellos que son supresores de alguna de las mutaciones ya descritas, tal y como es el caso de sni1 (suppressor of npr1 inducible; Li et al., 1999) o ssi (suppressor of $\underline{S} A$ insensitivity; Shah et al., 1999), está permitiendo el continuo esclarecimiento de los componentes que intervienen en la regulación de la respuesta defensiva de las plantas.

\subsubsection{Respuestas sistémicas dependientes de JA/ET: Resistencia Sistémica Inducida (ISR).}

Por los estudios realizados con anterioridad, se conoce que la resistencia a patógenos biotrofos depende en gran medida del SA. Sin embargo, la resistencia a patógenos necrotrofos (Botrytis cinerea, Phythium sp y Alternaria brassicicola), está mediada por otras moléculas señalizadoras, tales como, el ácido jasmónico y el etileno 
(JA/ET). Se sabe que el jasmonato de metilo (MeJA) está directamente implicado en la respuesta defensiva de las plantas frente a patógenos necrosantes (Devoto y Tumer, 2003; Devoto et al., 2005).

Existe un mecanismo de resistencia de amplio espectro similar a SAR, que no depende de la señal del SA, pero que sí parece estar regulado por JA y ET. Esta resistencia se induce tras la colonización de las raíces por ciertas bacterias de la rizosfera, como por ejemplo Pseudomonas fluorescens, y confieren protección en tejidos sistémicos alejados de la zona infectada. Esta resistencia se manifiesta tanto en una reducción de los síntomas de la enfermedad como por una inhibición del desarrollo patogénico en infecciones subsiguientes, conformando lo que se ha dado en llamar Resistencia Sistémica Inducida (ISR) (Pieterse et al., 1999). Este fenómeno no es exclusivo de Arabidopsis, sino que también se ha demostrado en otras especies vegetales, como por ejemplo guisante, tabaco, tomate, pepino y rábano (lavicoli et al., 2003).

Algunos estudios genéticos han demostrado que la ISR es un rasgo monogénico dominante que no está presente en todos los ecotipos de Arabidopsis. Por ejemplo, se conoce que el ecotipo Wasilewska está afectado en la respuesta a ISR (Ton et al., 1999). Este carácter cosegrega con una elevada resistencia basal a una cepa virulenta de Pseudomonas syringae, lo cual parece indicar que ISR y las respuestas de resistencia general están íntimamente relacionadas (Ton et al., 1999).

En algunos casos se ha descrito que la SAR se solapa con la ISR. Recientes estudios revelan que SAR es efectiva frente a la infección por el virus Turnip Crinkle Virus (TCV) pero ISR no; por el contrario, ISR confiere resistencia frente a Alternaria brassicicola pero SAR no (Ton et al., 2002). Sin embargo en el caso de patógenos que son afectados por 
ambos tipos de respuestas, el nivel de resistencia obtenido se ve incrementado cuando SAR e ISR están activadas simultáneamente, indicando que los efectos de estas dos respuestas defensivas pueden resultar aditivos (Ton et al., 2002).

Estas divergencias podrían ser debidas a que los mecanismos de cada una de ellas son muy diferentes. Así, el establecimiento de SAR viene acompañado de un incremento en los niveles de SA tanto local como sistémicamente, además de una activación de un gran número de genes, incluyendo aquellos que codifican proteínas PR (Maleck et al., 2000); por el contrario, aunque ISR funciona independientemente de SA necesita la acción del gen NPR1, implicado en la activación de PRs, siendo este un punto en el que convergen ambas rutas de señalización para separarse inmediatamente después, pues durante el establecimiento de ISR no se aprecian cambios en los niveles de expresión de los genes PR (Verhagen et al., 2004).

Curiosamente, aunque para el establecimiento de la respuesta ISR se requieren elementos de las rutas de JA/ET, está no va asociada a incrementos en los niveles de estas dos moléculas, y tampoco se observa inducción de los genes regulados por dichas moléculas (PDF1.2, HEL, CHI-B, VSP, LOX1, LOX2) (Pieterse et al., 2001). Así, se asume que la dependencia de ET y JA mostrada por ISR está basada en un aumento de la sensibilidad a estas hormonas y no a un incremento en su producción (Verhagen et al., 2004).

Recientes estudios a nivel de trascriptoma de Arabidopsis en un contexto de ISR han permitido esclarecer otros aspectos relacionados con este tipo de respuesta defensiva (Cartieaux et al., 2003; Verhagen et al., 2004). Verhagen et al., (2004) observaron cambios en la expresión de algunos genes en el tejido infectado con rizobacteria, algunos de ellos, como es el caso de ERF1(Ethylene Response 


\section{$\underline{\text { Introducción }}$}

Factor1), ERBP1 y ERBP2 (Ethylene Response element Binding Proteins 1 y 2), reguladores positivos de los procesos dependientes de ET, están reprimidos, indicando que tal vez el establecimiento de ISR vaya aparejado con una reducción en la señalización por ET. Sin embargo, no encontraron cambios aparentes en el tejido sistémico que expresa ISR. Esta observación condujo a establecer la hipótesis de que la efectividad de ISR para la contención de infecciones subsiguientes debe basarse en el establecimiento de un estado de prealerta (priming) que proporciona a la planta una mayor capacidad para responder rápida y eficientemente a una infección, pero que sólo se activaría tras el contacto con el patógeno.

Recientemente se ha sugerido que los mecanismos implicados en la ISR dependen también del patógeno. Así, se ha descrito la existencia de una ruta de señalización de ISR dependiente de SA, promovida por la infección de Panibacillus polymyxa (Timmusk y Wagner, 1999).

\section{Principales rutas de señalización defensiva.}

Entre la percepción inicial de cualquier agresor y la activación de los componentes de la respuesta que tiende a neutralizar la agresión, y que opera local y sistémicamente existe un mensaje que alerta del ataque y activa las defensas (Figura 1). Esa corriente de información en forma de flujo de señales es lo que constituye el proceso de transducción de las señales defensivas y entre las que destacaremos la concerniente al ácido salicílico (SA), el ácido jasmónico (JA) y el etileno (ET) (Pieterse et al., 2001; Kunkel y Brooks, 2002; Nandi et al., 2003; Spoel et al., 2003; O'Donnell et al., 2003b) 


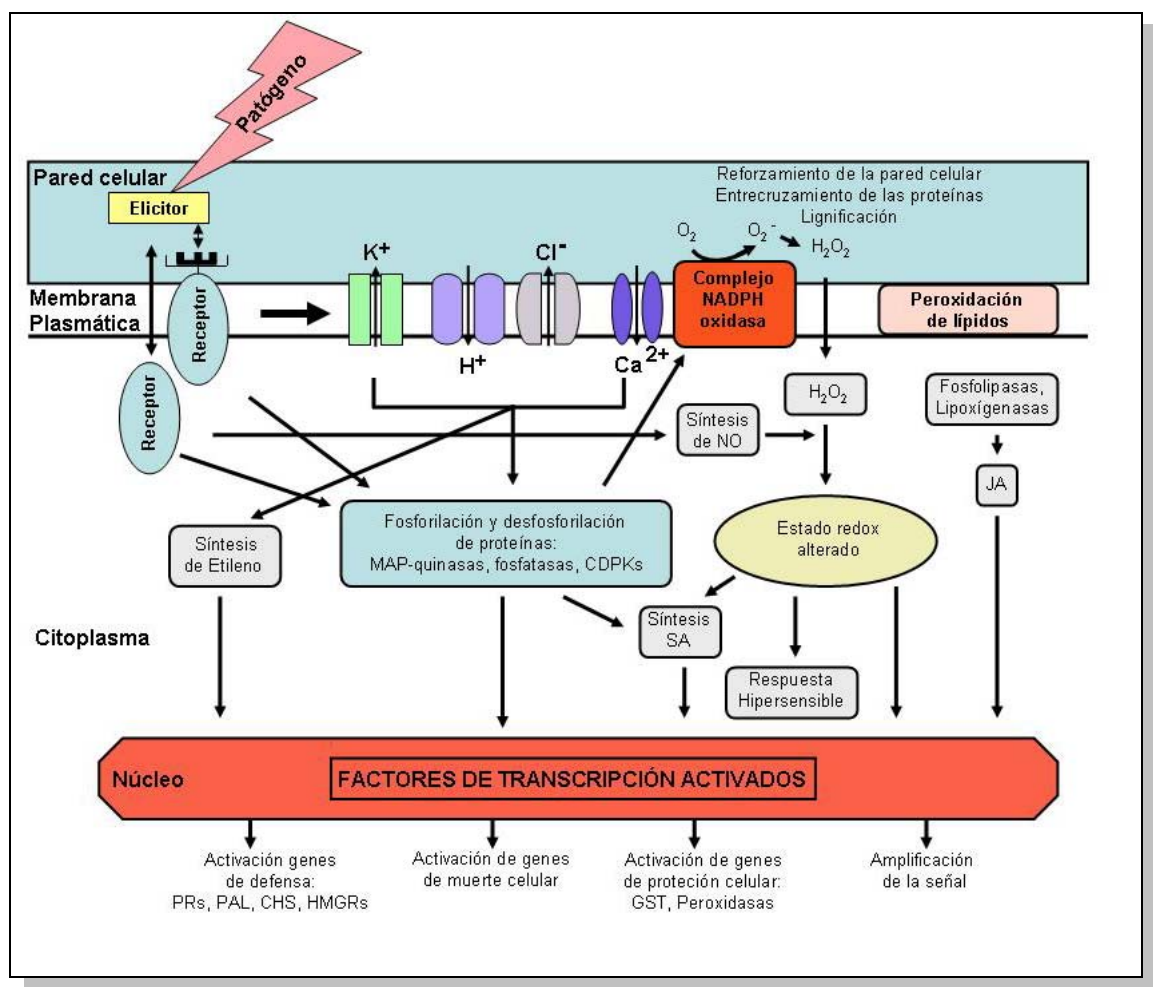

Figura 1: Componentes principales de la cadena de transmisión de señales de defensa. Las abreviaturas corresponden a: NO, óxido nítrico; $\mathrm{SA}$, ácido salicílico; JA, ácido jasmónico; CDPKs, protein-quinasas dependientes de calcio (calcium dependent protein kinase. Adaptado de Numberger y Scheel, 2001

Cada una de estas señales intermediarias es capaz de inducir la expresión de múltiples genes, para lo cual, como veremos, existen datos crecientes que apoyan la idea de la existencia de elementos en cis en los promotores de dichos genes que posibilitan su inducción por cada una de estas señales. 


\subsection{Ruta del Ácido Salicílico (SA).}

Como mencionamos anteriormente, el SA está implicado en la activación de defensas locales y en la resistencia sistémica adquirida (SAR) (Dempsey et al., 1999; Shah et al., 1999). El aumento en los niveles endógenos de SA y de sus conjugados en plantas inoculadas con patógenos coincide con la elevada expresión de genes que codifican proteínas relacionadas con la patogénesis (PR) y la activación de resistencia a la enfermedad. EI SA está también implicado en el desarrollo de síntomas de enfermedad (Shah, 2003; O'Donnell et al., 2003a). Por otra parte, aplicaciones exógenas de SA o de sus análogos funcionales sintéticos como el tioéster metílíco del ácido benzo-(1,2,3) tiadiazol-7- tiocarbónico (BTH) activan la expresión de genes PRs y elevan la resistencia a patógenos (Shah, 2003).

El papel central del SA en las defensas inducibles de las plantas se puso de manifiesto con la utilización de las plantas transgénicas NahG. Estas plantas expresan constitutivamente el gen bacteriano NahG, que codifica una salicilato hidroxilasa de Pseudomonas putida, que convierte el SA en catecol. Las plantas NahG de tabaco y Arabidopsis thaliana muestran una mayor susceptibilidad a una amplia gama de patógenos (oomicetos, hongos, bacterias y virus) (Delaney et al., 1995; Kachroo et al., 2000).

El SA es un componente de la denominada ruta de los fenilpropanoides cuyo primer paso es la conversión de la fenilalanina en ácido trans-cinámico, catalizado por la enzima fenilalanina amonioliasa (PAL) (Verberne et al., 1999). 
Las plantas de Arabidopsis se vuelven susceptibles a patógenos fúngicos avirulentos cuando la PAL es específicamente inhibida, pero la resistencia puede recuperarse mediante aplicación de SA, indicando que la síntesis y acumulación de SA son necesarios para la expresión de la resistencia (Boller et al., 2001).

La síntesis del SA se inicia a partir de fenilalanina. Sin embargo, la vía de la PAL no parece producir todo el SA en las células de las plantas, sugiriendo que debe haber rutas alternativas de biosíntesis. En algunas bacterias, el SA es sintetizado a partir de corismato vía isocorismato. Las enzimas isocorismato sintasa (ICS) e isocorismato piruvato liasa (IPL) catalizan los dos pasos de corismato a SA (Serino et al., 1995). Recientemente, estudios genéticos realizados en Arabidopsis con el fin de descubrir rutas defensivas en plantas han permitido identificar mutantes recesivos afectados en la señalización por SA que muestran también un aumento de su sensibilidad a la infección. Por ejemplo, los mutantes sid1, sid2, y pad4 son defectivos en la acumulación de SA en respuesta a la infección patogénica. Como resultado, estos mutantes presentan mayor susceptibilidad al patógeno bacteriano Pseudomonas syringae pv. tomato 0 al oomiceto Peronospora parasitica (Zhou et al., 1998; Nawrath y Métraux, 1999), lo que confirma la importancia del SA en la resistencia basal contra diferentes tipos de patógenos.

Un estudio reciente realizado en Arabidopsis sugiere la existencia de una ruta análoga en plantas (Wildermuth et al., 2001). El gen SALICYLIC-ACID-INDUCTION DEFICIENT2 (SID2), que codifica una posible ICS localizada en el cloroplasto se activa por patógenos en tejidos que muestran SAR. La aplicación de SA complementa el defecto que tiene el mutante de sid2 para sintetizar SA y establecer la respuesta SAR, confirmando la implicación de SID2 en la síntesis de SA 


\section{$\underline{\text { Introducción }}$}

(Wildermuth et al., 2001; Nawrath y Metraux, 1992). Aunque la actividad bioquímica de SID2 no ha sido demostrada, la evidencia lograda hasta el presente sostiene fuertemente la existencia de un camino alternativo para la síntesis de SA que implica al corismato y al isocorismato en Arabidopsis.

El gen ENHANCED DISEASE SUSCEPTIBILITY (EDS5), codifica una hipotética proteína que tiene homología con la familia de transportadores de proteínas de la multidroga y toxina de extrusión (MATE) (Nawrath et al., 2002). En el mutante eds5/sid1 la activación de la síntesis de SA inducida por luz UV o por patógenos queda bloqueada (Nawrath et al., 2002). EDS5 puede haber evolucionado para transportar compuestos fenólicos precursores de la biosíntesis de SA. Los mutantes eds1(enhanced disease susceptibility1) y phytoalexin deficient4 (pad4) comprometen también la síntesis de SA en las interacciones planta-patógeno (Jirage et al., 1999; Feys et al., 2001), y en mutantes constitutivos de la señalización por SA (Clarke et al., 2001; Jirage et al., 2001) eds1 y pad4 bloquean también la expresión de EDS5, activada por patógenos, sugiriendo que EDS1 y PAD4 funcionan con anterioridad a EDS5 en la regulación de la síntesis de SA. También han sido identificados varios mutantes de Arabidopsis que acumulan altos niveles de SA constitutivamente, expresan genes PR y presentan mayor resistencia (Feys y Parker, 2000; Dong, 2001; Kunkel et al., 2002).

Aunque no todos estos genes pueden ser asociados directamente con la defensa de las plantas, algunos pueden unir sucesos señalizadores anteriores con la síntesis de SA, mientras que otros pueden tener como diana mecanismos de retroalimentación (feedback) que implican al SA (Shah, 2003). 
Una señal activada por patógeno estimula la producción de SA en las plantas. Además, estimula el desarrollo de lesiones asociadas con la HR. EDS1(ENHANCED DISEASE SUSCEPTIBILITY) se necesita en dos estadios de la señalización. Es necesario para el desarrollo de la HR y para la activación de la señalización de defensas mediadas por genes $R$ tipo NBS-LRR. Además EDS1 y PAD4 son necesarios para la resistencia basal y para que se produzca el aumento de la acumulación de SA en respuesta a una serie de patógenos. EDS5 actúa muy probablemente "aguas arriba" de SID2 en la regulación de la biosíntesis de SA, ya que la expresión inducida por patógeno de EDS5 no se ve alterada en el mutante sid2.

El gen NON-EXPRESSOR OF PR1 (NPR1), también llamado NON-INDUCIBLE IMMUNITY (NIM1), es un componente importante de la señalización por SA. Los mutantes npr1 y nim 1 son insensibles al SA, lo que compromete su resistencia a la enfermedad (Cao et al., 1994; Delaney et al., 1995; Glazebrook et al., 1996). Estudios recientes han demostrado que en Arabidopsis opera también un mecanismo mediado por SA pero independiente de NPR1 (Dong, 2001).

El SA puede activar la expresión de genes de proteínas relacionadas con la patogénesis (PRs) y otros genes de resistencia, mediante dos mecanismos. El primero requiere el gen NPR1. La interacción de NPR1 con TGA2, activa la expresión del gen PR-1, presumiblemente contrarrestando el efecto inhibidor de SUPRESSOR OF npr1-1 INDUCIBLE 1 (SNI1).

Se requiere una señal lipídica generada por SFD1 (SUPPRESSOR OF FATTY ACID DESATURASE DEFICIENCY1) para la activación, por SA, de la ruta mediada por NPR1. El punto exacto de entrada de esta señal derivada de SFD1 en esta ruta no se conoce. El 
SA y el BTH no activan la resistencia en el mutante npr1; ello indica que los mecanismos dependientes de SA, e independientes de NPR1, requieren una señal adicional al SA. Esta segunda señal podría ser proporcionada por la muerte celular. EI ET y el JA potencian la señalización a través de esta ruta independiente de NPR1.

Recientemente, se ha propuesto que la expresión de genes inducidos por SA implica la acción concertada de dos rutas, en cada una de las cuales está implicada, respectivamente, la proteína NPR1 (Alborn et al., 1997)(de la que ya se ha hablado anteriormente) y AtWhy. Esta última proteína pertenece a una familia de factores de transcripción que regula la expresión génica a través de la caja GTCAAAAA/T del promotor. En tejidos no inducidos, la actividad de unión de AtWhy1 al DNA está reprimida por el inhibidor SNI1, que inhibe la expresión génica mediante un mecanismo desconocido. Después de un tratamiento con SA la actividad de unión a DNA de AtWhy es inducida mediante la separación de un inhibidor. NPR1 es activado y elimina la represión impuesta por SNI1 (Li et al., 1999). AtWhy se une a elementos PB Binding Promoter element) para activar la expresión génica. NPR1 contribuye también a la activación génica, probablemente interaccionando con factores de transcripción TGA y aumentando la actividad de unión a elementos tipo as-1 (Despres et al., 2000; Desveaux et al., 2004).

En conclusión el factor de transcripción AtWhy, es un importante componente de la ruta de señalización que se activa independientemente del regulador de SAR NPR1. Sin embargo, tanto NPR1 como AtWhy1, son necesarios para una inducción adecuada de las defensas mediada por SA. AtWhy es también necesaria para la respuesta apropiada de las defensas en interacciones compatibles e incompatibles, añadiendo un componente importante tanto a la 
respuesta inmune como a la específica (Desveaux et al., 2000; Desveaux et al., 2004).

En relación con los posibles mecanismos mediante los cuales el SA induce las respuestas defensivas, se han identificado varias proteínas efectoras que interaccionan con el SA: a destacar son una catalasa (SABP) (Chen et al., 1993), la proteína SABP2 (Du y Klessig, 1997), ascorbato peroxidasa (APX) (Durner y Klessig, 1995), una aconitasa (Ruffer et al., 1995) y la proteína SABP3 (Slaymaker et al., 2002). La SABP (Salycilic Acid-binding Protein) es la proteína "citosólica peroxisómica de tabaco", catalasa (CAT) y se ha demostrado que es capaz de unir SA de manera reversible (Chen et al., 1993). EI SA y sus análogos funcionales inhiben la actividad catalasa (Conrath et al., 1995; Anderson et al., 1998). Así, se hipotetizó que la inhibición, mediada por SA de CAT podría generar la rápida acumulación de $\mathrm{H}_{2} \mathrm{O}_{2}$ observada durante la HR (Chen et al., 1993). En apoyo de esta hipótesis, se demostró subsiguientemente que el SA inhibe la ascorbato peroxidasa (APX) citosólica, el otro principal enzima que elimina el $\mathrm{H}_{2} \mathrm{O}_{2}$ en las células vegetales (Durner et al., 1995; Rao et al., 1997). Otros estudios, sin embargo, han sugerido que el SA funciona mas allá del $\mathrm{H}_{2} \mathrm{O}_{2}$ en la ruta de la señalización de las defensas (Nardini y Dijkstra, 1999; Wesley et al., 2001). La proteína citosólica SABP2 fue identificada en tabaco como una proteína de $25 \mathrm{kDa}$, soluble, de muy baja abundancia y que presenta alta afinidad por SA (Du y Klessig, 1997). Esta unión es reversible y específica para SA y sus análogos que inducen SAR (Gaffney et al., 1993). Esta proteína pertenece a la superfamilia de proteínas con actividad lipasa, y que es estimulada por la unión de SA. Su expresión es inducida por la infección del virus del mosaico del tabaco (TMV). La observación de que SABP2 se une a SA con alta afinidad en concentraciones muy bajas, unida a que la actividad 


\section{$\underline{\text { Introducción }}$}

enzimática es estimulada a través de SA, sugiere que podría ser un receptor de SA. En apoyo de esta hipótesis, las plantas con SABP2 silenciado carecen de resistencia local y sistémica. Se ha constatado la existencia de otra proteína que une SA (SABP3) en la fracción soluble de los cloroplastos de hoja de tabaco y se identifica como anhidrasa carbónica (CA) cloroplástica. Los autores sugieren que la CA funcionaría en la señalización defensiva a través de su función antioxidante.

Posiblemente, la capacidad del SA de inhibir tanto a los enzimas antioxidantes citosólicos como a los cloroplásticos, permitiría aumentar los niveles de ROS, que podrían activar un bucle positivo de retroalimentación, que amplificaría la producción de SA e induciría respuestas defensivas después de la infección por patógenos (Draper, 1997; Shirasu et al., 1997).

Un mecanismo alternativo por medio del cual la inhibición, mediada por SA, de CAT puede señalizar las respuestas defensivas, es a través de la generación de radicales libres de SA, que podrían entonces activar una ruta de peroxidación de lípidos (Durner y Klessig, 1996; Anderson et al., 1998); esta posibilidad permanece como materia de debate (Tenhaken y Rubel, 1997).

La señalización por SA en la defensa de las plantas no debe ser vista como una ruta lineal, sino como una red compleja. Numerosos estímulos pueden activar la síntesis/señalización de/por SA. EI SA puede unirse específicamente a diversas proteínas afectando su actividad (Dempsey et al., 1999; Shah et al., 1999; Slaymaker et al., 2002). Puede también activar la expresión de genes o su actividad mediante diversos mecanismos y en diferentes pasos de la señalización defensiva. Además, el SA influye, como veremos, sobre otras rutas de 
señalización defensivas en las plantas (Feys y Parker, 2000; Pieterse et al., 2001; Kunkel et al., 2002). La síntesis de SA, y la señalización mediada por dicha molécula, están implicadas en la transducción de señales no solamente de respuesta a patógenos sino a muchos otros factores ambientales y relacionados con el desarrollo de las plantas. Un mecanismo de feedback podría mediar la integración de estas señales, permitiendo así el ajuste fino entre la señalización por SA y las respuestas defensivas de las plantas. La desregulación de alguna de estas vías de entrada podría potencialmente activar o reprimir las defensas mediadas por SA.

La clonación de SID2 ha permitido obtener los primeros datos en el sentido de que el cloroplasto juegue un papel importante en la síntesis del SA. Los cloroplastos y los plastidios son también importantes en el metabolismo de los lípidos y en la generación de señales derivadas de los lípidos. Las mutaciones en varios genes que codifican proteínas localizadas en los cloroplastos y en los plastidios alteran la síntesis de SA y la señalización de las defensas en las plantas (Ishikawa et al., 2001; Kachroo et al., 2001; Mach et al., 2001; Wildermuth et al., 2001; De Leon et al., 2002; Slaymaker et al., 2002), sugiriendo que el funcionamiento y la integridad de estos orgánulos es importante en las interacciones planta-patógeno. Como sucede con las mitocondrias en los animales, los cloroplastos y plastidios podrían ser fuente de señales que afectan a las respuestas contra los patógenos. 


\subsection{Ruta del Ácido Jasmónico (JA).}

Los jasmonatos son compuestos derivados de ciclopentanonas, que se encuentran ampliamente distribuidos y en todo el reino vegetal y fueron descubiertos inicialmente en el aroma de la flor de jazmín (Demole et al., 1962). Los jasmonatos se encuentran también en ciertos hongos, y de hecho el ácido jasmónico fue aislado por primera vez a partir de filtrados del cultivo celular del hongo Lasiodiplodia theobromae (Aldridge et al., 1971). Datos obtenidos recientemente indican que no sólo el ácido jasmónico y su éster metílico, sino otros compuestos relacionados con ellos y que derivan de ácidos grasos, pueden tener un papel señalizador tanto en procesos de desarrollo como en la respuesta de las plantas frente a distintas situaciones de estrés causadas por agentes de distinta naturaleza, biótica y abiótica. Este conjunto de compuestos reciben el nombre de oxilipinas y más comúnmente reciben la denominación de jasmonatos (JAs). El ácido jasmónico (JA) y su éster metílico (MeJA), son las moléculas mejor estudiadas en plantas (Berger, 2002).

Los JAs, además de actuar en la resistencia a patógenos necrotrofos (Thomma et al., 1999), están implicados en otros procesos de desarrollo vegetales, como son: la elongación de las raices, el desarrollo del polen, la dehiscencia de las anteras, la maduración de las semillas y la defensa contra los daños producidos por herida, ozono o insectos (Devoto et al., 2003).

La biosíntesis de JA y MeJA, tiene lugar a través de la ruta octadecanoica y comienza con la liberación de ácido linolénico (18:3) de las membranas plasmáticas (Vick y Zimmerman, 1984). La herida provoca la activación de fosfolipasas de tipo $D$ y $A_{2}$ que liberan ácidos grasos insaturados de las membranas (Lee et al., 1997; Ryu y Wang, 
1998; Narvaez-Vasquez et al., 1999). El ácido linolénico es transformado en ácido 13(S)-hidroxiperoxilinolénico por la acción de una lipoxigenasa. Éste, a su vez, es oxidado y ciclado a ácido 12-oxofitodienoico (OPDA) por la acción sucesiva de una óxido de aleno sintasa y una óxido de aleno ciclasa. Por último, el ácido fitodienoico es reducido por una 12-oxo-PDA reductasa y a continuación se producen tres etapas de $\beta$-oxidación que originan el ácido jasmónico. La síntesis de ácido fitodienoico tiene lugar en el cloroplasto y las tres etapas de $\beta$ oxidación deben de ocurrir en los peroxisomas (Creelman y Mullet, 1997; Schaller, 2001). La reciente clonación de LeOPR3, la isoforma de la 12-oxo-PDA reductasa de tomate implicada en la biosíntesis de ácido jasmónico, ha permitido determinar su localización en los peroxisomas y no en el citosol, como se pensaba con anterioridad a estos estudios. Así pues, la biosíntesis de JA parece implicar dos compartimentos celulares: los cloroplastos y los peroxisomas (Strassner et al., 2002).

Las respuestas mediadas por JAs pueden ser activadas por un conjunto de diversos agentes estresantes tanto bióticos como abióticos. Se piensa que diferentes estímulos pueden interaccionar con un receptor común que regule la biosíntesis de JA o, más probablemente, que interaccionen con diferentes receptores que regulan diferentes rutas de señalización que convergen en la vía de biosíntesis de JA (Devoto et al., 2003).

La evidencia genética acerca del papel del JA en el sistema defensivo de las plantas se ha deducido fundamentalmente a partir de los análisis de mutantes de Arabidopsis alterados en la biosíntesis, en la percepción o en su modo de acción. Actualmente, han sido identificados dos mecanismos mediante los cuales los jasmonatos pueden activar la expresión génica. En el caso de los receptores de JAs es importante 
resaltar que la búsqueda de mutantes afectados ha sido infructuosa debido, muy probablemente, a la redundancia funcional entre los receptores de dicha hormona (Staswick et al., 1992; Feys et al., 1994; Berger et al., 1996; Staswick et al., 1998; Xie et al., 1998; Ellis y Turner, 2001). Como resultados más interesantes conseguidos siguiendo esta búsqueda cabe destacar el hallazgo de los mutantes CORONATINE INSENSITIVE 1 (COI1) (Feys et al., 1994) y el JASMONIC ACID RESISTANT1 (JAR1) (Lorenzo et al., 2003). El mutante coi1 fue encontrado en la búsqueda de receptores de JA, utilizando un análogo estructural del JA llamado coronatina. Dicho mutante muestra una mayor susceptibilidad a los hongos necrotróficos Alternaria brassisicola y Botrytis cinerea (Thomma et al., 1999) y a Erwinia carotovora (Norman-Setterblad et al., 2000). Otro mutante de Arabidopsis insensible a JA, jar1, permite un aumento de los niveles de crecimiento de $P$. syringae pv. tomato en las hojas (Pieterse et al., 1998). Esto claramente demuestra que las defensas dependientes de JA contribuyen a la resistencia basal contra diferentes patógenos microbianos. Además, tanto el mutante jar1, como el triple mutante fad3 fad7 fad8 de Arabidopsis, que es deficiente en la síntesis del ácido linolénico, precursor del JA, presentan susceptibilidad al patógeno presente en el suelo Pythium sp. (Staswick et al., 1998; Vijayan et al., 1998), a diferencia de lo que sucede en las plantas silvestres, indicando que el JA juega un papel en la resistencia de no-huésped contra este tipo de patógenos. En otro estudio, este triple mutante mostró una mortalidad extrema ante el ataque por larvas del mosquito saprófago Bradysia impatiens (McConn et al., 1997), demostrando un papel importante del JA en la defensa primaria contra insectos herbívoros.

El gen COI 1 codifica una proteína que contiene repeticiones ricas en leucina y un motivo F-box (Xie et al., 1998). Las proteínas F-box son 
componentes de complejos SCF (proteínas F-box: SKP1, CDC53p/CUL1) (Bai et al., 1996; Xu et al., 2002), una de las seis familias de E3 ubiquitin ligasas que interaccionan con algunas subunidades del complejo COP9 (CSN) (Feng et al., 2003). Recientemente, Gagne et al., (2002) identificaron 694 posibles genes Fbox en $A$. thaliana, haciendo de este gen una superfamilia, aunque sólo en pocos casos se ha demostrado un papel para el complejo SFC (Gray et al., 1999; Samach et al., 1999; Dieterle et al., 2001; Woo et al., 2001; Devoto et al., 2002).

Parece que COI1 es necesario para que se produzca la degradación de un represor de la ruta de señalización del jasmonato (Devoto et al., 2002). Experimentos de co-inmunoprecipitación sugieren que COI1 forma parte del complejo de ubiquitina ligasa tipo E3, que interacciona con algunas subunidades del complejo COP9 (CSN) (Feng et al., 2003), que media la ubiquitinación de la desacetilasa de histonas, lo que conduce a la activación de genes de respuesta a jasmonato (Devoto et al., 2002). Una de las funciones de las desacetilasas de histonas es mantener el balance entre acetilación y desacetilación de estas proteínas nucleares y forma parte de un importante mecanismo en la regulación de la transcripción de genes en células eucariotas (Hassig et al., 1997; Pazin et al., 1998; Lusser et al., 2001). Se piensa que la desacetilación de histonas disminuye la accesibilidad de la cromatina a la maquinaria de transcripción. De acuerdo con el modelo que se admite, los genes de respuesta a JA se encuentran bloqueados por un represor $\mathrm{R}$ sensible a JA. R sería una desacetilasa de histonas. COI1, sKp1, AtCUL1 (Cullin) y AtRbx1 (Rbx1) forman un complejo ubiquitina ligasa. Una señal de estrés activa la síntesis de JA, que induce la fosforilación de R. R-P se une al complejo de ubiquitinación por medio de COI1. La proteína $\mathrm{R}$ es ubiquitinada y degradada en el proteasoma. 


\section{$\underline{\text { Introducción }}$}

De este modo, se desbloquearía la expresión de genes de respuesta a JA.

Se conoce que la mutación coil confiere resistencia a varias cepas de la bacteria biotrofa Pseudomonas syringae (Kloek et al., 2001; Ellis et al., 2002), viéndose implicados en ellas diferentes componentes de la ruta de señalización dependiente de SA, constituyéndose así COI1 como factor de conexión entre diferentes rutas de señalización. Sin embargo, otros estudios revelan que este mutante muestra una marcada susceptibilidad a diferentes patógenos necrotrofos (B. cinerea, E. carotovora, A. brassicicola y a P. parasítica) (Devoto et al., 2005).

Recientemente se ha aislado el mutante cos1 (coil suppressor1) que restablece la senescencia dependiente de JA, la expresión de algunos genes inducibles por JA ausentes en el mutante coil y la resistencia a Botrytis cinerea.

Otro de los mutantes de Arabidopsis deficiente en la respuesta a JA descrito por Lorenzo et al., 2004, jai1 (jasmonate-insensitive 1), tiene mutado un gen que codifica un factor de transcripción tipo bHLHzip que regula de forma antagonista dos ramas de la ruta de señalización de JA de manera dependiente de COI1. 


\subsection{Ruta del Etileno (ET).}

El etileno es la hormona vegetal de mayor simplicidad estructural. A pesar de ello, juega un papel importante en la regulación de un amplio espectro de procesos tales como maduración del fruto, senescencia de las hojas, desarrollo de las semillas, y la respuesta a una serie de agentes estresantes ambientales como el frío, la anegación, herida y el ataque por patógenos (Abeles et al., 1992).

Diferentes estudios genéticos han permitido identificar una serie de mutantes que tienen alterada la respuesta a etileno. La clonación de los genes correspondientes y su situación, por epistasia, en una ruta lineal, ha producido uno de los mapas más detallados entre los descritos sobre rutas de señalización en plantas (Johnson y Ecker, 1998; Srepanova y Ecker, 2000).

Es interesante resaltar que varios de los mutantes de etileno han sido también encontrados en búsquedas genéticas dirigidas a identificar componentes de otras rutas de señalización hormonal (Su y Howell, 1992; Fujita y Syono, 1996; Beaudoin et al., 2000; Ghassemian et al., 2000). El estudio de la respuesta de estos mutantes a otras hormonas ha sugerido que existe comunicación directa entre diferentes rutas de señalización (Beaudoin et al., 2000; Ghassemian et al., 2000).

La ruta de biosíntesis de etileno fue propuesta por primera vez en 1984 por Yang y colaboradores. El primer paso de esta ruta comienza a partir de S-adenosín-metionina (S-AdoMet, SAM), esta reacción está catalizada por la enzima S-adenosín-metionina sintasa (SAM sintasa). La S-AdoMet es el dador de grupos metilo a diversos aceptores, incluyendo ácidos nucleicos, proteínas y lípidos. Además, la S-AdoMet es el precursor biosintético de las poliaminas. El ácido aminociclopropano 1-carboxílico (ACC) es el precursor inmediato del 


\section{$\underline{\text { Introducción }}$}

etileno. La metiltioadenosina (MTA) es el otro producto generado junto con el ACC por la ACC sintasa. El reciclaje de la MTA a metionina conserva el grupo metilo y ayuda a mantener el nivel de metionina constante, aun cuando la velocidad de síntesis de etileno sea elevada. La conversión del ACC en malonil-ACC (MACC) hace descender el nivel de ACC y reduce la producción de etileno. El paso final de esta ruta biosintética es la conversión de ACC en etileno catalizada por la ACC oxidasa, obteniéndose también, anhídrido carbónico y ácido cianhídrico.

La conversión de la S-AdoMet en ACC por la ACC sintasa (ACS) es el paso limitante de la velocidad del proceso en circunstancias normales, y la actividad de esta enzima está estrechamente regulada. Múltiples genes de ACS están diferencialmente regulados por distintos factores de desarrollo y ambientales, tanto transcripcionalmente como post-transcripcionalmente. En algunos tejidos y en ciertas condiciones la biosíntesis de etileno también puede estar regulada en el paso correspondiente a la conversión de $\mathrm{ACC}$ en etileno catalizado por la ACC oxidasa (ACO). Se cree que existe un mecanismo regulador de fosforilación /desfosforilación de la ACC sintasa mediante fosfatasas y quinasas, siendo estas últimas presumiblemente activadas por agentes estresantes de distinta naturaleza.

Conocer el mecanismo mediante el cual las células perciben y responden a la hormona ha sido objeto de un intenso estudio. Sin embargo, sólo la utilización de aproximaciones de genética molecular durante la última década ha llevado a identificar las moléculas responsables de percibir el etileno y de responder a esta hormona vegetal (Stepanova y Ecker, 2000). Esta aproximación ha tomado como base la respuesta inducida por el etileno en plántulas de Arabidopsis cultivadas en la oscuridad. Estos cambios inducidos por etileno, lo que se ha llamado "triple respuesta", consisten en epinastia apical, 
engrosamiento radial e inhibición de la elongación del hipocotilo y de la raíz (Ecker, 1995). Se conocen un gran número de mutantes de Arabidopsis que tienen afectada su respuesta a etileno y pueden ser clasificados en tres grupos: insensibles a etileno (ein; ethylene insensitive) (Bleecker et al., 1988; Guzman y Ecker, 1990; Chao et al., 1997; Sakai et al., 1998; Solano et al., 1998; Alonso et al., 1999), específicos de tejido (eir1; ethylene insensitive root1 y hls1; hookless1) (Guzman et al., 1990; Roman et al., 1995; Guo y Ecker, 2004) y aquellos que presentan triple respuesta en ausencia de etileno exógeno. Este último grupo puede ser dividido en: sobreproductores de etileno (eto; ethylene overproducer) y mutantes con triple respuesta constitutiva (ctr; constitutive triple response) (Guzman et al., 1990; Kieber et al., 1993). La clonación y caracterización de los genes correspondientes está permitiendo obtener una visión completa de la señalización por etileno.

Recientemente se ha propuesto que la percepción y la señalización de etileno esta mediada por una familia de 5 receptores asociados a la membrana del retículo endoplasmático ( ETR1, ETR2, EIN4, ERS1 Y ERS2 "ethylene response sensor 1 y 2") (Stepanova y Ecker 2000; Chen y Chen, 2002). Estos receptores se caracterizan por contener 3 ó 4 regiones de apertura de membrana en su extremo amino terminal y un dominio histidina quinasa en su extremo carboxilo terminal. Su función es actuar como reguladores negativos de la respuestas a etileno, estando funcionalmente activos en ausencia de etileno e inactivándose por la unión de dicha hormona. Los 5 receptores actúan simultáneamente en la precepción de la señal, pues una mutación dominante en cualquiera de ellos confiere insensibilidad constitutiva a dicha hormona. Sin embargo las mutaciones de pérdida 


\section{$\underline{\text { Introducción }}$}

de función no tienen ningún efecto sobre el fenotipo (Guo y Ecker, 2004).

La forma activada de estos receptores activa constitutivamente una serin-treonin quinasa, CTR1, que también se localiza en el retículo endoplasmático (Gao et al., 2003) probablemente por su interacción directa con los receptores a través de dominios histidin quinasas presentes en estos últimos (Clark et al., 1998).

Entre los componentes "aguas abajo" en la ruta del etileno se encuentran varios reguladores positivos (EIN1, EIN5, EIN6 y los factores de transcripción EIN3, EIL1 y 2 “EIN3-like 1 y 2"). El nivel de la proteína EIN3 está controlada por etileno posiblemente vía proteasoma (Ub/26S) (Guo y Ecker, 2004).

Se sabe que varios factores de transcripción EREBP son dianas directas de EIN3/EIL1, los cuales pueden unirse a elementos primarios de la respuesta a etileno (PERE), en los promotores de los genes EREBP (Ethylene response element binding proteins), estos fueron identificados originalmente en base a su capacidad de unirse a las cajas GCC, un motivo de ADN asociado a la expresión de genes mediados por etileno, sin embargo posteriormente se ha demostrado que sólo unos pocos de ellos están regulados por etileno, estando involucrados pues en otros estímulos como es el caso de la respuesta a salinidad o la sequia y respondiendo a otras señales, como el SA o el JA.

Un EREBP llamado ERF1 (ETHYLENE-RESPONSIVE FACTOR 1), está también implicado en la regulación génica mediada por JA. Es probable que un factor de transcripción (TF) regulado por JA, no identificado todavía, pueda también unirse al promotor de ERF1 para activar su expresión. Por consiguiente, el promotor de ERF1 podría funcionar integrando señales tanto de la ruta del etileno como del JA. 
Otros EREBP pueden actuar de un modo semejante en la integración de acciones del etileno con señales del desarrollo y/o de otras señales hormonales. Se sabe que muchas proteínas EREBP regulan la expresión génica mediante la interacción con un elemento cis llamado caja GCC que se ha encontrado en varios genes de respuesta a etileno incluyendo el PDF1.2 (PLANT DEFENSIN 1.2) y HOOKLES 1 (HLS1). Estos genes codifican proteínas efectoras necesarias para que se produzca una amplia variedad de respuestas a etileno que van desde la resistencia a enfermedades al crecimiento celular diferencial (Guo et al., 2004).

Como ya se ha indicado, la ruta de señalización del etileno es una de las mejor definidas en las plantas. Sin embargo, el conocimiento detallado de los mecanismos bioquímicos de acción de cada uno de los componentes conocidos de dicha ruta está en sus inicios. Todavía no está claramente determinado qué actividad de los receptores de etileno está regulada por este compuesto ni cómo la unión del etileno modula la función de estos receptores. Independientemente de que existe evidencia de que CTR1 está regulado directamente por los receptores de etileno, los pasos bioquímicos que controlan tal regulación no se conocen bien. La implicación de una cascada MAPK y su papel en la transmisión de la señal de etileno son todavía difusas, y son necesarias pruebas genéticas más concluyentes.

Otra cuestión importante por resolver es la función de EIN2, una proteína que juega un papel esencial en la mediación de todas las respuestas a etileno conocidas. En Arabidopsis, la alteración de las respuestas patogénicas como consecuencia de la mutación ein2, se asemejan a lo que ocurre en los mutantes coi1 y jar1. Por ejemplo, la expresión de varios genes de defensa dependientes de JA, como 


\section{$\underline{\text { Introducción }}$}

PDF1.2, THI2.1(Thionin2.1), CHIB (chitinaseB), requieren la actividad de EIN2 (Penninckx et al., 1998; Norman-Setterblad et al., 2000).

También representa un desafío conocer los sucesos nucleares que determinan el modo en que el etileno controla la estabilidad/actividad de factores de transcripción primarios EIN3/EIL, así como dilucidar los pasos siguientes en la regulación génica.

Los experimentos encaminados a la determinación de los patrones globales de expresión génica demuestran que centenares de genes son inducidos o reprimidos por etileno (Alonso et al., 2003).

El etileno modula las respuestas de otras hormonas vegetales, tales como el JA, SA, auxinas, ácido abscísico (ABA) y citoquininas, pero estamos muy lejos de conocer los mecanismos que controlan cada una de estas importantes interacciones entre hormonas. Claramente, queda como desafío para el futuro empezar a integrar estas rutas hormonales de señalización, identificar sus puntos de intersección y determinar el significado de estas intercomunicaciones a nivel biológico.

\section{Interconexión entre las rutas defensivas.}

En la defensa de las plantas cabe distinguir, por una parte, el sistema de señales que conducen desde la percepción del patógeno a las respuestas y, por otra, los componentes de dichas respuestas. En todo este sistema hay una serie de relaciones de convergencia, divergencia, interacciones, etc., que contribuyen a conferir un carácter coordinado e integrado a todo el arsenal que componen el complejo sistema defensivo de las plantas.

Tal y como se ha expuesto anteriormente, no hay suficientes evidencias que demuestran que las rutas de señalización del JA, SA y 
ET no funcionan de forma independiente sino que están implicadas en una compleja red de señalización en la cual una de las rutas influencia al resto a través de interacciones reguladoras tanto sinérgicas como antagónicas.

Un elemento de coordinación e integración del sistema lo constituyen los factores de transcripción. En este sentido, se han descritos "cajas" o motivos de unión (PB/ as-1/ W-box/ GCC-Box) a proteínas reguladoras, activadas por estas moléculas señal (SA, ET, JA, $A B A$, etc). Así por ejemplo, sucede con el factor de transcripción AtWhy1, que se induce por SA (Ramachandran et al., 1994; OhmeTakagi et al., 2000; Desveaux et al., 2004).

Un punto de convergencia entre las rutas de etileno y $\mathrm{JA}$ en Arabidopsis es la activación transcripcional del factor de respuesta a etileno ERF1, factor de transcripción que regula la expresión de genes de respuesta a patógenos, impidiendo la progresión de la enfermedad (Lorenzo et al., 2003). Se conoce que la sobreexpresión de ERF1 puede contrarrestar los defectos de la respuesta de defensa de coi1 y de ein2, restaurando la expresión de los genes de proteínas PRs. Ello sugiere que ERF1 constituye un elemento de convergencia de las rutas de señalización de etileno y de jasmónico situado "aguas abajo" de ambos componentes. Datos en apoyo de esta idea han sido proporcionados por el análisis transcriptómico de plantas que sobreexpresan ERF1 (35S:ERF1), en las que se ha visto un solapamiento entre los genes activados y reprimidos por etileno y jasmonato (Devoto et al., 2003).

Otro ejemplo interesante lo constituyen los elementos cis responsables de la activación de genes que incluyen una secuencia GBox (CACGTG) y han sido identificados en las regiones del promotor de diversos genes de respuesta a jasmónico. En particular, se identificó un 


\section{$\underline{\text { Introducción }}$}

elemento de respuesta a elicitores y a jasmónico (JERE) en el promotor del gen Strictosidina sintasa (Str), que es un gen de biosíntesis de metabolitos secundarios de Catharanthus roseus (Menke et al., 1999). Posteriormente, se encontró que dos proteínas de respuesta de Catharanthus, inducibles por la ruta de los octadecanoides y con dominio-AP2 "APETALA2" (ORCAs), ORCA2 y ORCA3, median la expresión de genes de respuesta a jasmonato a través de la interacción con JERE (Menke et al., 1999; Van der Fits y Memelink, 2000). Las ORCAs pertenecen a la familia de factores de transcripción con dominio AP2/ERF. Cabe resaltar que esta familia de factores de transcripción está implicada en muchas respuestas inducidas por etileno (EREBF/ERF), estrés por frío (CBF/DREB1), y estrés ‘por sequía (DREB2) (Memelink et al., 2001; Cheong et al., 2003).

Los jasmonatos actúan sinérgicamente o antagónicamente con otras fitohormonas, tales como ET, SA, auxinas y ácido abscísico (ABA). En particular, combinaciones de MeJA y etileno, inducen sinergísticamente un grupo de genes de defensa (Creelman y Rao, 2002; Wasternack y Hause, 2002). El mutante de Arabidopsis cev1 produce constitutivamente jasmonatos y etileno, y presenta elevada resistencia a patógenos (Ellis y Turner, 2001). Resulta curioso, por tanto, que la inhibición del gen CEV1 (que codifica una celulosa sintasa de la pared celular) produzca la activación de genes de respuesta a jasmonatos y etileno (Cheong y Choi, 2003).

Se ha identificado un factor de transcripción, WRKY70, que es clave en el control de la respuesta a Erwinia carotovora, una bacteria necrotrofa que puede disparar la señalización de las defensas dependientes tanto de SA como de JA/ET (Kariola et al., 2003). La resistencia a este patógeno puede ser inducida por activación de rutas defensivas mediada por SA (Palva et al., 2000; Kariola et al., 2003) o 
por JA (Norman-Setterblad et al., 2000; Kariola et al., 2003). Estos autores caracterizaron la expresión de WRKY70 en respuesta a hormonas vegetales y a elicitores de patógenos y produjeron plantas transgénicas para identificar genes diana controlados por WRKY70. EI perfil de expresión en las plantas transgénicas sugiere que WRKY70 puede funcionar como un regulador positivo o negativo de la expresión de genes PRs. Estos estudios identificaron subconjuntos de genes divergentemente controlados por WRKY70 e indicaron que WRKY70 es un nodo de convergencia importante que integra la señalización de SA y JA durante la respuesta defensiva. Por otra parte, en este trabajo se demuestra que cuando los niveles de SA aumentan, se activa la expresión de genes WRKY70 y, por el contrario, cuando los niveles de JA aumentan, se reprime su expresión. También se demuestra que niveles altos del transcrito de WRKY70 promueven la activación de un subconjunto de genes PRs de respuesta a SA, mientras que niveles bajos favorecen la expresión de genes de respuesta a JA. Este modelo explicaría en parte el antagonismo mutuo entre la señalización de las defensas mediada por SA y JA e identificaría a WRKY70 como el nodo de interacción entre estas vías (Li et al., 2004).

Por otra parte, distintos estudios han demostrado que la activación de una determinada ruta afecta negativamente a la resistencia frente a ciertos grupos de patógenos o insectos.

Se ha demostrado también que la aplicación de BTH, inductor de SAR, también tiene un efecto negativo sobre la resistencia a insectos. Así, Thaler et al., 1999, demostraron que la aplicación de BTH a plantas de tomate cultivadas en el campo disminuía la resistencia a las larvas de Spodoptera exigua. En la mayor parte de los casos, la reducción de la resistencia a insectos observada en plantas que expresan SAR se ha 


\section{$\underline{\text { Introducción }}$}

atribuido a la inhibición de la producción de JA por BTH o aumento de los niveles de SA.

Aunque la existencia de interacciones negativas entre las rutas de defensa contra patógenos e insectos ha sido claramente demostrada, no siempre se produce esta relación negativa. Un ejemplo muy ilustrativo de resistencia simultánea frente a patógenos e insectos fue aportado por Zehnder et al., 2001. En experimentos llevados a cabo en campo con pepino, estos autores observaron que la inducción de ISR mediada por rizobacterias, contra la bacteria Erwinia tracheiphila, transmitida por insectos, estaba asociada con una reducción del desarrollo del insecto vector. Parece que la inducción de ISR estaba relacionada con el descenso de las concentraciones de cucurbitacina, un metabolito secundario y poderoso estimulante de la alimentación para el escarabajo de la calabaza. La inducción de ISR contra E. tracheiphila fue eficaz también en ausencia del escarabajo vector, sugiriendo que la ISR protege a la calabaza contra la podredumbre bacteriana, no solo reduciendo la alimentación y, por lo tanto, la población del insecto vector y la transmisión del patógeno, sino también mediante la inducción de respuestas defensivas que son activas directamente contra el patógeno.

La cuestión de si las resistencias mediadas por SA y por JA contra patógenos pueden ser expresadas simultáneamente fue abordada por van Wees et al. 2000. En Arabidopsis, las respuestas SAR (dependientes de SA) y activadas por patógenos y las ISR (mediadas por JA/ET) y activadas por rizobacterias no patogénicas, son eficaces contra varios patógenos, aunque sus espectros de eficacia divergen en parte. Sin embargo, ambas rutas son eficaces contra $P$. syringae pv. tomato. La activación simultánea de SAR y de ISR produjo un efecto aditivo en el nivel de protección inducida contra este patógeno. 
El análisis genético y molecular de mutantes y plantas transgénicas alterados en su resistencia a patógenos ha revelado que las rutas de señalización dependientes de SA, JA y ET juegan un papel dominante en el sistema de defensas inducibles de las plantas. Las tres moléculas están implicadas en la activación de distintos grupos de genes relacionados con la defensa, produciendo una resistencia diferencial frente a grupos específicos de patógenos. Existe una amplia evidencia de que las rutas mediadas por estas tres moléculas pueden interaccionar entre sí, tanto positiva como negativamente. Esta comunicación entre rutas proporciona un gran potencial regulador para activar múltiples mecanismos de resistencia en combinaciones variables y puede ayudar a priorizar una ruta frente a otra, proporcionando, así, una defensa óptima y eficaz.

Finalmente, es interesante resaltar que algunas cascadas de MAPKs (MAPK kinasas, MAPKKs y las MAPKKKs), constituyen elementos de convergencia de las rutas de señalización de la respuesta a agentes estresantes ambientales, tanto bióticos (diferentes patógenos), como abióticos (herida, cambios de temperatura, sequía, salinidad, radiaciones UV, ozono, especies reactivas de oxígeno). Moléculas intermediarias en la señalización, tales como el SA, el etileno o la sistemina, también activan MAPKs. A pesar de que el número de MAPKs que parecen estar implicadas es pequeño, las posibilidades de diversidad y especificidad de su señalización en los distintos casos pueden estar multiplicadas mediante factores cinéticos y grados de activación diferenciales. También es posible que las MAPKs controlen un subconjunto de respuestas defensivas compartidas por diferentes estímulos (Zhang y Klessig, 2001; Chinnusamy et al., 2004). 

II. Objetivos. 



\section{Objetivos.}

Con el fin de profundizar en el estudio del gen Ep5C y su participación en los mecanismos de defensa de las plantas frente a patógenos, nos propusimos los siguientes objetivos:

1. Aislamiento y caracterización del gen Ep5C de tomate. Implicación funcional de $E p 5 C$ en plantas transgénicas de tomate. Análisis de la expresión de dicho gen en plantas transgénicas de Arabidopsis thaliana.

2. Identificación de mutantes de Arabidopsis thaliana alterados en la regulación transcripcional de Ep5C-GUS. Caracterización genética y molecular del mutante ocp3 de Arabidopsis thaliana. Cartografiado del gen OCP3. Evaluación del comportamiento del mutante ocp3 de Arabidopsis thaliana frente a la infección por diferentes patógenos. 

III.Resultados. 

III.a. Capítulo 1. 



\title{
The $\mathrm{H}_{2} \mathrm{O}_{2}$-regulated $\mathrm{Ep} 5 \mathrm{C}$ gene encodes a peroxidase required for bacterial speck susceptibility in tomato
}

\author{
Alberto Coego, Vicente Ramirez, Phillipe Ellul, Esther Mayda ${ }^{\dagger}$ and Pablo Vera* \\ Instituto de Biología Molecular y Celular de Plantas, U.P.V.-C.S.I.C., Camino de Vera, s/n 46022 Valencia, Spain \\ Received 3 November 2004; revised 10 January 2005; accepted 18 January 2005. \\ *For correspondence (fax 34-963877859; e-mail vera@ibmcp.upv.es). \\ ${ }^{\dagger}$ Present address: Division of Molecular Pathology, Department of Pathology, Walter Reed Army Institute of Research, 503 Robert Grant Avenue, Silver Spring, MD \\ 20910, USA.
}

\begin{abstract}
Summary
Bacterial speck caused by the pathogen Pseudomonas syringae pv. tomato $(P$. $s$. tomato) is a devastating disease of tomato plants. Here we show that inhibition of Ep5C gene expression, which encodes a secreted cationic peroxidase, is sufficient to confer resistance against $P$. $s$. tomato. The inhibition of Ep5C protein accumulation in antisense tomato plants established resistance that was not accompanied by the preactivation of known defense pathways. Therefore, Ep5C inhibition represents a novel form of disease resistance based on a loss-of-gene function in the plant required for successful infection by a compatible bacterial pathogen. Ep5C expression is rapidly induced by $\mathrm{H}_{2} \mathrm{O}_{2}$, a reactive oxygen intermediate normally generated during the course of a plant-pathogen interaction. This was corroborated by monitoring the expression of an Ep5C-GUS gene in transgenic Arabidopsis plants. Collectively, these results identify a signaling pathway that uses early signals generated during the oxidative burst, such as $\mathrm{H}_{2} \mathrm{O}_{2}$, for the selective activation of host factors required for mounting a compatible interaction. Thus, Ep5C provides a new resource for developing bacterial speck disease-resistant varieties.
\end{abstract}

Keywords: defense, PRs, pathogen, disease, susceptibility.

Introduction

In nature, plants are constantly challenged by diseasecausing pathogens, and, as a result, they have evolved intricate defense mechanisms to recognize and defend themselves against a wide array of these pathogens. Preformed physical and chemical barriers constitute the first line of defense. Superimposed upon these is a battery of inducible responses, their engagement being dependent upon successful recognition of the invading pathogen (Hammond-Kosack and Jones, 1996). Systemic acquired resistance (SAR; Ross, 1961; Sticher et al., 1997) is one such inducible defense response that is triggered in the plant by previous exposure to pathogens that cause cell death. A more rapid defense response that precedes the onset of SAR is the hypersensitive response (HR; Agrios, 1988), which is localized at the site of attempted pathogen entry. The HR is characterized by programmed death of host cells and is a consequence of an exquisitely specific recognition event thought to be mediated via the direct or indirect interaction between the product of a pathogen avirulence (avr) gene and the corresponding plant disease resistance $(R)$ gene product. Tightly correlated with the HR and SAR is the production of antimicrobial compounds, the increased expression of a subset of the pathogenesis-related (PR) proteins, many of which possess antimicrobial activities, and the reinforcement of previously established physical/chemical barriers (Sticher et al., 1997).

One of the most rapid defense responses engaged following pathogen recognition is the so-called oxidative burst, which constitutes the production of reactive oxygen intermediates, primarily superoxide $\left(\mathrm{O}_{2}\right)$ and $\mathrm{H}_{2} \mathrm{O}_{2}$, at the site of attempted invasion (Apostol et al., 1989; Baker and Orlandi, 1995). The emerging evidence suggests the oxidative burst and cognate redox signaling may play a central role in the integration of a diverse array of plant defense responses (Grant and Loake, 2000; Loake, 2001). Subsequent to this rapid oxidative burst, two major pathways through which defense genes can be activated have been described (Dong, 1998; Kunkel and Brooks, 2002); one requires the synthesis and accumulation of salicylic acid (SA), while the other requires ethylene and jasmonic acid (JA). To date 
the oxidative burst and cognate redox signaling remains poorly understood. In contrast signaling through the SA and JA pathways have been relatively well defined (HammondKosack and Parker, 2003). From these studies the signaling networks underlying the establishment of disease resistance are beginning to emerge.

At variance with knowledge about how plants achieve both broad-range and pathogen-specific resistance, very little is known of the mechanisms and genes required for pathogen susceptibility. Plant susceptibility factors, here defined as host determinants required for pathogen growth and reproduction, have been largely overlooked. In an effort to identify these factors, Vogel et al. (2002) sought to identify mutants in Arabidopsis that do not support the growth of the powdery mildew pathogen Erysiphe cichoracearum in the absence of activated cell death, SA or JA response pathways. As a result, they identified the PMR6 gene encoding a pectate lyase-like protein involved in the remodeling of the plant cell wall. Thus pmr6-mediated protection represented a novel form of disease resistance based on the loss of a key gene function required to establish a compatible interaction rather than the activation of known host defense pathways (Vogel et al., 2002). Likewise, the COI1 gene represents another example of a gene that is required for full susceptibility to virulent pathogens. Loss of COI1 function presumably results in reduced disease susceptibility due to a loss of sensitivity to the Pseudomonas syringae virulence factor coronatine (Feys et al., 1994; Kloek et al., 2001). In addition, in this context, there are some other type of plant metabolites that functioning as host susceptibility factors act as signal molecules to reprogram microorganisms for the induction of genes required for symbiosis or pathogenesis (Denarié et al., 1992; Stachel and Zambryski, 1986). In general, it is assumed that susceptibility factors function in plant growth and development and the pathogen, during the course of evolution, has adapted to manipulate these factors to aid host colonization.

Here, we report the characterization of $E p 5 C$, a gene from tomato plants encoding a secreted peroxidase enzyme whose expression is rapidly induced by $\mathrm{H}_{2} \mathrm{O}_{2}$. We also show that inducible expression of $E p 5 C$ is inhibited by means of Ep5C-antisense RNA. This resulted in tomato plants that exhibited reduced disease susceptibility toward $P$. syringae pv. tomato, the causal agent of speck disease. These results suggest that Ep5C may represent a novel host susceptibility factor that is required for successful colonization, growth and disease production by $P$. syringae.

\section{Results}

\section{Expression pattern of Ep5C in tomato plant}

Numerous cDNA clones representing genes upregulated in diseased tissues of tomato plant have been isolated (Gadea et al., 1996). While some of these genes have been characterized in detail (Carrasco et al., 2003; Mayda et al., 2000a,b), others remain unexplored. One of these latter genes, here named as Ep5C, corresponded to one of the previously described cDNA clones (e.g., pCEVI-16; Gadea et al., 1996). Ep5C encodes a 33-kDa cationic peroxidase homologous to a peroxidase, PNC2, and accumulates in the extracellular matrix of peanuts cells (Buffard et al., 1990). Ep5C was the subject of detailed study in the present work because it exhibited an interesting pattern of gene expression upon challenge with $P$. s. tomato, the causal agent of bacterial speck disease in tomato. Ep5C gene expression is induced in tomato leaves upon inoculation with $P$. s. tomato in a fashion similar to that observed for the induced expression of the classical $P R$ genes (e.g., PR-1) (Figure 1a). However, induction of Ep5C was not observed when leaf tissue was infiltrated with signal molecules that mediate induction of defenses such as SA, 1-aminocyclopropane-1-carboxylate (ACC, the precursor of ethylene), methyl jasmonate (MeJA), or wounding. In contrast, the corresponding marker genes used as positive controls (e.g., PR-1 for SA and ACC, or pinl for MeJA and wounding) were clearly induced in treated leaves (Figure 1a).

To understand in more detail how Ep5C gene expression might be regulated during the course of compatible and incompatible plant-pathogen interactions, we inoculated either resistant $\left(\mathrm{Pto}^{+}\right)$or susceptible $\left(\mathrm{Pto}^{-}\right)$tomato plants with $P$. s. tomato with or without the avrPto avirulence gene (Martin et al., 1993). Upon inoculation with P. s. tomatoavrPto, Ep5C transcripts accumulated at high levels at $2 \mathrm{~h}$ post-inoculation (h.p.i.) both in $\mathrm{Pto}^{+}$and $\mathrm{Pto}^{-}$plants (Figure 1b), but not in mock-inoculated plants (not shown). At 4-6 h post-inoculation Ep5c is expressed at lower levels in the compatible interaction when compared with the incompatible interaction, suggesting that triggering of an $H R$ response in the plant sets in motion a more rapid induction of this gene. The accumulation of Ep5C transcripts was transient in the incompatible interaction with no detectable level of mRNA accumulation remaining at 48 h.p.i.. In the course of the compatible interaction, however, the induced expression of Ep5C persisted at 48 h.p.i. (Figure 1b) and even after 72 h.p.i. (data not shown).

This abrupt induction of Ep5Cgene expression operates on a local basis as it occurs only in the tissues that are close to the inoculation site, and not in the non-inoculated tissues of the other half of the same leaf (Figure 1c). In tissues distal to the inoculation site Ep5C expression is not induced while activation of $P R-1$ marker gene expression is primed (Figure 1c).

\section{Ep5C induction by $\mathrm{H}_{2} \mathrm{O}_{2}$}

Extracellular superoxide production and subsequent generation of $\mathrm{H}_{2} \mathrm{O}_{2}$ are early signals generated during the oxidative burst triggered by both compatible and incompatible interactions (Sutherland, 1991). These are critical signals for 
(a)

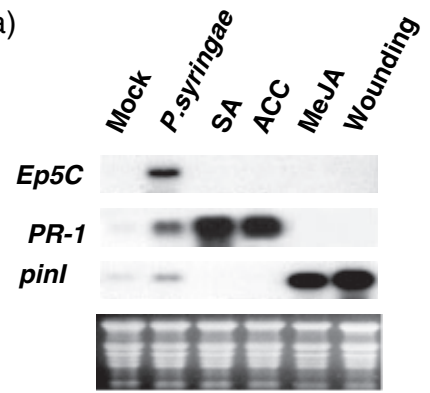

(b)

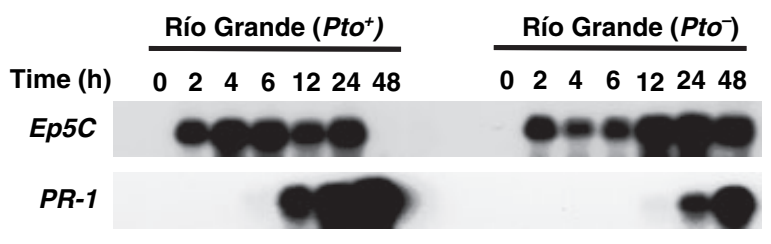

(c)

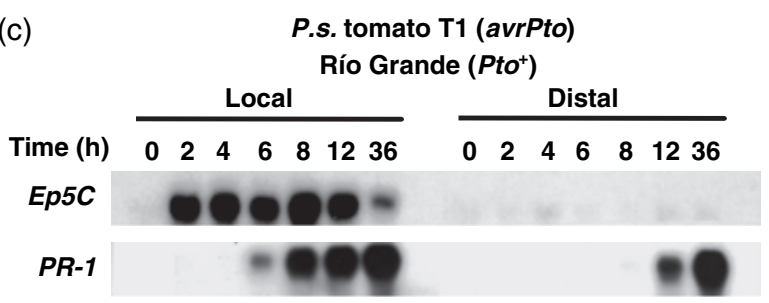

Figure 1. Local induction of $E p 5 C$ gene expression by $P$. s. tomato infection in tomato leaves.

(a) Comparative induction of $E p 5 C, P R-1$, and pinl mRNAs in leaf tissue of tomato plants $12 \mathrm{~h}$ after inoculation with $P$. $s$. tomato, or 1.5 days after infiltrating leaves with $0.5 \mathrm{~mm}$ salicylic acid (SA), with $0.1 \mathrm{~mm} 1$-aminocyclopropane-1-carboxylate (ACC), and in leaves that were severely wounded with a razorblade or that were infiltrated with $50 \mu \mathrm{m}$ of methyl jasmonate (MeJA). Mock represent leaves infiltrated with buffer.

(b) Time course for accumulation of Ep5C and PR-1 mRNAs in the resistant $\left(\mathrm{Pto}^{+}\right)$and susceptible $\left(\mathrm{Pto}^{-}\right)$Rio Grande isogenic lines of tomato after inoculation with $P$. s. tomato carrying the avirulence gene avrPto.

(c) Local, but not distal, accumulation of Ep5C mRNA in the resistant (Pto ${ }^{+}$) Rio Grande tomato leaves after inoculation with $P$. s. tomato carrying the avirulence gene avrPto. Here inoculation was performed only in one half of the leaflet, considered as local leaf tissue, and the other non-inoculated half was considered as distal leaf tissue. The numbers on top indicate time after inoculation in hours. The experiments were repeated two times with similar results. Loading was monitored by staining the gels with ethidium bromide.

initiating an HR cell death program (Jabs et al., 1996) and also for the induction of protective genes (Alvarez et al., 1998; Grant and Loake, 2000). We therefore addressed whether local production of extracellular superoxide [via infiltration of xanthine and xanthine oxidase (X-XO) into intercellular spaces] or $\mathrm{H}_{2} \mathrm{O}_{2}$ [via infiltration of glucose and glucose oxidase (G-GO) into intercellular spaces] would trigger Ep5C gene expression. The results in Figure 2(a,b) indicate that both treatments were able to trigger the accumulation of $E p 5 C$ transcripts to a similar magnitude. This suggests that the characteristic expression pattern of this gene following inoculation with $P$. s. tomato may be modulated by either superoxide or $\mathrm{H}_{2} \mathrm{O}_{2}$ generated in the (a)

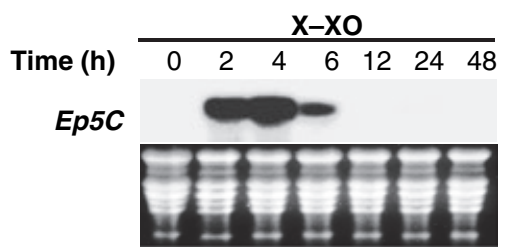

(b)

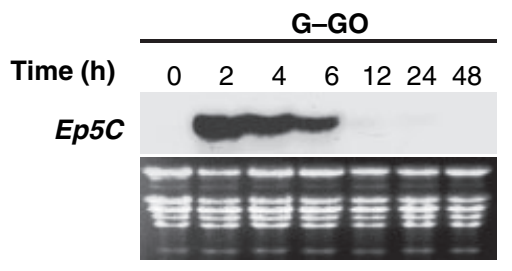

(c)

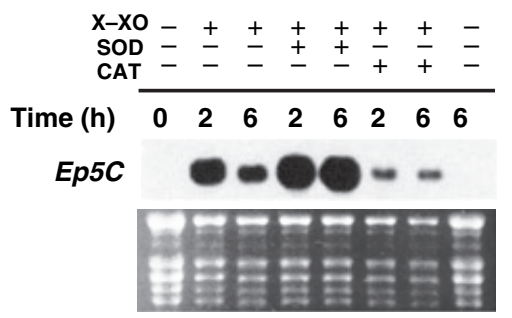

(d)

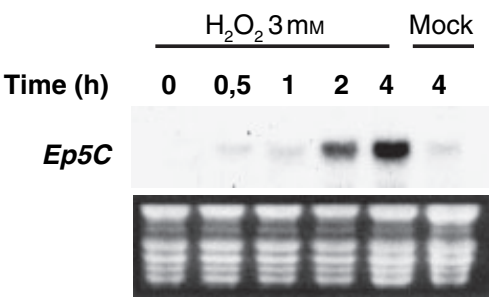

(e)

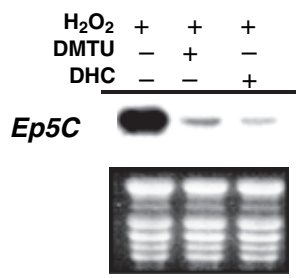

Figure 2. Reactive oxygen intermediate-mediated induction of Ep5C in tomato leaves.

(a) Time course for the induction of Ep5C transcripts by superoxide as generated via inoculation of xanthine and xanthine oxidase (X-XO) into intercellular spaces.

(b) Time course for the induction of $\mathrm{Ep} 5 \mathrm{C}$ transcripts by $\mathrm{H}_{2} \mathrm{O}_{2}$ as generated via inoculation of glucose and glucose oxidase (G-GO) into intercellular spaces. (c) Selective inhibition of the X-XO-mediated induction of Ep5C transcript accumulation by catalase. A superoxide generating cocktail (X-XO) was infiltrated in the intercellular spaces either alone or in the presence of superoxide dismutase (SOD) or catalase (CAT). Only the $\mathrm{H}_{2} \mathrm{O}_{2}$-degrading CAT, and not the superoxide-degrading SOD, was able to inhibit induction of $E p 5 C$. (d) Time course for accumulation of Ep5C transcripts by $3 \mathrm{~mm} \mathrm{H}_{2} \mathrm{O}_{2}$ when directly infiltrated into intercellular spaces of tomato leaves.

(e) Inhibition of $E p 5 C$ induction by $\mathrm{H}_{2} \mathrm{O}_{2}$ traps. 2,5-dihydroxycinnamic acid methyl ester (DHC, $50 \mu \mathrm{m}$ ) or dimethylthiourea (DMTU, $0.2 \mathrm{~mm}$ ) were simultaneously infiltrated with a 3-mM $\mathrm{H}_{2} \mathrm{O}_{2}$ solution into the apoplast of tomato leaves and mRNA isolated $3 \mathrm{~h}$ later. Time scales are expressed in hours. (-/+) symbols denote absence and presence, respectively, of the relevant component. These experiments were repeated two times with similar results. 
(a)

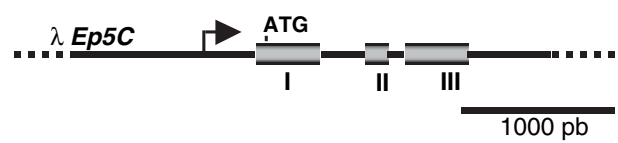

(b)

-1140 GTCGACCTGCAGGTCAACGGATCTCATACTTTAGTACTAGTAAAGAGTAA

-1090 TCCCTACCTTTTCTTTAGTCAACATTTCACATTATTAGCTTATCACTTGT

-1040 GACACCCAAACACCCTACAAAATTCACTATTTTATGCCTACAAATTTACG

-990 TGCAAATCTCATATATTATGAATACGTAATATATAAATATATTTTTTAAC

-940 TTGACTTTATTTTATATTTGTATTTTTTAATTTTGAATGTGTATAAGTAG

-890 CTATTTAAATCTATACATAGAGTTGAACAAGTAGACACATGAGTCCGATG

-840 TGACATACTACACGCAGAGCACCACATAGAACACAAATTGTTAGGTAGGA

-790 TGTCACGTGGGACGTATTTGTTTATTTGTTCAATTT $\overline{\overline{T A T A C A A}} \overline{\text { GTTTGA }}$

-740 TGTCTACTTATGCATACTCAAAGTTGGACCCCATAAATGTAAAATGACGT

-690 AAAGTTAAAAGGGCATATTTATGTATTATGCCTATATATTAATTACAAAC

-640 ATGAGCTAAAAGAGACGAGACAAAACAAGGACGCTATTTTTTTTAAAAAA

-590 TCTCAATTTATAGAACATTTTATTTTTTAGTCTTTATAAAATGAATTATA

-540 TAATTCTATATTTAGTAAAAGTTTTATTTTAAAATGATCATTTTAATAAA

-490 ATGATTTGTGGTCATACAACATCTGTAACTTATTTTAAATTATATATTTT

-440 AAATTTTAATCTTTTTTTCGTAAATTTTATATCAAAAAGATACTAATCTA

-390 TATCACATAAATTGAAACACAGAGAATAACGGTTAGTTGCTTGCCAACTC

-340 ATGACCACAAAACAGCGTTGAATTCTTGATCCACCACTCACCTCACCTCA

-290 AAAAAGCTTTAAAAAACACACACAATTAGTAATTTTCATTAATAAAGAAG

-240 AAAAAAAATAAAATCAAACGCGTATAGGCCCCATATAGTCATTTTCAAGT

-190 ATTGTTAGCCACCTTTGCTTACTCGTAGTCTCTTACTCCATTGATCTAGC

-140 TACAAAAGTTGCATGTATATCCTTTATTTACTTGTGCCTATAAATATATC

-90 CAGGTTTCTTATACAATTTCAATCATTAAGCAACGTAACGAAAACTAAAA

- 40 GAAAGTAGAATTTTATCACAGTACGTACATAACACCAAAT

apoplast following plant-pathogen interactions (HammondKosack and Jones, 1996). As extracellular generation of superoxide during pathogenic interactions is rapidly converted to $\mathrm{H}_{2} \mathrm{O}_{2}$ by the action of extracellular superoxide dismutase (SOD) (Sutherland, 1991), we entertained the possibility that the cue for $E p 5 \mathrm{C}$ expression may be $\mathrm{H}_{2} \mathrm{O}_{2}$ rather than superoxide. Consistent with this idea, co-infiltration of catalase (which degrades $\mathrm{H}_{2} \mathrm{O}_{2}$ ) in combination with $\mathrm{X} / \mathrm{XO}$, significantly reduced Ep5C expression (Figure 2c). Conversely, when the enzyme SOD (which converts superoxide into $\mathrm{H}_{2} \mathrm{O}_{2}$ ) was co-infiltrated with $\mathrm{X}$-XO, expression of $E p 5 C$ was super-induced with respect to the level of induction observed with $\mathrm{X}-\mathrm{XO}$ alone. As a complementary test, we examined whether $\mathrm{H}_{2} \mathrm{O}_{2}$, when infiltrated into intercellular spaces, is able to promote expression of $E p 5 C$. Figure 2(d) demonstrates that $\mathrm{H}_{2} \mathrm{O}_{2}$ per se is able to promote induction of $\mathrm{Ep} 5 \mathrm{C}$. Furthermore, dimethylthiourea (DMTU) which functions as a trap for $\mathrm{H}_{2} \mathrm{O}_{2}$ and also 2,5-dihydroxycinnamic acid methyl ester (DHC) which functions as a peroxidase-mediated trap for $\mathrm{H}_{2} \mathrm{O}_{2}$ are able to block Ep5C induction by exogenous $\mathrm{H}_{2} \mathrm{O}_{2}$ (Figure 2e). In sum these data suggest that $\mathrm{H}_{2} \mathrm{O}_{2}$ may be the signal that sets in motion the characteristic expression of $\mathrm{Ep} 5 \mathrm{C}$.

Analysis of Ep5C gene expression in transgenic Arabidopsis plants containing a promoter-GUS fusion

To gain further insight into Ep5C expression, an Ep5C cDNA was used as a probe to isolate the cognate structural gene from a $\lambda$-EMBL3 genomic library from tomato. This
Figure 3. Characterization of the $E p 5 C$ genomic clone.

(a) Schematic representation of the Ep5C gene. Boxes represent the three exons.

(b) Nucleotide sequence of the $5^{\prime}$ promoter region of $\mathrm{Ep} 5 \mathrm{C}$. The first nucleotide preceding the initiation ATG codon is used to number $(-1)$ the promoter sequence. The ATTGTTA sequence indicative of the MYB motif is double underlined. The GGTAGG and CACGTG motifs corresponding to $\mathrm{H}$ and $\mathrm{G}$ boxes, respectively, are also underlined. screening rendered the isolation of a genomic clone with a $22-\mathrm{kb}$ insert that was sequenced and characterized. Alignment of the genomic and cDNA sequences revealed the presence of two introns in the transcribed region (Figure 3a). Furthermore, Southern blot analysis with tomato DNA digested with different enzymes indicated that $\mathrm{Ep} 5 \mathrm{C}$ is present as a single copy gene per haploid genome (data not shown).

Inspection of conserved motifs in the $5^{\prime}$ promoter sequence of the $E p 5 C$ gene revealed the presence of a conserved AAATTGTTA cis-acting element, between positions -806 and -798 , which is characteristic of some mybregulated genes (Gubbler et al., 1999; Figure 3b). Adjacent to this motif is the presence of an $\mathrm{H}$ box-like sequence (GGTAGG; at -797 to -792 ) and a $\mathrm{G}$ box (CACGTG; at -787 to -782) similar to those conserved in some genes of the phenylpropanoid pathway (Loake et al., 1992; Figure 3b).

To further explore the control of Ep5C expression, $1140 \mathrm{bp}$ of the $5^{\prime}$ promoter sequence was fused to the GUS reporter gene. This was introduced into Arabidopsis plants by transformation with Agrobacterium tumefaciens, and the transgenic plants were used to study the transcriptional regulation of $E p 5 C$. Several transgenic lines containing a single insert for the Ep5C-GUS construct were selected and assayed for GUS expression at the tissue level.

None of the selected transgenic lines showed constitutive expression of Ep5C-GUS, but instead showed induction of GUS expression upon challenge with different cues, in a manner that reproduced the data derived from the previous Northern blot analysis. In fact, GUS expression was locally 
Figure 4. Localized Ep5C-GUS gene expression in transgenic Arabidopsis plants.

(a) Histochemical localization of GUS activity at different times after inoculation of leaves from Ep5C-GUS transgenic Arabidopsis plants with the virulent P.s.t. DC3000 (upper panel), with the avirulent P.s.t. DC3000 (avrRpm 1) (middle panel), or with $10 \mathrm{mM} \mathrm{MgCl}_{2}$ (lower panel).

(b) Induced GUS activity in leaves $12 \mathrm{~h}$ after infiltrating a 3-m $\mathrm{H}_{2} \mathrm{O}_{2}$ solution into the intercellular spaces.

(c) Quantitative effect on induction level of GUS activity by $\mathrm{H}_{2} \mathrm{O}_{2}$ or by a superoxide-generating cocktail $(\mathrm{X}-\mathrm{XO})$ infiltrated into the intercellular spaces either alone or simultaneously with $600 \mathrm{U} \mathrm{ml}^{-1}$ of SOD or $100 \mathrm{U} \mathrm{ml}^{-1}$ of CAT. Note that only the $\mathrm{H}_{2} \mathrm{O}_{2}$-degrading catalase, and not the superoxide-degrading SOD, was able to inhibit induction of GUS activity by the X-XO cocktail. GUS activities are the mean \pm SD from at least three independent experiments. (a)

$\mathbf{O h}$

\section{P.s.t DC3000}

\section{P.s.t DC3000 (AvrRpm1)}

Mock induced upon inoculation with P. s. tomato DC3000 (P.s.t. DC3000; Whalen et al., 1991) which renders a compatible interaction in the Col-0 ecotype used to generate the transgenics (Figure 4a). Similarly, inoculation of the same transgenic Arabidopsis lines with a PstDC3000 carrying the avirulence avrRpm1 gene (Debener et al., 1991) results in an incompatible interaction that resulted in the local induction of GUS activity at the site of bacterial inoculation. However, this latter induction of GUS expression was not durable as it disappeared soon after the HR program was executed (Figure 4a). No GUS activity was observed in mock-inoculated plants (Figure 4a). Thus, the results parallel those obtained in tomato plants (Figure 1). In total these data suggest that the profile of Ep5C expression is similar in response to either virulent or avirulent strains of $P$. syringae and is limited to the area surrounding the site of attempted infection. The direct infiltration of an $\mathrm{H}_{2} \mathrm{O}_{2}$ solution into the intercellular spaces of Arabidopsis leaves (Figure 4b) or its direct generation from a G-GO cocktail (data not shown) triggered local induction of GUS activity driven by the Ep5C promoter. Furthermore, $\mathrm{X}-\mathrm{XO}$ cocktail combinations in which catalase or SOD enzymes are co-infiltrated into intercellular spaces of transgenic Arabidopsis leaves (Figure 4c) also reproduced the data derived from tomato plants (Figure 2).These data again favor the interpretation that $\mathrm{H}_{2} \mathrm{O}_{2}$ is most likely the signal molecule that triggers expression of Ep5C. Therefore, these studies confirmed that information for all major aspects of Ep5C gene induction is contained within the first $1140 \mathrm{bp}$ of the $5^{\prime}$ promoter region.
Generation of transgenic tomato plants with increased and reduced Ep5C protein level

To study the potential role of Ep5C in the host resistance response against $P$. syringae a series of sense and antisense transgenic tomato plants were generated. To upregulate the expression of $E p 5 C$, the complete coding sequence of $E p 5 C$ was introduced in the sense orientation downstream from the constitutive $35 \mathrm{~S}$ promoter of $\mathrm{CaMV}$ to generate construct 35S-Ep5Csense as described in Experimental procedures. Similarly, to downregulate expression of $E p 5 C$, a partial sequence of the $E p 5 C$ gene was introduced in the antisense orientation downstream of the $35 \mathrm{~S}$ promoter to generate construct 35S-Ep5Cantisense. These constructs were used to generate transgenic tomato plants via Agrobacteriummediated transformation as described previously (Mayda et al., 1999).

RNA gel blot analysis was used to detect the accumulation of transcripts from the transgenes in several $\mathrm{T}_{2}$ transgenic lines selected and containing a single insertion for each gene construct. The results shown in Figure 5(a) indicate that both, the sense and the antisense RNAs were produced, albeit with different levels of accumulation, in the transformed lines selected but not in the untransformed UC82B wild-type line. To complement these studies at the protein level, we generated an antibody against the $\mathrm{C}$-terminal region of Ep5C. For this, a GST-Ep5C fusion protein was constructed and purified as described in Experimental procedures. The GST-Ep5C protein was used as immunogen in rabbits to generate polyclonal antibodies. These antibodies were 
(a)

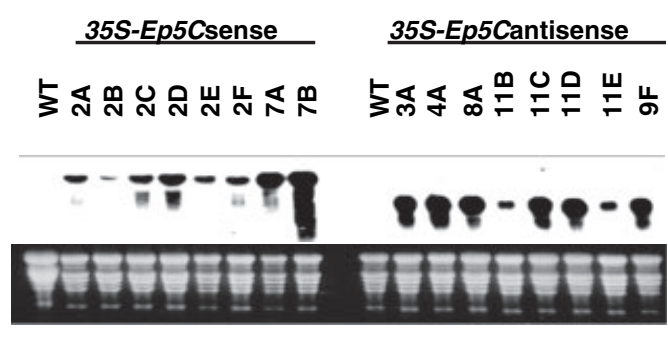

(b)

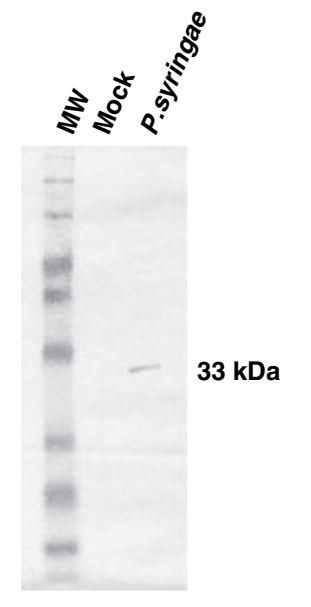

(c)

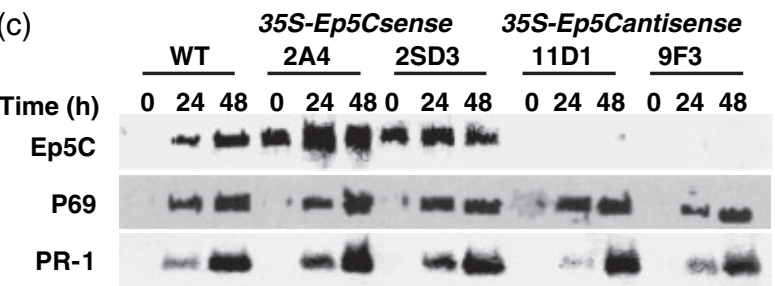

Figure 5. Immunoblot and RNA gel blot analysis of Ep5c in sense and antisense transgenic lines.

(a) Total RNA was extracted from leaves from wild type (WT) and eight transformed lines generated with the sense (35S::Ep5Csense) and with the antisense (35S-Ep5Cantisense) constructs and samples were hybridized with an Ep5C gene-specific probe.

(b) Immunoblot analysis with the Ep5C antibody of proteins extracted from wild-type plants that were inoculated with either a mock solution or $P$. $s$. tomato.

(c) Protein gel blot analysis with Ep5C antibody of proteins extracted from WT plants, from plants representing two sense transgenic lines (2A4 and 2SD3) and from plants representing two antisense transgenic lines (11D1 and 9F3) that were inoculated with $P$. s. tomato for 0,24 , or $48 \mathrm{~h}$. The same protein extracts were also analyzed for induced accumulation of the PR-1 and P69 using specific antibodies for these defense-related proteins from tomato.

specific toward a 33-kDa protein that accumulates to detectable levels in $P$. s. tomato-infected tomato leaves while no protein is recognized by the same antibody in crude protein extracts from mock-inoculated plants (Figure 5b). Using this specific antibody, we studied the presence of the Ep5C protein in crude protein extracts derived from the sense and the antisense plants. Most of the selected sense lines showed constitutive accumulation of Ep5C protein while the wild type and all the antisense transgenic lines did not (see below). In addition, neither sense nor antisense expression of Ep5C in transgenic tomato plants had any noticeable effect on normal growth and development in successive generations.

Because expression of Ep5C is rapidly induced by $P$. $s$. tomato infection in wild-type tomato plants, some of the selected transgenic lines were evaluated for the induced accumulation of Ep5C protein after inoculation with $P$. $s$. tomato. We show here the results for two of the sense lines (lines 2A4 and 2D3) and for two antisense lines (lines 11D1 and 9F3). The results were compared with wild-type plants and also with azygotic plants derived from the initial $T_{1}$ transgenic plants and verified to be devoid of any transgene (data not shown). Western blots of wild-type plants show that $\mathrm{Ep5C}$ is absent in untreated plants but accumulates to high levels at 24 and $48 \mathrm{~h}$ after inoculation with P. s. tomato (Figure 5c). Each of the transgenic lines expressing the sense construct (Figure $5 \mathrm{c}$ ) shows that the Ep5C protein accumulates to high levels in untreated plants. Furthermore, slight increases in the accumulation of Ep5C over its constitutive level were detected upon challenge with $P$. $s$. tomato. Conversely, none of the transgenic lines expressing the antisense construct (results shown for lines 11D1 and 9F3, Figure 5c) showed detectable Ep5C following inoculation with $P$. s. tomato. Thus, the antisense plants are blocked in the induced accumulation of Ep5C protein, while the sense plants are clear overproducers of the same protein. Furthermore, as transcript accumulation of the endogenous Ep5C gene upon induction by $P$. s. tomato infection is unaffected in the antisense plants (data not shown), the lack of accumulation of $\mathrm{Ep5C}$ protein in the antisense lines is attributable to an inhibition of the translation of the endogenous Ep5C mRNA by interference with the antisense transcripts. The results thus indicate that inhibition of Ep5C protein accumulation in the antisense plants, or alternatively its constitutive accumulation in the sense plants, is significant and shows the efficiency of the antisense strategy used. Moreover, protein samples derived from the sense and antisense plants were also assayed for the accumulation of defense-related proteins normally induced by $P$. s. tomato infection of tomato such as PR-1 (Tornero et al., 1997) and P69 (Jordá et al., 1999). The results shown in Figure 5(c) indicate that both P69 and PR-1 are absent in all non-inoculated plants but become highly induced, and with similar kinetics in all wild type and transgenic plants, upon inoculation with $P$. $s$. tomato. These results reveal that neither sense nor antisense tomato plants show constitutive expression or hyper-accumulation of these SA-dependent plant defenses.

\section{Antisense Ep5C plants reduce foliar disease development and increase resistance to $\mathrm{P}$. s. tomato}

The bacterial-induced expression of Ep5C could be a consequence of its role in either host defense or successful pathogenesis. To investigate this duality, we studied the 

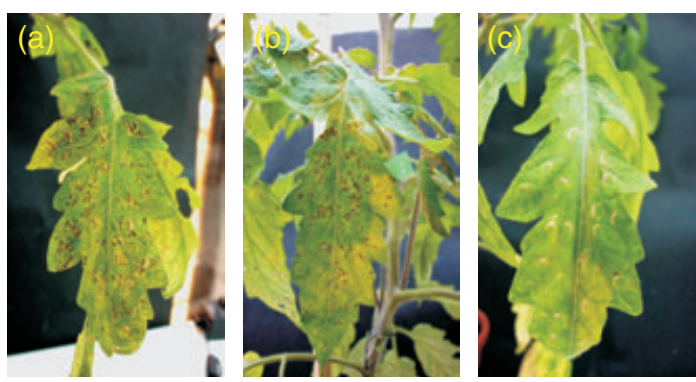

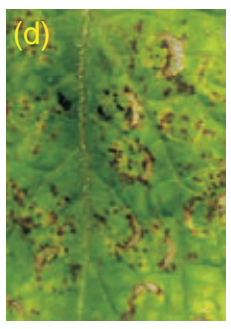

WT

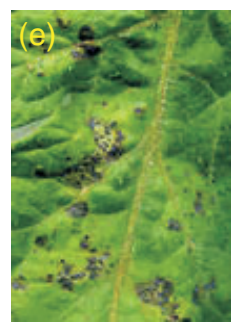

35S-Ep5C sense 35S-Ep5C antisense (2A4)

(11D1) (g)

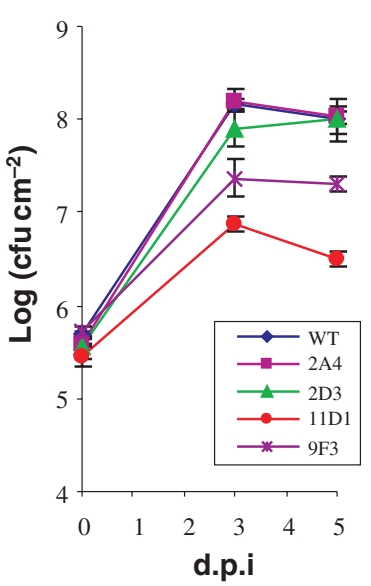

Figure 6. Increased resistance of 35S-Ep5Cantisense plants to $P$. s. tomato. Six-week-old tomato plants were infiltrated with a virulent strain of $P$. $s$ tomato. Disease symptoms caused by $P$. s. tomato infection in wild-type plants (a, d), in 35S-Ep5Csense-transformed plants (line 2A4) (b, e) and in 35SEp5Cantisense-transformed plants (line 11D1) (c, f). Disease symptoms are documented 8 days after inoculation. (g) Growth of $P$. s. tomato on leaves of wild type, 35S-Ep5Csense (lines 2A4 and 2D3) and 35S-Ep5Cantisense (lines $9 \mathrm{~F} 3$ and 11D1) plants. Leaf bacteria were measured as described in Experimental procedures. Each value represents an average of three measurements. Error bars indicate standard error. The same experiment was repeated three times and the results obtained were similar in all the experiments.

response of transgenic tomato plants to the bacterial pathogen $P$. s. tomato which causes bacterial speck disease in tomato. The disease is non-systemic and thus symptoms only develop on bacterial-inoculated leaves. The symptoms of foliar disease include the formation of necrotic primary lesions that later expand and become surrounded by regions of chlorotic tissue. Later symptoms consist of widespread necroses and ultimately leaf abscission (Jones et al., 1991). For these studies we inoculated different sense, antisense as well as wild-type seedlings with $P$. s. tomato, and examined resistance by comparing disease symptoms and bacterial growth. Figure 6 shows that 7 days after inoculation with P. s. tomato normal lesions of speck disease were detected in leaves of wild type (Figure 6a,d) and Ep5C over-accumulating plants (Figure $6 \mathrm{~b}, \mathrm{e}$; results shown correspond to line $2 \mathrm{~A} 4$, a representative line). There were thus no visible differences between wild type and sense plants in the number or size of the lesions that formed in response to infections. Analysis of symptoms in several independent Ep5C antisense lines, however, revealed a significant decrease in disease symptoms compared to that in wild type and in Ep5C over-accumulating lines (Figure 6c,f; results shown correspond to transgenic line 11D1, a representative line). The data thus suggest that the induction and correct accumulation of Ep5C is pivotal for the development of bacterial speck disease symptoms.

We next investigated whether the development or nondevelopment of disease symptoms were further correlated with the extent of bacterial growth in the inoculated leaves. Figure $6(\mathrm{~g})$ shows that at 3-5 days after inoculation with $P$. s. tomato, the Ep5C over-accumulating plants (results shown in Figure $6 \mathrm{~g}$ represent bacterial growth curves for two of these lines - 2A4 and 2D3) behave as wild-type plants, neither reducing nor increasing bacterial growth. Conversely, bacterial growth was drastically reduced in antisense plants where the number of colony-forming units (c.f.u.) was in the range of 10 - to 100 -fold lower than in wild-type plants. The results in Figure 6(g) are presented for two of these antisense transgenic lines (11D1 and 9F3). Thus, Ep5C-antisense plants exhibit resistance to the growth of the virulent bacteria concomitantly with a reduction in disease damage. Furthermore, this resistance seems not to be mediated by preactivation of the SA pathway as the expression of the SAresponsive markers (PR-1 and P69; Figure 5c) was similar in the wild type and in the antisense plants. Likewise, expression of pinl, or wipll, which are normally used as markers of the jasmonate pathway in tomato, or expression of the basic glucanase gene $\left(Q^{\prime} b\right)$, used as markers of the ethylene pathway, remained similar in wild type and antisense Ep5C plants (data not shown). Thus, the resistance pathway controlled by JA/ethylene pathway is not compromised in the antisense transgenic lines. These results support the idea that the peroxidase enzyme encoded by the Ep5C gene is a plant factor required for the correct growth and virulence of $P$. s. tomato. Thus, Ep5C-antisense-mediated disease resistance represents a novel form of protection based on the loss of a gene function required for a successful compatible interaction between $P$. syringae and tomato plants.

\section{Discussion}

In this paper we have characterized $E p 5 C$, a gene from tomato plants whose function is required for disease 
susceptibility toward $P$. syringae pv. tomato. Ep5C encodes a protein that shares significant sequence similarity to plant extracellular cationic peroxidases (Gadea et al., 1996; Hiraga et al., 2001). Peroxidase isozymes are numerous in plants, most of them localize extracellularly and in vacuoles (Carpin et al., 1999), and their genes can be induced by a great variety of stimuli including wounding (Price et al., 2003), pathogens (Lamb and Dixon, 1997), and development cues (de Marco et al., 1999). In particular, some cationic peroxidases act in the polymerization of phenolic monomers into lignin and suberin or mediate the cross-linking of polysaccharides and proteins in cell walls (Whetten and Sederoff, 1995). In general, peroxidases become implicated in all these biological processes by catalyzing many oxidation-reduction reactions in the presence of $\mathrm{H}_{2} \mathrm{O}_{2}$ that functions as an oxidizing substrate. It is interesting to note here that $\mathrm{H}_{2} \mathrm{O}_{2}$ plays a dual role for $E p 5 C$; it functions as a co-substrate for the encoded peroxidase enzyme and also as an inducing signal that sets in motion the transcriptional activation of Ep5C following perception of the bacterial pathogen $P$. $s$. tomato. In this respect, Ep5C expression is rapidly induced, albeit with different intensities, during the course of both compatible and incompatible interactions with $P$. s. tomato. This pattern of gene expression is consistent with the early and local generation of $\mathrm{H}_{2} \mathrm{O}_{2}$ by the plant cell once the presence of bacteria is perceived (Grant and Loake, 2000). At variance with what has been observed for other defenserelated genes (e.g., $P R$ genes), Ep5C expression is not induced by $S A$, ethylene, or jasmonate. This suggests a certain independence of Ep5C expression from these classical defense-related signals.

Another interesting aspect of the role of Ep5C during plant-pathogen interactions is the finding that the lack of expression of this gene, as derived from antisense tomato plants, confers strong resistance to $P$. $s$. tomato. This bacterium is an extracellular pathogen that infects a wide variety of plants (Gardan et al., 1999). In contrast to our significant understanding of the mechanisms underlying resistance to bacterial speck disease (Kim et al., 2002; Mysore et al., 2002; Tang et al., 1996), very little is known about the molecular basis of host susceptibility to virulent strains of $P$. syringae (Greenberg and Vinatzer, 2003). It is widely recognized that plants, even in the absence of genefor-gene interaction, can mount an active defense response that partially limits virulent $P$. syringae (Glazebrook et al., 1996). It is not clear what triggers this resistance, but it may be the perception of damage by the plant, the ability to detoxify the polyketide coronatine synthesized by the bacteria (Zhao et al., 2003), the recognition of pathogen-associated molecular patterns (Asai et al., 2002), a weak recognition of type III effectors injected within the plant cell (Chang et al., 2002) or even a combination of one or more of the above. The requirement of Ep5C to establish a compatible interaction between $P$. s. tomato and tomato plants can be explained by two possible scenarios. Ep5C could be required to facilitate bacterial growth, or alternatively loss of Ep5C function somehow results in the activation of host defenses that halt bacterial infection. Because constitutive expression of marker genes for classical defense responses is not observed in uninfected antisense plants, the Ep5Cantisense-mediated reduced susceptibility seems not to be mediated by a constitutive activation of the SA-dependent or the JA/ET-dependent defense pathway. Likewise, the kinetics of PR1 or P69 gene expression in the Ep5C antisense lines, which paralleled those established in wild-type plants, suggests that resistance is not established by potentiated defense gene expression. Therefore, Ep5C-antisense-mediated reduction in susceptibility to $P$. $s$. tomato is distinct from previously described mechanisms, which provide protection from pathogen ingress by virtue of enhanced expression of defense-related genes (Hammond-Kosack and Parker, 2003). However, definitive proof can only be addressed genetically by crossing Ep5C-antisense plants to defense-susceptible tomato mutants.

What might account for the reduced disease susceptibility observed in Ep5C-antisense plants? It is tempting to speculate that in wild-type plants in response to infection by $P$. $s$. tomato, accumulating extracellular Ep5C might process/ modify a cell surface molecular target that could be a component of a basal host defense complex. An alternative suggestion is that induction and correct deposition of Ep5C might be essential for the generation of an unknown signal molecule, whose intermediate could be produced either by the plant or by the bacteria, that might be important for the growth of the bacteria in planta. These considerations are consistent with Ep5C functioning as a host factor from tomato plants required for susceptibility to $P$. s. tomato infection.

Recently, the PMR6 gene from Arabidopsis, which encodes an extracellular pectate lyase-like protein, has been shown to be required for growth of the powdery mildew pathogen Eryshiphe cichoracearum (Vogel et al., 2002). The observed pmr6-mediated resistance in Arabidopsis does not require the activation of classical defense pathways and thus has been catalogued as a novel form of disease resistance (Vogel et al., 2002). Like PMR6 for E. cichoracearum and some other extracellular proteins specific for additional types of pathogens (Vorwerk et al., 2004), Ep5C may represent a novel plant factor that would be required for growth of $P$. syringae, and by reducing its accumulation one would expect to reduce pathogen growth. Such a reduction in pathogen growth can be considered a novel form of disease resistance based on the loss of the host's ability to support the pathogen, which acts independently of $R$ gene-mediated resistance or the activation of host defenses.

In summary, our findings suggest that susceptibility factors may be more common than previously anticipated. Insights into the biological function(s) of these factors may 
provide novel opportunities for the development of diseaseresistant crops.

\section{Experimental procedures}

\section{Generation and analysis of transgenic plants}

For generation of the sense construct, the Ep5C cDNA fragment was cut from pCEVI16 with Smal and Kpnl and ligated between the cauliflower mosaic virus (CaMV) $35 \mathrm{~S}$ promoter and the NOS terminator of plasmid pBI121 (Clontech, Palo Alto, CA, USA) to give p35S-Ep5Csense.

For the $E p 5 C$ antisense construct, a fragment containing the 309 nucleotides proximal to the 3 'end of pCEVI16 was amplified by PCR using Pfu DNA polymerase (Stratagene, San Diego, CA, USA) and subcloned in antisense orientation into the binary vector $\mathrm{pBI} 121$ (Clontech) under the control of the constitutive CaMV 35 S promoter to give $p 35 S-E p 5 C a n t i s e n s e$. The constructs were mobilized into A. tumefaciens LB4404 and used to transform UC82b tomato plants, basically as described before (Mayda et al., 1999, 2000a) using the method of Ellul et al. (2003). The resulting transformants were selected by kanamycin resistance. A total of 25 primary transformants was produced, 15 with p35S-Ep5Csense and 10 with p35SEp5Cantisense. The inheritance of the transgene was tested by PCR amplification of the transgene and by estimating the percentage of R2 seedlings that grew on kanamycin agar. This latter test allowed plants to be designated tentatively as azygous, hemizygous, or homozygous. All experiments were performed with seedlings that were homozygous for each of the transgenes under consideration.

The $1140 \mathrm{bp}$ full-length $E p 5 C$ promoter and $5^{\prime}$ deletions of this promoter were generated by PCR using sequence-specific primers where synthetic restriction sites were incorporated by site-directed mutagenesis (Kunkel et al., 1987). The corresponding DNA fragments were cloned upstream of the $\beta$-glucuronidase gene in pBI101.1 (Jefferson, 1987) resulting in transcriptional fusions to the coding sequence of the GUS reporter gene. The resulting fusions were verified by nucleotide sequence analysis using primers specific for the promoter regions. The plasmids were then mobilized into A. tumefaciens C58 and used to transform Arabidopsis thaliana Col-0 as described (Bechtold et al., 1993). Transformants were assayed for GUS activity by a fluorimetric assay or by an in situ assay using the colorigenic substrate X-gluc (Jefferson, 1987).

\section{Bacterial inoculation, c.f.u. determination, and chemical treatment}

Pseudomonas syringae strains were grown overnight in King's B medium containing antibiotics, washed twice, resuspended, and diluted in $10 \mathrm{~mm} \mathrm{MgCl}$ at the indicated densities. The bacterial suspensions were infiltrated on the abaxial surface of leaves using a 1-ml syringe without a needle as described for tomato (Mayda et al., 1999) and for Arabidopsis (Mayda et al., 2000b). Three leaf disks $\left(1 \mathrm{~cm}^{2}\right.$ each) from P. s. tomato $\left(2.5 \times 10^{5}\right.$ c.f.u. $\left.\mathrm{ml}^{-1}\right)$ infiltrated leaves were excised from independent leaves at the indicated times. The disks were randomly divided into sets of three and macerated in $10 \mathrm{~mm} \mathrm{MgCl} 2$. The density of the bacterial populations was determined by the plating of serial dilutions and the counting of c.f.u. on King's medium B supplemented with rifampicin $\left(50 \mu \mathrm{g} \mathrm{ml}^{-1}\right)$ at $28^{\circ} \mathrm{C}$.

Leaves were inoculated with a superoxide generating system [xanthine $(5 \mathrm{~mm})$ and xanthine oxidase $\left(0.05 \mathrm{U} \mathrm{ml}^{-1}\right)(\mathrm{X}-\mathrm{XO})$ ] or with an $\mathrm{H}_{2} \mathrm{O}_{2}$-generating system [2.5 mM D-glucose and glucose oxidase $\left(2.5 \mathrm{U} \mathrm{ml}^{-1}\right)(\mathrm{G}-\mathrm{GO})$ ] freshly prepared in $20 \mathrm{~mm}$ sodium phosphate buffer ( $\mathrm{pH}$ 6.5) as described previously (Mayda et al., 1999). When indicated, $600 \mathrm{U} \mathrm{ml}^{-1}$ of SOD from horseradish (Sigma, St Louis, MO, USA) or $100 \mathrm{U} \mathrm{ml}^{-1}$ of catalase (Sigma) was included in the mix.

\section{Library screening and DNA sequence analysis}

A tomato genomic DNA library constructed in $\lambda$-EMBL3 (Clontech) was screened with a radiolabeled Ep5C cDNA probe, and the positive clones were isolated, purified, and characterized as described (Tornero et al., 1997). DNA sequencing was performed on an ABI PRISM DNA sequencer 377 (Perkin-Elmer, Foster City, CA, USA). Computer-assisted analyses of DNA sequences were carried out using the University of Wisconsin Genetics Computer Group (GCG) package (Genetics Computer Group, Inc., Madison, WI, USA).

\section{RNA blot analysis}

RNA was purified from tomato leaves as described (Jordá et al., 1999), and $15 \mu \mathrm{g}$ of total RNA was electrophoresed on $1 \%$ agarose gels containing formaldehyde and blotted onto Nytran membranes (Schleicher \& Schuell, Dassel, Germany). Equal loading of RNA was verified by ethidium bromide staining of the gel before transfer to the membrane. Radiolabeled probes were prepared by random priming using T7 polymerase (Pharmacia, Barcelona, Spain). Hybridization and washing conditions of filters were as described (Jordá et al., 1999).

\section{Production of recombinant $\mathrm{Ep} 5 \mathrm{C}$ and generation of polyclonal antiserum}

The coding sequence of Ep5C (excluding the first 31 amino acids corresponding to signal peptide) was amplified by PCR using Pfu DNA polymerase and specific primers and subcloned into the pGEX vector (Amersham Biosciences, Barcelona, Spain) for expression in Escherichia coli as a protein fusion to glutathione $S$-transferase (GST). However, this construct never renders accumulation of any recombinant protein, thus indicating that the full mature Ep5c protein was either unstable or toxic to the bacteria. Alternatively, a partial sequence representing a truncated version of Ep5C (from amino acid 85 to amino acid 332) was similarly amplified with sequence-specific primers and subcloned into the pGEX vector. This time the recombinant protein accumulated to high levels upon induction and was affinity-purified through a glutathione-Sepharose 4B column (Amersham Biosciences) following the manufacturer's instructions. Fifty micrograms of the purified fusion protein was suspended in Freund's complete adjuvant and subcutaneously injected into a New Zealand white rabbit. Booster injections were followed at 2-week intervals for 2 months. The rabbit was then bled and the serum collected.

\section{Western blot}

Crude leaf extracts from tomato leaves were prepared in $20 \mathrm{~mm}$ HEPES-KOH pH 7.6, $40 \mathrm{~mm} \mathrm{KCl,} 5 \mathrm{~mm} \mathrm{MgCl}_{2}, 0.1 \mathrm{~mm}$ EDTA, $1 \mathrm{~mm}$ DTT, $0.5 \mathrm{~mm}$ PMSF or directly in SDS loading buffer. SDSPAGE and Western blot were performed according to standard procedures. A 1:500 dilution of the anti-Ep5C antiserum was used. 


\section{Acknowledgements}

We thank R. Chetelat for RioGrande tomato seeds, G. Martin for providing $P$. syringae (avrPto) strains, J. Dangl. for providing Pst. DC3000 (avrRpm1) strains. We also thank Pablo Tornero for comments on the manuscript and especially to $G$. Loake for his revision and suggestions. We acknowledge the support of the Spanish Ministry of Science and Technology (Grant BMC2003-00267 to P.V.) for financial support.

\section{References}

Agrios, G.N. (1988) Plant Pathology. London: Academic Press.

Alvarez, M.E., Pennell, R.I., Meijer, P.-J., Ishikawa, A., Dixon, R.A. and Lamb, C. (1998) Reactive oxygen intermediates mediate a systemic signal network in the establishment of plant immunity. Cell, 92, 773-784.

Apostol, I., Heinstein, F.H. and Low, P.S. (1989) Rapid stimulation of an oxidative burst during elicitation of cultured plant cells. Role in defense and signal transduction. Plant Physiol. 90, 109-116.

Asai, T., Tena, G., Plotnikova, J., Willmann, M.R., Chiu, W.L., Gomez-Gomez, L., Boller, T., Ausubel, F.M. and Sheen, J. (2002) MAP kinase signalling cascade in Arabidopsis innate immunity. Nature, 415, 977-983.

Baker, C.J. and Orlandi, E.W. (1995) Active oxygen species in plant pathogenesis. Annu. Rev. Phytopathol. 33, 299-321.

Bechtold, N., Ellis, J. and Pelletier, G. (1993) In planta Agrobacterium-mediated gene transfer by infiltration of adult Arabidopsis thaliana plants. C. R. Acad. Sci. Paris Life Sci. 316, 1194-1199.

Buffard, D., Breda, C., van Huystee, R.B., Asemota, O., Pierre, M., Ha, D.B.D. and Esnault, R. (1990) Molecular cloning of complementary DNAs encoding two cationic peroxidases from cultivated peanut cells. Proc. Natl Acad. Sci. USA, 87, 8874-8878.

Carpin, S., Crèvecoeur, M., Greppin, H. and Penel, C. (1999) Molecular cloning and tissue-specific expression of an anionic peroxidase in zucchini. Plant Physiol. 120, 799-819.

Carrasco, J.L., Ancillo, G., Mayda, E. and Vera, P. (2003) A novel transcription factor involved in plant defense endowed with protein phosphatase activity. EMBO J. 22, 3376-3384.

Chang, J.H., Tai, Y.S., Bernal, A.J., Lavelle, D.T., Staskawicz, B.J. and Michelmore, R.W. (2002) Functional analyses of the Pto resistance gene family in tomato and the identification of a minor resistance determinant in a susceptible haplotype. Mol. Plant Microbe Interact. 15, 281-291.

Debener, T., Lehnackers, H., Arnold, M. and Dangl, J.L. (1991) Identification and molecular mapping of a single Arabidopsis thaliana locus determining resistance to a phytopathogenic Pseudomonas syringae isolate. Plant J. 1, 289-302.

Denarié, J., Debelle, F. and Rosenberg, C. (1992) Signaling and host range variation in nodulation. Annu. Rev. Microbiol. 46, 497-531.

Dong, X. (1998) SA, JA, ethylene, and disease resistance in plants. Curr. Opin. Plant Biol. 1, 316-323.

Ellul, P., García-Sogo, B., Pineda, B., Ríos, G., Roig, L.A. and Moreno, V. (2003) The ploidy level of transgenic plants in Agrobacteriummediated transformation of tomato cotyledons (Lycopersicon esculentum L. Mill.) is genotype and procedure dependent. Theor. Appl. Genet. 106, 231-238.

Feys, B.J., Benedetti, C.E., Penfold, C.N. and Turner, J.G. (1994) Arabidopsis mutants selected for resistance to the phytotoxin coronatine are male sterile, insensitive to methyl jasmonate, and resistant to a bacterial pathogen. Plant Cell, 6, 751-759.

Gadea, J., Mayda, E., Conejero, V. and Vera, P. (1996) Characterization of defense-related genes ectopically expressed in viroidinfected tomato plants. Mol. Plant Microbe Interact. 9, 409-415.
Gardan, L., Shafik, H., Belouin, S., Broch, R., Grimont, F. and Grimont, P.A. (1999) DNA relatedness among the pathovars of Pseudomonas syringae and description of Pseudomonas tremae sp. nov. and Pseudomonas cannabina sp. nov. (ex Sutic and Dowson 1959). Int. J. Syst. Bacteriol. 49, 469-478.

Glazebrook, J., Rogers, E.E. and Ausubel, F.M. (1996) Isolation of Arabidopsis mutants with enhanced disease susceptibility by direct screening. Genetics, 143, 973-982.

Grant, J.J. and Loake, G.J. (2000) Role of reactive oxygen intermediates and cognate redox signaling in disease resistance. Plant Physiol. 124, 21-29.

Greenberg, J.T. and Vinatzer, B.A. (2003) Identifying type III effectors of plant pathogens and analysing their interaction with plant cells. Curr. Opin. Microbiol. 6, 20-28.

Gubbler, F., Raventos, D., Keys, M., Watts, R., Mundy, J. and Jacobsen, J.V. (1999) Target genes and regulatory domains of the GAMYB transcriptional activator in cereal aleurone. Plant J.17, $1-9$.

Hammond-Kosack, K.E. and Jones, J.J. (1996) Resistance genedependent plant defense responses. Plant Cell, 8, 1773-1791.

Hammond-Kosack, K.E. and Parker, J.E. (2003) Deciphering plantpathogen communication: fresh perspectives for molecular resistance breeding. Curr. Opin. Biotechnol. 14, 177-193.

Hiraga, S., Sasaki, K., Ito, H., Ohashi, Y. and Matsui, H. (2001) A large family of class III plant peroxidases. Plant Cell Physiol. 42, 462-468.

Jabs, T., Dietrich, R.A. and Dangl, J.L. (1996) Initiation of runaway cell death in an Arabidopsis mutant by extracellular superoxide. Science, 273, 1853-1856.

Jefferson, R.A. (1987) Assaying chimeric genes in plants: the GUS gene fusion system. Plant Mol. Biol. Rep. 5, 387-405.

Jones, J.B., Jones, J.P., Stall, R.E. and Zitter, T.A. (1991) Compendium of Tomato Diseases. St Paul, MN: APS Press.

Jordá, L., Coego, A., Conejero, V. and Vera, P. (1999) A genomic cluster containing four differentially regulated subtilisin-like processing protease genes is in tomato plants. J. Biol. Chem. 274, 2360-2365.

Kim, Y.J., Lin, N. and Martin, G.B. (2002) Two distinct Pseudomonas effector proteins interact with the Pto kinase and activate plant immunity. Cell, 109, 589-598.

Kloek, A.P., Verbsky, M.L., Sharma, S.B., Schoelz, J.E., Vogel, J., Klessig, D.F. and Kunkel, B.N. (2001) Resistance to Pseudomonas syringae conferred by an Arabidopsis thaliana coronatine-insensitive (coi1) mutation occurs through two distinct mechanisms. Plant J. 26, 509-522.

Kunkel, B.N. and Brooks, D.N. (2002) Cross talk between signaling pathways in pathogen defense. Curr. Opin. Plant Biol. 5, 325-331.

Kunkel, T.A., Roberts, J.D. and Zakour, R.A. (1987) Rapid and efficient site-specific mutagenesis without phenotypic selection. Methods Enzymol. 154, 367-381.

Lamb, C. and Dixon, R.A. (1997) The oxidative burst in plant disease resistance. Ann. Rev. Plant Physiol. Plant Mol. Biol. 48, 251-275.

Loake, G.J. (2001) Plant cell death: unmasking the gatekeepers. Curr. Biol. 11, 1028-1031.

Loake, G.J., Faktor, O., Lamb, C.J. and Dixon, R.A. (1992) Combination of $\mathrm{H}$-box [CCTACC $(\mathrm{N})_{7} \mathrm{CT}$ ] and G-box (CACGTG) cis elements is necessary for feed-forward stimulation of a chalcone synthase promoter by the phenylpropanoid-pathway intermediate p-coumaric acid. Proc. Natl Acad. Sci. USA, 89, 9230-9234.

de Marco, A., Guzzardi, P. and Jamet, E. (1999) Isolation of tobacco isoperoxidases accumulated in cell-suspension culture medium and characterization of activities related to cell wall metabolism. Plant Physiol. 120, 371-382.

Martin, G.B., Brommonschenkel, S.H., Chunwongse, J., Frary, A., Ganal, M.W., Spivey, R., Wu, T., Earle, E.D. and Tanksley, S.D. 
(1993) Map-based cloning of a protein kinase gene conferring disease resistance in tomato. Science, 262, 1432-1436.

Mayda, E., Tornero, P., Conejero, V. and Vera, P. (1999) A tomato homeobox gene (HD-Zip) is involved in limiting the spread of programmed cell death. Plant J. 20, 591-600.

Mayda, E., Marqués, C., Conejero, V. and Vera, P. (2000a) Expression of a pathogen-induced gene can be mimicked by auxin insensitivity. Mol. Plant Microbe Interact. 13, 23-31.

Mayda, E., Mauch-Mani, B. and Vera, P. (2000b) The Arabidopsis $d$ th9 mutant is compromised in systemic acquired resistance without affecting SA-dependent responses. Plant Cell, 12, 21192128.

Mysore, K.S., Crasta, O.R., Tuori, R.P., Folkerts, O., Swirsky, P.B. and Martin, G.B. (2002) Comprehensive transcript profiling of Ptoand Prf-mediated host defense response to infection by Pseudomonas syringae pv. syringae. Plant J. 32, 299-315.

Price, N.J., Pinheiro, C., Soares, C.M., Ashford, D.A., Ricardo, C.P. and Jackson, P.A. (2003) A biochemical and molecular characterization of LEP1, an extensin peroxidase from lupin. J. Biol. Chem. 278, 41389-41399.

Ross, A.F. (1961) Systemic acquired resistance induced by localized virus infections in plants. Virology, 14, 340-358.

Stachel, S.E. and Zambryski, P.C. (1986) VirA and VirG control the plant-induced activation of the T-DNA transfer process of $A$. tu mefaciens. Cell, 46, 325-333.

Sticher, L., Mauch-Mani, B. and Métraux, J.-P. (1997) Systemic acquired resistance. Annu. Rev. Phytopathol. 35, 235-270.
Sutherland, M.W. (1991) The generation of oxygen radicals during host plant responses to infection. Physiol. Mol. Plant Pathol. 39, 79-93.

Tang, X., Frederick, R., Zhou, J., Halterman, D., Jia, Y. and Martin, G.B. (1996) Initiation of plant disease resistance by physical interaction of AvrPto and Pto kinase. Science, 274, 2060-2063.

Tornero, P., Gadea, J., Conejero, V. and Vera, P. (1997) Two PR-1 genes from tomato are differentially regulated and reveal a novel mode of expression for a pathogenesis-related gene during the hypersensitive response and development. Mol. Plant Microbe Interact. 5, 624-634.

Vogel, J., Raab, T.K., Schiff, C. and Somerville, S.C. (2002) PMR6, a pectate lyase-like gene required for powdery mildew susceptibility in Arabidopsis. Plant Cell, 14, 2095-2106.

Vorwerk, S., Somerville, S. and Somerville, C. (2004) The role of plant cell polysaccharide composition in disease resistance. Trends Plant Sci. 9, 203-209.

Whalen, M.C., Innes, R.W., Bent, A.F. and Staskawicz, B.J. (1991) Identification of Pseudomonas syringae pathogens of Arabidopsis and a bacterial locus determining avirulence on both Arabidopsis and soybean. Plant Cell, 3, 49-59.

Whetten, R. and Sederoff, R. (1995) Lignin biosynthesis. Plant Cell, 7, 1001-1013.

Zhao, Y., Thilmony, R., Bender, C.L., Schaller, A., He, S.Y. and Howe, G.A. (2003) Virulence systems of Pseudomonas syringae pv. tomato promote bacterial speck disease in tomato by targeting the jasmonate signal pathway. Plant J. 36, 485-499.

Sequence data from this article have been deposited with the EMBL/GenBank data libraries under accession number AJ634698. 

III.b. Capítulo 2. 



\title{
An Arabidopsis Homeodomain Transcription Factor, OVEREXPRESSOR OF CATIONIC PEROXIDASE 3, Mediates Resistance to Infection by Necrotrophic Pathogens
}

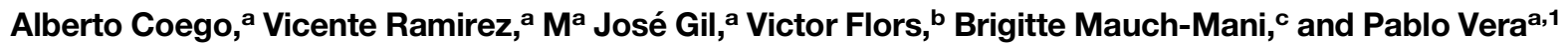 \\ a Instituto de Biología Molecular y Celular de Plantas, Universidad Politécnica de Valencia-Consejo Superior de \\ Investigaciones Científicas, 46022 Valencia, Spain \\ b Plant Physiology Section, Department of Experimental Sciences, Universidad Jaime I, Castellón 12071, Spain \\ c University of Neuchâtel, Faculty of Sciences, Institute of Botany, Biochemistry, $\mathrm{CH}-2007$ Neuchâtel, Switzerland
}

\begin{abstract}
The mechanisms controlling plant resistance to necrotrophic fungal pathogens are poorly understood. We previously reported on Ep5C, a gene shown to be induced by the $\mathrm{H}_{2} \mathrm{O}_{2}$ generated during a plant-pathogen interaction. To identify novel plant components operating in pathogen-induced signaling cascades, we initiated a large-scale screen using Arabidopsis thaliana plants carrying the $\beta$-glucuronidase reporter gene under control of the $\mathrm{H}_{2} \mathrm{O}_{2}$-responsive Ep5C promoter. Here, we report the identification and characterization of a mutant, ocp3 (for overexpressor of cationic peroxidase 3), in which the reporter construct is constitutively expressed. Healthy ocp 3 plants show increased accumulation of $\mathrm{H}_{2} \mathrm{O}_{2}$ and express constitutively the Glutathione S-transferase1 and Plant Defensine1.2 marker genes, but not the salicylic acid (SA)-dependent pathogenesisrelated $P R-1$ gene. Strikingly, the ocp3 mutant shows enhanced resistance to the necrotrophic pathogens $B o t r y t i s$ cinerea and Plectosphaerella cucumerina. Conversely, resistance to virulent forms of the biotrophic oomycete Hyaloperonospora parasitica and the bacterial pathogen Pseudomonas syringae pv tomato DC3000 remains unaffected in ocp3 plants when compared with wild-type plants. Consistently with this, ocp3 plants are not affected in SA perception and express normal levels of $P R$ genes after pathogen attack. To analyze signal transduction pathways where ocp3 operates, epistasis analyses between ocp3 and pad4, nahG, npr1, ein2, jin1, or coi1 were performed. These studies revealed that the resistance signaling to necrotrophic infection in ocp3 is fully dependent on appropriate perception of jasmonic acid through COI1 and does not require SA or ethylene perception through NPR1 or EIN2, respectively. The OCP3 gene encodes a homeodomain transcription factor that is constitutively expressed in healthy plants but repressed in response to infection by necrotrophic fungi. Together, these results suggest that OCP3 is an important factor for the COI1-dependent resistance of plants to infection by necrotrophic pathogens.
\end{abstract}

\section{INTRODUCTION}

Plants react to attack by phytopathogenic microorganisms with an array of inducible responses that lead to local and systemic expression of a broad spectrum of antimicrobial defenses. These include the strengthening of mechanical barriers, an oxidative burst, de novo production of antimicrobial compounds, and the induction of the hypersensitive response $(\mathrm{HR})$ mechanism, where the tissue at the infection site dies and in turn confines the pathogen growth and prevents its spreading (Hammond-Kosack and Parker, 2003). Our understanding of how plants activate defense responses has grown substantially, and this in part has been facilitated by the cloning and characterization of plant disease resistance factors that recognize the corresponding

\footnotetext{
1 To whom correspondence should be addressed. E-mail vera@ibmcp. upv.es; fax 34-96-3877859.

The author responsible for distribution of materials integral to the findings presented in this article in accordance with the policy described in the Instructions for Authors (www.plantcell.org) is: Pablo Vera (vera@ibmcp.upv.es).

Article, publication date, and citation information can be found at www.plantcell.org/cgi/doi/10.1105/tpc.105.032375.
}

avirulence factors from the pathogen to trigger the HR (Dangl and Jones, 2001). The induction of HR is often associated with the development of systemic acquired resistance, another wellstudied defense response that provides long-lasting protection throughout the plant against a broad spectrum of pathogens (Durrant and Dong, 2004)

The characterization of cellular components involved in signal transduction and the understanding of the role of plant defense signal molecules is being aided by the isolation and analysis of mutants with altered defense responses (Kunkel and Brooks, 2002; Durrant and Dong, 2004). These studies are of paramount importance for understanding the coupling of pathogen recognition to the activation of defense responses in the plant. Salicylic acid (SA), a benzoic acid derivative, has emerged as a pivotal signal molecule mediating different aspects of HR and systemic acquired resistance responses. SA synthesis and accumulation have long been shown to be indispensable for mounting an efficient defense response against oomycete and bacterial pathogens (Gaffney et al., 1993), and its signaling is mostly mediated by an ankyrin repeat protein, NPR1/NIM1/SAI1 (Cao et al., 1997), albeit NPR1-independent pathways for funneling SA signaling have been proposed and genetically identified (Clarke et al., 1998, 2000; Shah et al., 1999; Mayda et al., 2000). 
In addition to SA, some other signaling molecules, such as jasmonic acid (JA) and ethylene (ET), either alone or in concerted combination, have been shown to regulate other distinct aspects of the plant defense responses (Kunkel and Brooks, 2002; Turner et al., 2002), and genetic evidence for the implication of JA/ET in the response to fungal pathogens also has been provided. For example, Arabidopsis thaliana mutants impaired in production of JA (e.g., the fad3 fad7 fad8 triple mutant) or perception of this hormone (e.g., coi1, jin1, or jar1/jin4) resulted in an altered susceptibility of Arabidopsis plants to different necrotrophic pathogens (Staswick et al., 1998; Thomma et al., 1998, 2001; Vijayan et al., 1998; Kunkel and Brooks, 2002; Lorenzo et al., 2004). Moreover, during the disease resistance response, mutual antagonistic relationships between SA and JA signaling pathways have been described (Kunkel and Brooks, 2002). In this respect, Arabidopsis mutants either deficient in SA accumulation (e.g., pad4 and eds1) or with an impaired response to SA (e.g., npr1) all exhibit enhanced induction of JA-responsive genes (Penninckx et al., 1996; Clarke et al., 1998; Gupta et al., 2000). The suppression of JA response genes by SA has been postulated to be regulated by the differential cellular localization of the NPR1 protein (Spoel et al., 2003). Likewise, genetic studies provide evidence indicating that JA signaling can also negatively control the expression of SA-responsive genes in Arabidopsis (Petersen et al., 2000; Li et al., 2004). The molecular mechanism explaining such pathway crosstalk remains poorly understood. Therefore, the characterization of molecular components that ultimately coordinate the SA and JA signaling pathways is paramount for understanding, and eventually engineering, highly regulated mechanisms of resistance that provide efficient protection to specific subsets of pathogens.

In addition to the signal molecules mentioned above, the production and accumulation of reactive oxygen species (ROS), primarily superoxide $\left(\mathrm{O}_{2}^{-}\right)$and hydrogen peroxide $\left(\mathrm{H}_{2} \mathrm{O}_{2}\right)$, during the course of a plant-pathogen interaction has long been recognized (Apostol et al., 1989; Baker and Orlandi, 1995). Evidence suggests that the oxidative burst and the cognate redox signaling engaged subsequently may play a central role in the integration of a diverse array of plant defense responses (Alvarez et al., 1998; Grant and Loake, 2000). Furthermore, crosstalk between ROS and SA-dependent defense responses has also been documented in plants (Kauss and Jeblick, 1995; Shirasu et al., 1997; Mur et al., 2000; Tierens et al., 2002), but the exact mechanisms and components linking redox signaling to the induced defense response remain poorly understood.

Recently, the Ep5C gene from tomato (Lycopersicon esculentum) plants, encoding a cationic peroxidase, has been identified and used as a marker for early transcription-dependent responses controlled by $\mathrm{H}_{2} \mathrm{O}_{2}$ after perception of a pathogen, with a mode of gene activation conserved both in tomato and Arabidopsis plants (Coego et al., 2005). Because pathogeninduced expression of Ep5C relies on the production and accumulation of $\mathrm{H}_{2} \mathrm{O}_{2}$ by the afflicted plant cell, this points to Ep5C as a marker to search for novel defense components participating in the still poorly understood defense-related pathways in plants.

Toward this end, we describe here the isolation and characterization of the overexpression of cationic peroxidase 3 (ocp3) mutant from Arabidopsis, which is deregulated in the expression of Ep5C. We show that OCP3 encodes a predicted homeoboxlike transcription factor that regulates different aspects of the defense response. Through the analysis of ocp3 mutant plants and epistasis analysis with other defense-related mutants, we propose that OCP3 controls critical aspects of the JA-mediated pathway to necrotrophic pathogens.

\section{RESULTS}

\section{Isolation and Characterization of the Arabidopsis ocp3 Mutant}

Ep5C encodes an extracellular cationic peroxidase and is transcriptionally activated by the $\mathrm{H}_{2} \mathrm{O}_{2}$ generated during the course of plant-pathogen interactions (Coego et al., 2005). To identify signals and mechanisms involved in the induction of the Ep5C gene and study the impact this pathway may have on disease resistance, we searched for mutants using transgenic Arabidopsis plants that harbor an Ep5C- $\beta$-glucuronidase (GUS) gene fusion. Our screening rationale was that by looking for mutants showing constitutive expression of the reporter gene in plants grown under noninductive conditions, we would identify mutations affecting the regulation of this signal pathway. We therefore mutagenized one of our previously characterized Ep5C-GUS transgenic Arabidopsis Columbia (Col-0) lines with ethyl methanesulfonate, and M2 plants were screened for constitutive expression of GUS in the absence of any pathogenic insult. From 10,000 M2 plants screened, 18 constitutive GUS expressers were identified that could be selfed. GUS activity was assayed again in progeny of all these putative mutants to confirm whether the phenotype was heritable. Eight lines, corresponding to six complementation groups (data not shown), maintained constitutive GUS activity in subsequent generations. We named these mutants ocp (for overexpression of cationic peroxidase gene promoter), and the mutant selected for further analysis was ocp3 because it was the one to show the highest GUS activity. Macroscopically, ocp3 plants are not very dissimilar to wild-type plants both in terms of plant architecture and growth habit (Figure 1A). However, at early stages of plant development, ocp3 plants show retardation in growth rate compared with wild-type plants. This retardation in the growth rate is also accompanied by a less intense green color in young leaves (data not shown).

Histochemical staining was performed to investigate the pattern of constitutive reporter gene expression in the ocp3 mutants compared with the parental nonmutagenized wild-type plants. As shown in Figure 1B, in the parental seedlings, no GUS activity was detected except in a discrete zone at the root-stem junction (see arrow in the left panel of Figure 1B). Conversely, in ocp3 seedlings, GUS activity was detected in expanding leaves as well as in the cotyledons and the stem, but very poorly in roots. In rosette leaves of ocp3 plants, GUS activity was distributed throughout the leaf blade, whereas leaves from the parental plants did not show detectable GUS expression (Figure 1C).

Because $\mathrm{H}_{2} \mathrm{O}_{2}$ was proposed to be the signal molecule that sets in motion the transcriptional activation of Ep5C after pathogen perception (Coego et al., 2005), we hypothesized that 

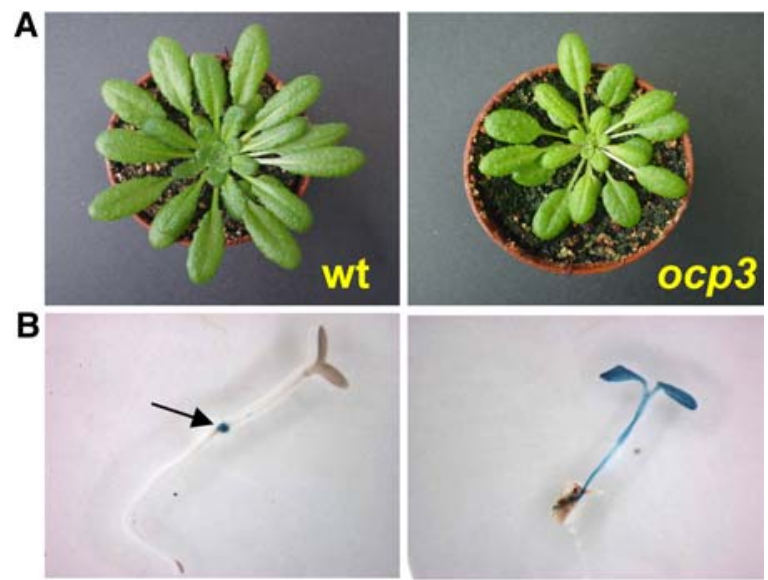

C

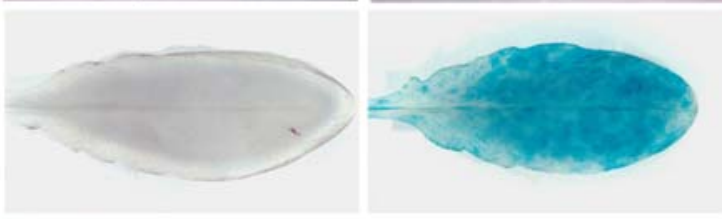

$\mathbf{D}^{\prime}$
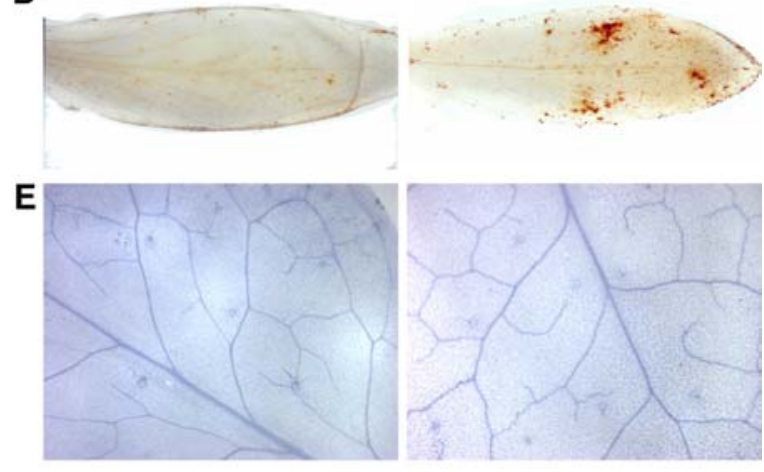

F

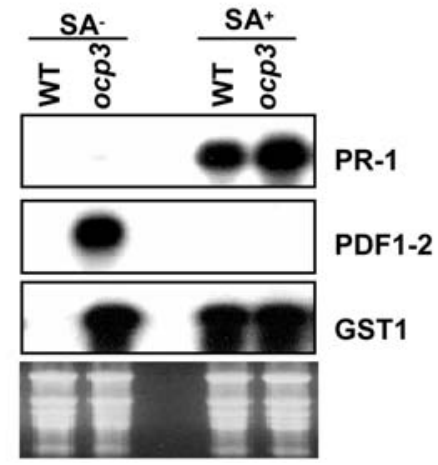

Figure 1. Characterization of ocp3 Plants and Comparison with WildType Plants.

(A) A comparison of the macroscopic appearance of a 3.5-week-old parental wild-type plant (left) and ocp3 plant (right).

(B) Histochemical staining of GUS activity driven by the Ep5C promoter in a 10-d-old wild-type transgenic seedling (left) and an ocp3 seedlings (right) grown on MS agar medium. The arrow points to a discrete tissue zone in the junction of the hypocotyl and the root where GUS activity is observed in wild-type seedlings.

(C) Fully expanded rosette leaf from a wild-type transgenic plant (left) and from an ocp3 plant (right) stained for GUS activity. either $\mathrm{H}_{2} \mathrm{O}_{2}$ accumulation is increased in ocp3 plants or, alternatively, the ocp3 mutant is hypersensitive to this ROS molecule. To examine if ocp3 plants showed any phenotype in relation to this, we studied the sensitivity to $\mathrm{H}_{2} \mathrm{O}_{2}$ and to reagents that generate directly or indirectly $\mathrm{H}_{2} \mathrm{O}_{2}$. Seeds from ocp3 and from wild-type plants were germinated on MS media containing different amounts of $\mathrm{H}_{2} \mathrm{O}_{2}$ (ranging from 2 to $20 \mathrm{mM}$ ), and growth was recorded at different time intervals. No significant differences in growth inhibition were found for ocp3 with respect to wild-type seedlings (data not shown). Likewise, growth inhibition was similar in wild-type and ocp3 seedlings when assayed in the light either in the presence of the ROS-generating molecules Rose Bengal (4,5,6,7-tetrachloro-2', 4',5',7' -tetraiodofluorescein; 0.1 to $2 \mu \mathrm{M}$ ) or paraquat (methyl viologen; 0.1 to $2 \mu \mathrm{M}$ ) (data not shown). Thus, from these assays, the ocp3 mutation does not seem to confer increased sensitivity or enhanced resistance to oxidative stress. However, RNA gel blot analyses with mRNA from wild-type and ocp3 plants revealed (Figure 1F; lanes on the left) that mutant seedlings expressed constitutively Glutathione S-transferase1(GST1), a gene previously shown to be controlled by $\mathrm{H}_{2} \mathrm{O}_{2}$ (Levine et al., 1994; Alvarez et al., 1998). This reflects that ocp3 plants may be producing and/or accumulating higher levels of $\mathrm{H}_{2} \mathrm{O}_{2}$ than those normally found in wild-type plants. To test this, leaves were stained in situ with 3,3'-diaminobenzidine (DAB), a histochemical reagent that polymerizes in the presence of $\mathrm{H}_{2} \mathrm{O}_{2}$, forming reddish-brown precipitates (Thordal-Christensen et al., 1997). Little DAB staining was evident in the leaves of wild-type plants (Figure 1D, left). Conversely, leaves from ocp3 plants showed distinct foci of DAB staining scattered throughout the leaf blade (Figure 1D, right). Moreover, ocp3 does not show any sign of cell death or cell collapse as revealed by staining with trypan blue (Figure 1E) nor does it show any differences with the wild type when assayed for the production of superoxide anions $\left(\mathrm{O}_{2}^{-}\right)$by staining with nitroblue tetrazolium (data not shown). Thus, the observed increased accumulation of $\mathrm{H}_{2} \mathrm{O}_{2}$ and induction of GST transcripts in ocp3 plants suggests that the mutation presumably cues a signal related to oxidative stress but not to prime a cell death response. This explains previous observations in which $\mathrm{H}_{2} \mathrm{O}_{2}$, but none of the other reactive oxygen intermediate (ROI) species generated during pathogenesis or by in situ infiltration with different $\mathrm{H}_{2} \mathrm{O}_{2}$-generating systems, is the signal that sets in motion the characteristic transcriptional activation of Ep5C-GUS in transgenic Arabidopsis plants (Coego et al., 2005). Therefore, both the generation of $\mathrm{H}_{2} \mathrm{O}_{2}$ and the activation of the signaling

(D) Production of $\mathrm{H}_{2} \mathrm{O}_{2}$ in wild-type (left) and ocp3 (right) plants. $\mathrm{H}_{2} \mathrm{O}_{2}$ production was assayed using $3,3^{\prime}$-diaminobenzidine. The reddishbrown coloration indicates the polymerization of $3,3^{\prime}$-diaminobenzidine at the site of $\mathrm{H}_{2} \mathrm{O}_{2}$ production.

(E) Staining of leaf tissue from wild-type (left) and ocp3 (right) plants with trypan blue in search for signs of cell death. The absence of cell collapse is revealed by the lack of intense blue spots after staining with trypan blue.

(F) Expression of PR-1, Plant Defensine 1.2 (PDF1.2), and GST1 marker genes in wild-type and ocp3 plants $36 \mathrm{~h}$ after the plants were sprayed with $(+S A)$ or without $(-S A)$ a buffer solution containing $0.3 \mathrm{mM} \mathrm{SA}$. 
mechanism leading to transcriptional activation of Ep5C concurred in the ocp3 mutant.

\section{The ocp3 Mutant Has Enhanced Resistance to Necrotrophic but Not to Biotrophic Pathogens}

To study a causal link between the signal pathway mediating the activation of Ep5C-GUS in ocp3 and that mediating disease susceptibility, we tested the response of this mutant to different pathogens that generate disease in Arabidopsis. The response of ocp3 plants to the obligate biotroph oomycete Hyaloperonospora parasitica and its comparison to the response of wild-type plants is shown in Figure 2. Growth of the pathogen was assayed by direct observation of stained hyphae in infected leaves (Figure $2 \mathrm{~A})$ and by counting the spores produced on infected leaves (Figures 2B). Using both measurements, there was no significant difference in pathogen growth between wild-type and ocp3 plants. Sporulation occurred on $50 \%$ of the leaves from either wild-type plants or ocp3 plants. Therefore, the ocp3 mutation did not affect the susceptibility of the plant to colonization by $H$. parasitica.

Changes in the susceptibility of ocp3 plants to pathogens were investigated further using the virulent bacterial pathogen $P$ seudomonas syringae pv tomato DC3000 (Pst DC3000) and monitoring the growth rate of these bacteria in extracts from inoculated leaves; the resulting growth curves are shown in
A

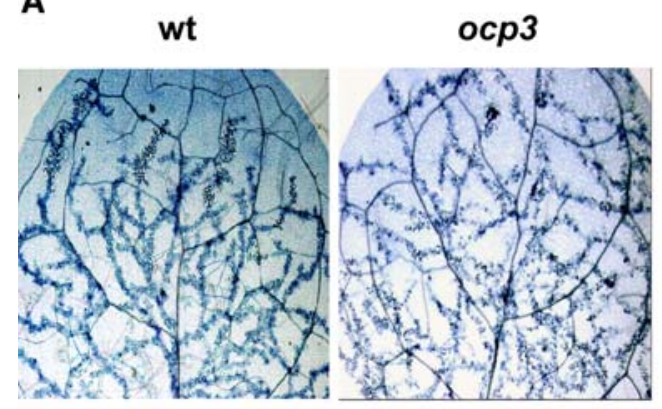

D

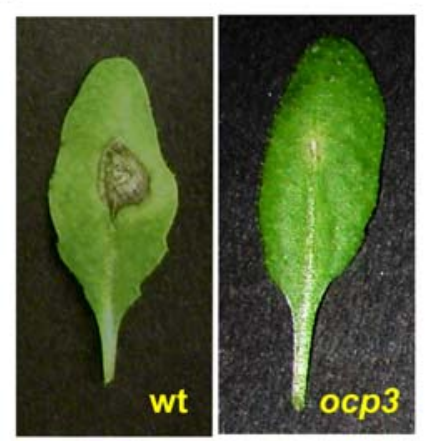

E

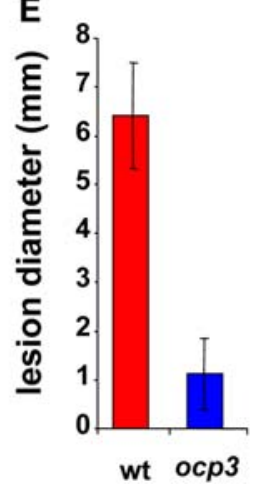

B

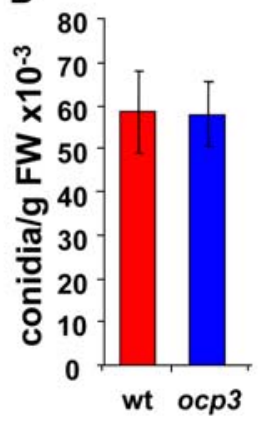

$\mathbf{F}$

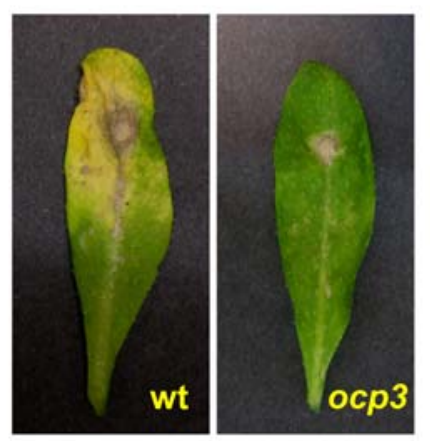

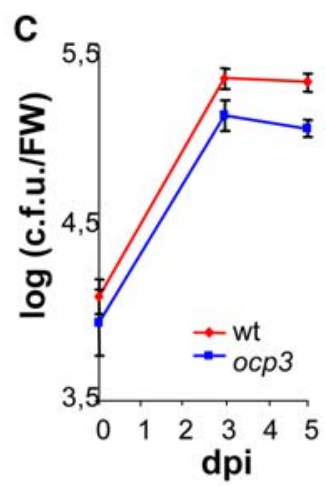

G

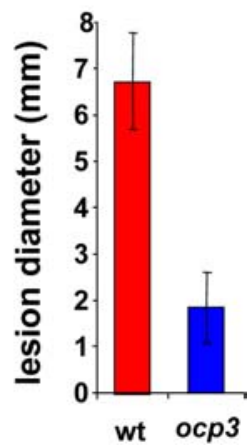

Figure 2. оср3 Plants Are Resistant to Necrotrophic but Not Biotrophic Pathogens.

(A) Resistance response of wild-type and ocp3 mutant Arabidopsis plants to virulent $H$. parasitica. Seven days after spray inoculation of 2-week-old plants with $10^{5}$ conidiospores per milliliter of water, leaves were stained with lactophenol-trypan blue and viewed under a microscope to reveal the characteristic extensive growth of hyphae.

(B) To quantify resistance to $\mathrm{H}$. parasitica, production of conidia was counted $7 \mathrm{~d}$ after inoculation with the aid of a haemocytometer. Plants carrying the ocp3 mutation were as resistant to this pathogen as wild-type plants. FW, fresh weight.

(C) Growth of Pst DC3000 in wild-type and ocp3 plants. Four-week-old plants were infiltrated with bacterial suspension, and the bacterial titer, measured as colony forming units (c.f.u) per fresh weight, was determined at 0,3 , and $5 \mathrm{~d}$ after infection for the wild type (red lines) and ocp3 (blue lines). Eight samples were taken for each genotype at each time point. The experiment was repeated three times with similar results. dpi, days postinoculation. (D) Representative leaves from wild-type and ocp3 plants at $4 \mathrm{~d}$ after inoculation with a $6-\mu \mathrm{L}$ droplet of $B$. cinerea spores $\left(2.5 \times 10^{4} \mathrm{conidia} / \mathrm{mL}\right)$.

(E) Lesion size as generated by $B$. cinerea was measured at $6 \mathrm{~d}$ after inoculation. Data points represent average lesion size \pm SE of measurements from a minimum of 30 lesions.

(F) Representative leaves from wild-type and ocp3 plants at $4 \mathrm{~d}$ after inoculation with a $6-\mu \mathrm{L}$ droplet of a spore suspension $\left(5 \times 10^{6} \mathrm{spores} / \mathrm{mL}\right)$ of P. cucumerina.

(G) Disease symptoms measured as lesion size were evaluated $6 \mathrm{~d}$ after inoculation with $P$. cucumerina by determining the average lesion diameters on three leaves of eight plants each. Data points represent average lesion size \pm SE of measurements.

All the experiments were repeated at least three times with similar results. 
Figure 2C. As with H. parasitica, the rate of growth of Pst DC3000 in ocp3 plants was not significantly different to that observed in wild-type plants. Therefore, the susceptibility of the wild type and the ocp3 mutant remains also nearly the same upon local inoculation with this pathogen.

To determine if the ocp3 mutation could provoke changes in the susceptibility to necrotrophic pathogens, we inoculated plants with Botrytis cinerea. Disease was scored between 5 and $10 \mathrm{~d}$ after inoculation by following the extent of necrosis appearing in the inoculated leaves. As expected, wild-type plants were highly susceptible to Botrytis, and all inoculated plants showed necrosis accompanied by extensive proliferation of the fungal mycelia (Figures 2D and 2E). However, and by marked contrast, none of the ocp3 plants that were inoculated with the same fungi showed extended necrosis in the inoculated leaves (Figures 2D and 2E). Furthermore, the proliferation of the fungal mycelia was drastically inhibited in ocp3 plants (data not shown). This indicates that resistance to this necrotrophic pathogen was dramatically enhanced, or susceptibility blocked, in the ocp3 mutant.

To test whether the altered disease susceptibility of ocp3 is specific to Botrytis, we challenged plants with Plectosphaerella cucumerina, another necrotroph. Infection of wild-type plants with $P$. cucumerina lead also to a strong degradation of the leaf tissue, manifested by extended lesions and chlorosis that increased in diameter as the infection progressed along the inoculated leaf (Figure 2F). Conversely, ocp3 plants showed a high degree of resistance to this fungal pathogen as the visible tissue deterioration in the inoculated leaves was drastically reduced (Figures $2 \mathrm{~F}$ and $2 \mathrm{G}$ ). Here also the proliferation of the fungal mycelia was drastically inhibited (data not shown).

On the basis of all these findings, it can be concluded that susceptibility to necrotrophic fungi is a characteristic trait linked to the OCP3 locus, and the identified mutation in this locus renders enhanced resistance to the same pathogens. This is in accordance with the observation that PDF1.2, an inducible marker for the ET/JA-responsive defense pathway against necrotrophic fungal pathogens (Turner et al., 2002), is constitutively expressed in ocp3 plants (Figure 1F).

\section{The Enhanced Resistance of ocp3 Plants to Necrotrophic Fungi Requires JA but Not SA or ET}

The constitutive expression in ocp3 plants of the $\mathrm{H}_{2} \mathrm{O}_{2}$-inducible GST and the JA-inducible PDF1.2, but not of the SA-inducible $P R-1$ (Figure 1F), suggests a link between oxidative stress and JA signaling that apparently is SA independent. In the complex network of interactions operating during plant resistance responses, an antagonistic relationship between the SA and JA/ET pathway has been well documented (Kunkel and Brooks, 2002) and indicates that, in ocp3 plants, the constitutive activation of the pathway leading to PDF1.2 gene expression could be negating expression of the SA-dependent genes. However, the exogenous application of SA promotes expression of the marker $P R-1$ gene in both ocp3 and wild-type plants (Figure 1F), indicating that ocp3 plants are not compromised in perception of $\mathrm{SA}$, and is in accordance with the observation that the resistance to biotrophic pathogens is also intact in this mutant (Figures $2 \mathrm{~A}$ to
2C). Furthermore, the exogenous application of SA abrogates the constitutive expression of PDF1.2 that occurs in ocp3 plants (Figure 1F). This antagonistic effect of SA was specific for PDF1.2 expression because GST1 expression was not repressed in ocp3 upon treatment with SA. Instead, SA promoted activation of GST1 in wild-type plants (Figure 1F). This latter observation reinforces the link existing between $S A$ and ROS as previously documented by others (Shirasu et al., 1997; Mur et al., 2000; Tierens et al., 2002) but also indicates that the oxidative stress mediating expression of GST1 in ocp3 plants and concurred expression of $P D F 1.2$ might be SA independent.

To more directly assess if SA could be contributing to the phenotype of ocp3 plants in relation to the observed resistance to necrotrophic pathogens, we crossed the nahG transgene into the ocp3 background. nahG encodes a bacterial salicylate hydroxylase that blocks the SA pathway by degrading SA (Delaney et al., 1994). The ocp3 nahG plants retained the resistance to $B$. cinerea (Figures $3 \mathrm{~A}$ and $3 \mathrm{~B}$ ) and $P$. cucumerina (Figure $3 C$ ) to levels similar to those of ocp3 plants. Likewise, the pad4 mutation compromises SA accumulation after pathogen attack (Zhou et al., 1998). When pad4 was introgressed in the ocp3 background, the resulting ocp3 pad4 plants remained as resistant to $B$. cinerea (Figures $3 \mathrm{~A}$ and $3 \mathrm{~B}$ ) or to $P$. cucumerina (Figure $3 \mathrm{C}$ ) as ocp3 plants.

To further extend these studies, we created an ocp3 npr1 double mutant. The npr1 mutant was originally identified by its insensitivity to SA and is considered the master regulator of SAmediated responses (Durrant and Dong, 2004). As observed for ocp3 nahG and ocp3 pad4 plants, the resistance of ocp3 npr1 plants to necrotrophic fungi also remained the same as observed in ocp3 plants (Figures $3 \mathrm{~A}$ to $3 \mathrm{C}$ ). All these results thus indicate that $S A$ seems not to be required for the enhanced resistance attributable to the ocp3 mutation against necrotrophic pathogens.

We also assessed the importance of JA in contributing to the phenotype of ocp3 plants. We tested whether a defect in the perception of this hormone might affect the observed enhanced resistance of ocp3 plants to necrotrophic fungi. The Arabidopsis coi1 mutant is fully insensitive to JA, and the COI1 protein is required for all JA-dependent responses so far identified. COI1 encodes an F-box protein involved in the ubiquitin-mediated degradation in JA signaling by means of forming functional E3-type ubiquitin ligase complexes (Xie et al., 1998; Devoto et al., 2002). Furthermore, coi1 plants are impaired in expression of PDF1.2 and show increased sensitivity to necrotrophic fungi (Thomma et al., 1998; Turner et al., 2002). All this supports the importance of JA in the resistance of plants to this type of pathogen and justified the introgression of coi1 in the ocp3 background to generate ocp3 coi1 double mutant plants (Figure 4). Importantly, the enhanced resistance observed in ocp3 plants to both $B$. cinerea and $P$. cucumerina is abrogated when the coi 1 mutation is present (Figures $4 \mathrm{~A}$ to $4 \mathrm{C}$ ). The ocp3 coi1 plants behave as coi1 plants upon infection of either fungi, with necrotic lesions spreading throughout the inoculated leaves as exemplified in Figure 4C for the response to $P$. cucumerina.

In addition to coi1, we studied jin1, another JA-insensitive mutant (Berger et al., 1996), in relation to the ocp3 mutant. JIN1 is a MYC-like transcription factor that functions in a 
A

B. cinerea

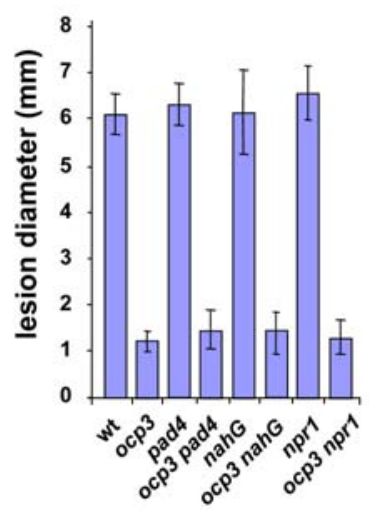

\section{P. cucumerina}

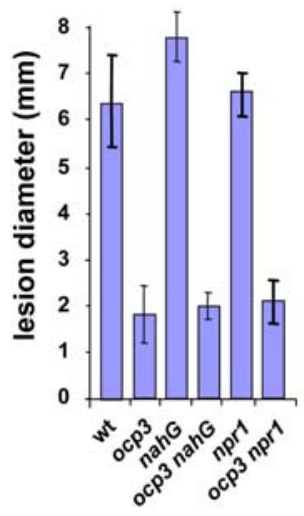

B

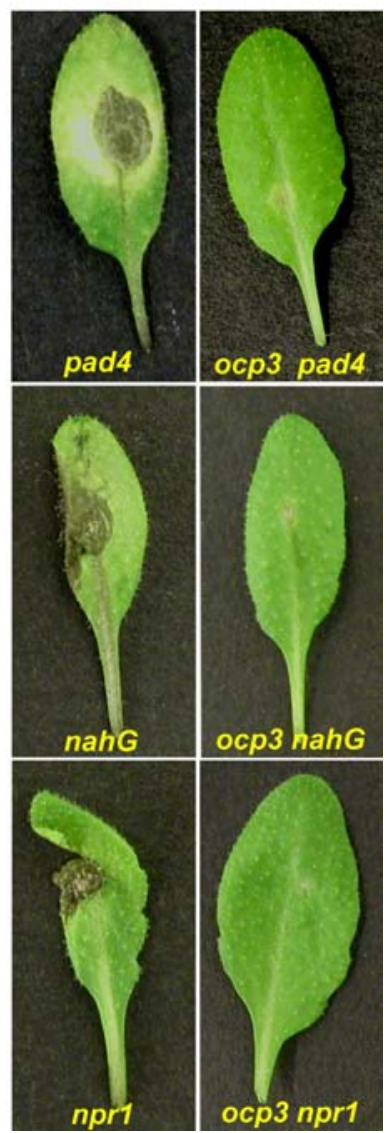

Figure 3. Effect of SA-Related Mutations on the Disease Resistance Response of ocp3 Plants.

(A) Resistance response of ocp3 nahG, ocp3 npr1, and ocp3 pad4 double mutants to $B$. cinerea compared with that of single mutant genotypes and wild-type plants. Plants were inoculated and disease symptoms were evaluated as described in Figure 2 by determining the average lesion diameters on three leaves of eight plants each.

(B) Representative leaves of each genotype showing symptoms of disease observed $5 \mathrm{~d}$ after inoculation with a $6-\mu \mathrm{L}$ droplet of $B$. cinerea spores $\left(2.5 \times 10^{4}\right.$ conidia $\left./ \mathrm{mL}\right)$.

(C) Resistance response of ocp3 nahG, ocp3 npr1, and ocp3 pad4 double mutants to $P$. cucumerina compared with that of the single mutant genotypes and wild-type plants. Lesion measurements were performed by determining the average lesion diameters on three leaves of eight plants each.

Data points represent average lesion size \pm SE of measurements.

COI1-dependent manner (Lorenzo et al., 2004). In contrast with coi1 and despite the defect in JA signaling, jin1 plants show increased resistance to necrotrophic pathogens, indicating that JIN1 may function as a repressor of the resistance to this type of pathogen. Interestingly, the ocp3 jin1 double mutant plants remained highly resistant when assayed against infection by $B$. cinerea (Figure $4 \mathrm{~A}$ ) and to levels comparable to those attained by either ocp3 plants or jin 1 plants. It is worth mentioning here that the ocp3 mutation neither confers insensitivity to JA

(according to the root-growth inhibition assay in the presence of JA; data not shown) nor is allelic to jin1. The lack of additive effect thus indicates that there might be a certain functional overlap between ocp3 and jin1 for the enhancement of resistance to $B$. cinerea that ultimately is primed by JA and controlled by COI1.

ET has also been shown to mediate certain aspects of the plant response to pathogens (Thomma et al., 2001; Berrocal-Lobo et al., 2002). However, ET signaling can also function independently of JA, or even inhibit JA-dependent responses (Ellis and

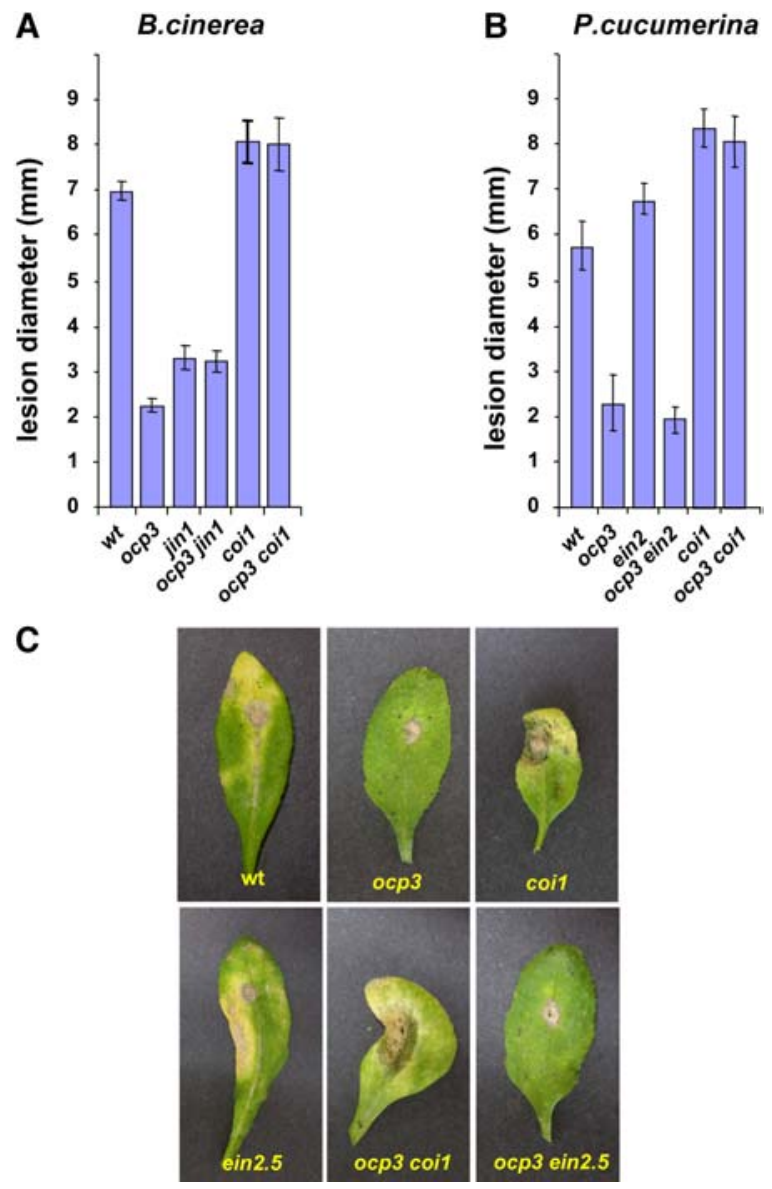

Figure 4. Effect of JA and ET-Related Mutations on the Disease Resistance Response of ocp3 Plants.

(A) Resistance response of ocp3 coi1 and ocp3 jin1 double mutants to $B$. cinerea compared with that of single mutant genotypes and wild-type plants. Plants were inoculated and disease symptoms were evaluated as described in Figure 2 by determining the average lesion diameters on three leaves of eight plants each.

(B) Resistance response of ocp3 coi1 and ocp3 ein2 double mutants to $P$. cucumerina compared with that of single mutant genotypes and wildtype plants. Disease symptoms were evaluated by determining the average lesion diameters on three leaves of eight plants each.

(C) Representative leaves of each genotype showing symptoms of disease observed $7 \mathrm{~d}$ after inoculation with a $6-\mu \mathrm{L}$ droplet of $P$. cucumerina spores $\left(5 \times 10^{6} \mathrm{spores} / \mathrm{mL}\right)$.

Data points represent average lesion size \pm SE of measurements. 
Turner, 2001; Thomma et al., 2001). To test the importance of ET in the resistance response mediated by the ocp3 mutation, we crossed ocp3 plants with the ET-insensitive ein2 mutant (Alonso et al., 1999) to generate the ocp3 ein2 double mutant. As observed in Figures $2 \mathrm{~B}$ and $2 \mathrm{C}$, the resistance of ocp3 ein2 plants to $P$. cucumerina remained the same compared with that observed in ocp3 plants (Figures $4 \mathrm{~A}$ to $4 \mathrm{C}$ ), thus indicating that for the observed resistance mediated by ocp3, the plant hormone ET is dispensable.

\section{Isolation of OCP3}

To determine the nature of the ocp3 mutation, a backcross was performed between ocp3/ocp3 plants and wild-type OCP3/ OCP3 plants containing the Ep5C-GUS transgene and the progeny analyzed. In the F1 plants resulting from this cross, constitutive expression of GUS activity was absent in all 21 seedlings tested, and in the F2 plants, expression was present in 31 of 118 seedlings. The F2 segregation ratio of the phenotype conferred by ocp3 was 1:3 (constitutive expressers:nonexpressers, $\chi^{2}=1.48 ; 0.1>P>0.5$ ), indicative of a single recessive mutation. The ocp3 mutant was backcrossed with wild-type Landsberg erecta to generate an F2 mapping population, and recombinant seedlings were identified with the use of simple sequence length polymorphism (SSLP) markers (Bell and Ecker, 1994). DNA was isolated, initially, from 38 ocp3 homozygous plants, and the segregation of SSLP markers indicated that ocp3 showed linkage to the Nga249 marker on chromosome 5 where all 76 alleles analyzed were Col-0 (data not shown). Further analysis of the ocp3 selected plants with additional available markers for chromosome 5 identified the SSLP markers Nga 249 and ca72 as the closest markers flanking the ocp3 mutation on each side (Figure $5 \mathrm{~A}$ ). Screening of 1100 randomly chosen plants from a Landsberg erecta $\times$ ocp3 F2 mapping population with the SSLP markers Nga249 and ca72 identified 29 plants having a recombination in the interval. Using these 29 recombinant plants, OCP3 was found to be located 4 centimorgans from Nga249 and 1.9 centimorgans from ca72. We designed further polymorphic markers for the region between Nga249 and ca72, and the position of OCP3 was narrowed down to a genomic region that included the end of $B A C$ clone T5K6 and the beginning of BAC clone F2l11. Nineteen genes are present on the annotated sequence within these two BAC clones (Figure $5 \mathrm{~B})$. The entire coding region of each of these genes was amplified from ocp3 plants, and the sequences of the PCR products were determined. The sequence corresponding to gene At5g11270 was identified as the only one to show a single nucleotide substitution (G-to-A on the coding strand; exon 3) causing a single amino acid substitution (Ala-to-Thr) (Figure 5C). No mutation was found in the remaining 18 genes. At5g11270 contains two introns and encodes a protein of 553 amino acids.

To assign unequivocally At5g11270 as OCP3, we introduced a 3.2-kb fragment containing At5g11270 into ocp3 by Agrobacterium tumefaciens-mediated transformation. Three transgenic lines were tested for constitutive expression of GUS and for disease resistance to $B$. cinerea and $P$. cucumerina. In all of them, the constitutive expression of GUS was abolished and the normal susceptibility to the fungal pathogens recovered, dem- onstrating that At5g11270 is OCP3 (Figures 5D and 5E show the result of this complementation for one of the transgenic lines generated; line 2AT).

\section{Aberrant Splicing of At5g11270 mRNA in the ocp3 Mutant}

To identify the structure of the OCP3 gene and its mutant allele ocp3, a 1.2-kb fragment was amplified by RT-PCR from wildtype and ocp3 mutant plants using primers designed according to the annotated sequence of gene At5g11270. Direct sequencing and comparison of the RT-PCR products revealed that the ocp3-derived cDNA carries an internal deletion of 36 nucleotides instead of the expected single nucleotide substitution identified in the genomic sequences (Figure 6). This deletion corresponded to the first 36 nucleotides of exon III. Thus, the transition of $G$ to $A$ identified at the genomic level on the coding strand of the ocp3 allele provokes an alteration in the normal splicing process for the ocp3-derived mRNA. This short deletion provokes a frame shift in the ocp3 open reading frame that results in the generation of an in-frame stop codon rendering a truncated protein of 210 amino acid residues instead of the 354 residues of the wild-type protein (see below, Figure 7). This deletion was further confirmed in different ocp3 plants by RT-PCR using a set of internal forward and reverse nested primers designed from the genomic sequence (Figure 6A). Products of the expected lengths were obtained in all reactions, except when using the primer internal to the deleted sequence that did not result in any RT-PCR product in ocp3-derived samples (Figure 6B). Thus, the lack of function genetically ascribed to the recessive ocp3 mutation is not because of an amino acid change but rather the result of an abnormal splicing of the transcribed ocp3 mRNA, which upon translation renders a truncated protein lacking 144 amino acid residues from the C-terminal part (Figures $6 \mathrm{C}$ and 7 ).

\section{OCP3 Encodes a Homeobox Transcription Factor}

DNA sequencing showed that the $O C P 3 \mathrm{CDNA}$ encodes a protein of 354 amino acid residues (Figures 7A and 7B), of 39,111 D, and a pl of 4.53. OCP3 contains various salient features. Close to the $\mathrm{C}$ terminus, a 60-amino acid domain (position 284 to 344) resembling that of a homeodomain encoded by homeobox genes of various organisms (Gehring et al., 1994) can be identified. The homeodomain of OCP3 shares most of the highly conserved amino acids characteristic of the 60-amino acid homeodomain module. The conservation of these critical residues (e.g., L-16, Y-20 instead of F-20, I/L-34, I/L/M-40, W-48, $\mathrm{F}-49$, and $\mathrm{R}-53$ ) is easily identified when compared with different Arabidopsis homeodomain-containing proteins that belong to different protein subgroups (Figure 7C). Inspection of the amino acid sequence of OCP3 also revealed the presence of two canonical bipartite nuclear localization signals (Dingwall and Laskey, 1991; Nigg, 1997): RK-(X) $)_{10}-$ KKNKKK at positions 64 to 81 and $\mathrm{KK}-(\mathrm{X})_{10}-\mathrm{RRSKR}$ at positions 294 to 310 , with the latter being buried within the homeodomain (Figures 7A and 7B). These features could be mediating targeting of the protein to the nuclei. Another salient feature of OCP3 is the presence of an extended region rich in acidic residues (positions 84 to 181), a feature common to several transcriptional activators (Cress and 
A
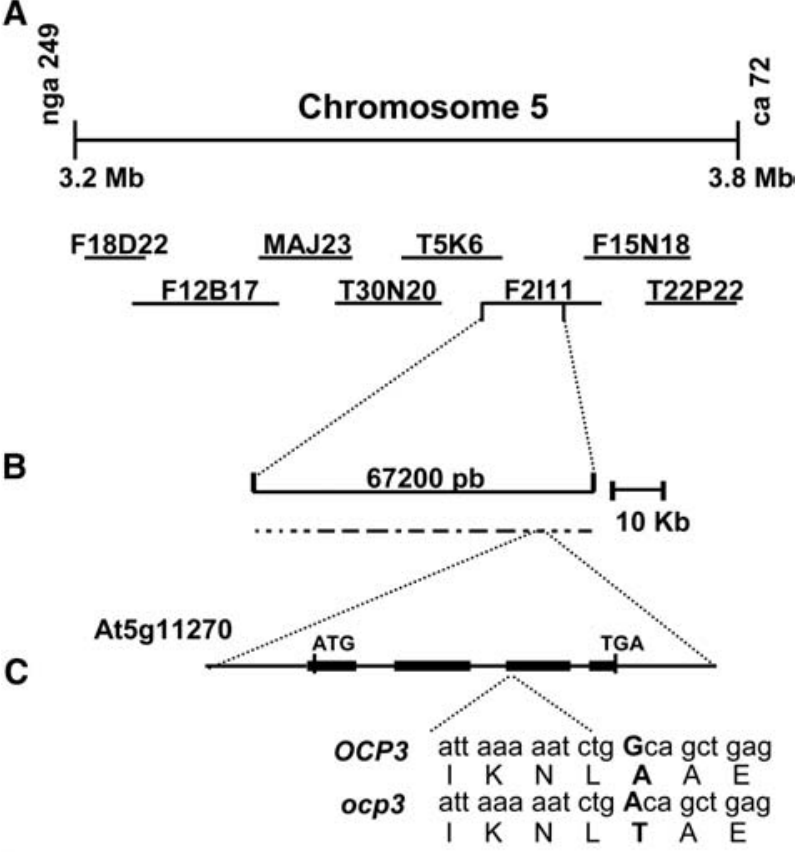

D
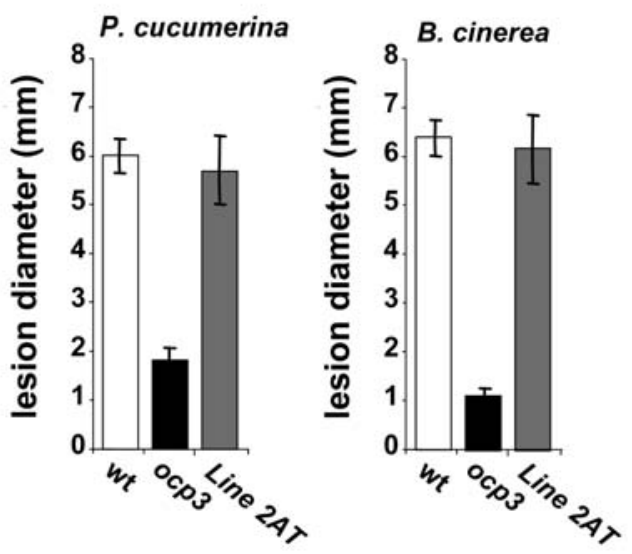

E

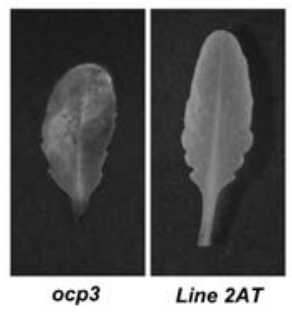

Figure 5. Positional Cloning of $\mathrm{OCP} 3$ and Complementation.

(A) Region of $0.6 \mathrm{Mb}$ on the top of chromosome 5 with overlapping BACs flanked by the SSLP markers Nga249 and ca72 used for the screening of recombinations in 2200 chromosomes.

(B) Location of OCP3 on the sequenced BAC clone F2I11. OCP3 was positioned between two SSLP markers comprising a $67.2-\mathrm{kb}$ region of BAC F2111. The 19 annotated genes included in this region are indicated. (C) Exon/intron structure of OCP3. The coding regions are indicated with thick lines. The insert shows the nucleotide exchange and its influence on the protein sequence. The mutant allele is indicated below the wild-type
Triezenberg, 1991). The last identifiable feature within OCP3 is the presence of the canonical LxxLL motif at positions 101 to 105 (Figures 7A and 7B). This motif is a signature sequence that facilitates the interaction of different transcriptional coactivators to nuclear receptors and is thus a defining feature identified in several nuclear proteins (Heery et al., 1997). All these structural motifs strongly indicate that OCP3 is a nuclear protein presumably involved in transcriptional regulation in Arabidopsis.

According to a general classification scheme for homeobox genes (http://www.homeobox.cjb.net/) OCP3 is unique as it is set apart from the major classes of homeodomain-containing proteins found in plants, including KNOX or HD-Zip. In addition $O C P 3$ is present as a single copy gene in the Arabidopsis genome. Sequence searches in databases revealed extensive identity of OCP3 with six other proteins - from tomato (GenBank accession number AW223899, 48.9\% identity), potato (GenBank BQ112211, 48.3\% identity), grape (GenBank CD003732, 51.1\% identity), rice (GenBank AY224485, 49.5\% identity), wheat (GenBank CK205563, 49.4\% identity), and maize (GenBank BG840814, 51.3\% identity) - which were found to have a high degree of sequence similarity with OCP3 and with conservation of all the major structural motifs discussed above (data not shown). This indicates that the function of this type of transcriptional regulator has been highly conserved in plants during evolution.

\section{Subcellular Localization of OCP3}

The subcellular localization of OCP3 was investigated using C-terminal green fluorescent protein (GFP) fusions of full-length OCP3. Expression of this construct, as driven by the $35 \mathrm{~S}$ promoter of Cauliflower mosaic virus in stable transgenic Arabidopsis plants and monitored in epidermal cells of leaves using confocal microscopy, demonstrated that, consistent with a role for OCP3 as a transcription factor, the fusion protein localized predominantly to the nucleus (Figure 7D). Parallel expression of native GFP under control of the 35S promoter in transgenic Arabidopsis plants did not reveal any preferential localization to

sequence. Lowercase letters mark nucleotide sequences at the beginning of exon III. The G-to-A transition is indicated in bold uppercase letters. The deduced amino acid sequences are indicated as uppercase single letter code below each nucleotide triplet, and the boldface letters mark the amino acid changes (Ala to Thr) in the protein sequences.

(D) Resistance response of transgenic ocp3 plants stably transformed with a 3.2-kb genomic DNA sequence encompassing the entire At5g11270 gene (line 2AT) and comparison to the resistance response observed in the wild type and the ocp3 mutant. Plants were inoculated as described in Figure 2 with $B$. cinerea (right) and $P$. cucumerina (left), and disease symptoms were evaluated by determining the average lesion diameters on three leaves of eight plants each. Data points represent average lesion size \pm SE of measurements.

(E) Histochemical staining of GUS activity driven by the Ep5C promoter in fully expanded rosette leaves obtained from ocp3 plants (left) and from transgenic ocp3 plants transformed with the At5g11270 gene (line 2AT) (right). 
A

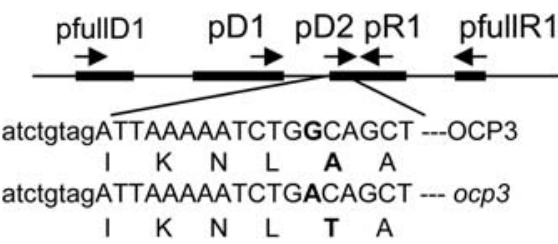

B

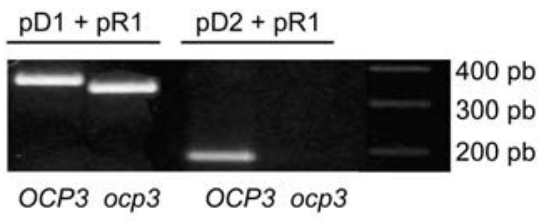

C

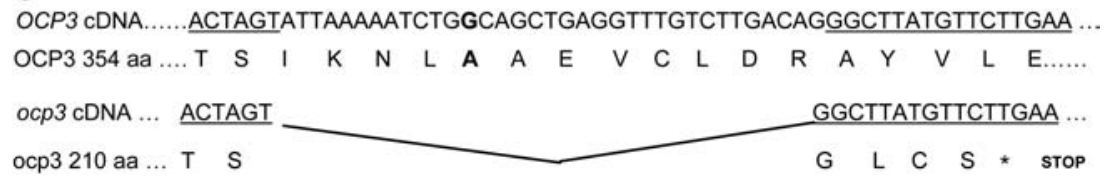

Figure 6. Analysis of $O C P 3$ and $O c p 3$ cDNAs.

(A) Diagram of exon/intron structure of OCP3. The exons are indicated with bold lines. The nucleotide sequence at the splice junction in exon 3 is indicated in the insert. Lowercase letters mark intron sequences, uppercase letters indicate exon sequences, boldface uppercase letters mark amino acids, and the arrow indicates the nucleotide and corresponding amino acid substitution. The arrows on top of the diagrammed gene denote the different positions of the primers used in the RT-PCR experiments. PfullD1 is located at the beginning of exon 1, pfullR1 is located at the end of exon 4, $\mathrm{pD} 1$ at the end of exon2, pD2 at the beginning of exon 3, and pR1 in the middle of exon 3. D denotes direct ( $5^{\prime}$ to $\left.3^{\prime}\right)$ orientation, and R denotes reverse ( $3^{\prime}$ to $\left.5^{\prime}\right)$ orientation.

(B) Agarose gel electrophoresis of RT-PCR products obtained when using mRNA from wild-type and ocp3 plants and different combinations of primers. Note the reduced molecular weight, and thus the faster migration, of the band amplified from ocp3 plants with primers pD1+pR1 when compared with that derived from wild-type plants. Also note the absence of amplified DNA product when using primers pD2+pR1 and reverse transcribed mRNA from ocp3 plants but not from wild-type plants. The absence of amplified product is indicative of a lack of recognition by one of the two primers in the cDNA template generated from ocp3 plants. The experiment was repeated several times with mRNA derived from four different wild-type and ocp3 plants. (C) Nucleotide sequence and derived amino acid sequence of cDNA clones derived from mRNA isolated from wild-type (OCP3) and mutant (ocp3) plants. Reverse transcribed products were amplified with primers pfullD1 and pfullR1 and completely sequenced on both strands. Note the 36nucleotide internal deletion in all ocp3 cDNAs sequenced. Underlined is the nucleotide sequence common to both ocp3 and OCP3 derived cDNAs. The internal deletion in ocp3 cDNAs influences the derived amino acid sequence and provokes a frame shift that generates a premature stop codon in the ocp3 protein. Boldface uppercase letters mark amino acids, and the asterisk indicates a stop codon. The arrow indicates the presence and position of the nucleotide $(\mathrm{G})$ in the $O C P 3 \mathrm{cDNA}$ that if mutated renders the ocp3 phenotype. The results were reproduced several times with mRNA derived from different wild-type and ocp3 plants and at different stages of growth.

the nucleus (Figure 7D). Thus, OCP3 carries all major determinants for a nuclear localization.

\section{OCP3 Expression Is Partially Repressed by Fungal Infection}

The expression of $\mathrm{OCP} 3$ in response to infection with a necrotrophic fungal pathogen was analyzed in wild-type plants at different time intervals after infection. OCP3 mRNA levels were undetectable by RNA gel blot analysis in any tissue analyzed, indicating that the OCP3 gene is transcribed at a very low rate. To circumvent this difficulty, the presence of OCP3 mRNAs was studied by RT-PCR. These analyses revealed that OCP3 is constitutively expressed in leaf tissue from healthy plants. Figure 8 shows that after infection with $P$. cucumerina, there is a decrease in the level of accumulation of the OCP3 mRNAs, being most evident at $72 \mathrm{~h}$ after infection. Concomitantly, and inversely correlated with this reduction, the JA and fungal-inducible marker gene PDF1.2 is upregulated upon infection with $P$. cucumerina.
At latter stages of infection, induced expression of the defenserelated gene $P R 1$ also takes place and is indicative of the tissue deterioration occurring as a result of the growth habit of the fungi.

The downregulation of $O C P 3$ upon fungal infection, its inverse correlation with the induced expression of PDF1.2, and the recessive nature of the ocp3 mutation favors the interpretation that OCP3 may be functioning as a repressor of the resistance response to fungal pathogens in wild-type plants.

\section{DISCUSSION}

The data presented in this article provide evidence for a role of $O C P 3$ in regulating disease resistance to necrotrophic pathogens. A recessive mutation in the OCP3 gene resulted in enhanced resistance of ocp3 plants to the fungal necrotrophs $B$. cinerea and $P$. cucumerina, whereas resistance toward infection by biotrophs, including the oomycete $H$. parasitica and the bacteria Pst DC3000, remained invariant in the same plants. 
A

1 MIKAMALSSAGVVSHLHPPSFSSSSGLSVNRVLFRNRNASPCGLSLPILNPSRSVLVFAR

61 GKNRKGFVSSSSSSPKKNKKKSLDGADNGGGEEEEDPFEALFNLLEEDLKNDNSDDEEIS

121 EEELEALADELARALGVGDDVDDIDLFGSVTGDVDVDVDNDDDDNDDDDNDDDDDDSEED

181 ERPTKLKNWQLKRLAYALKAGRRKTS IKNLAAEVCLDRAYVLELLRDPPPKLLMLSATLP

241 DEKPPVAAPENSSPDPSPVESLSAEDVVVEPKEKVKDEAVHVMQQRWSAQKRVKKAHIET

301 LEKVYRRSKRPTNAVVSSIVQVTNLPRKRVLKWFEDKRAEDGVPDKRAPYQAPV

B

NLS LxxLL

NLS

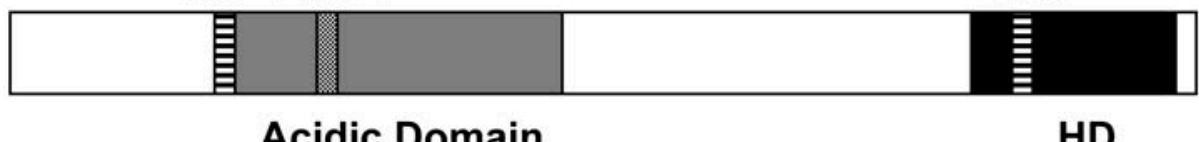

Acidic Domain

HD

C

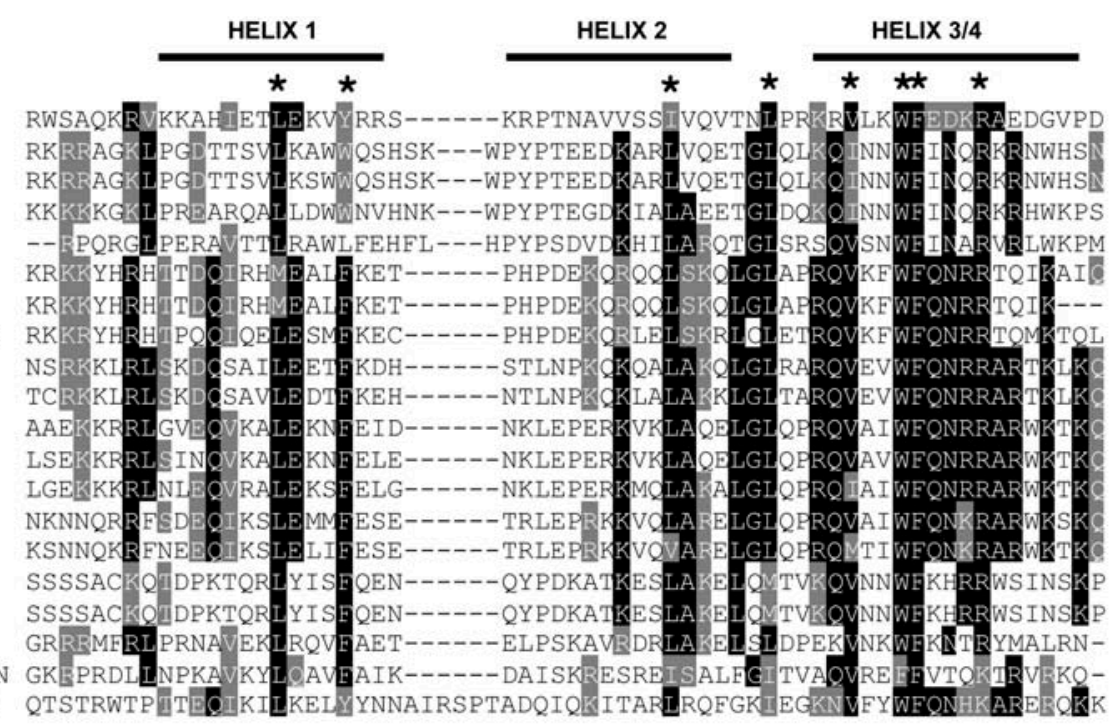

D

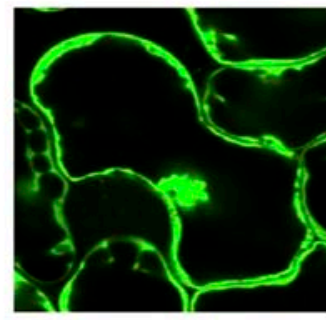

35S:GFP

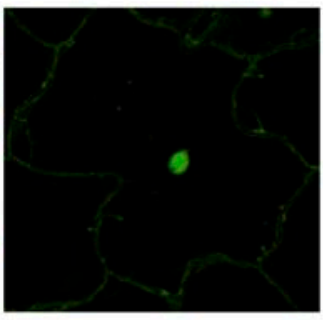

35S:GFP-OCP3

Figure 7. ОСP3 Protein and Comparison with Other Arabidopsis Homeodomain-Containing Proteins.

(A) Predicted amino acid sequence of OCP3. The homeodomain is shown in boldface letters. The two conserved signatures for nuclear localization are underlined. The acidic domain is shown in italics and the nuclear protein interacting domain (LxxLL), embedded within this acidic region, is shown underlined.

(B) Predicted protein structure of OCP3. The relative position of nuclear localization signals (NLS), nuclear protein interacting domain (LxxLL), acidic domain, and homeodomain are indicated.

(C) Sequence alignment showing the C-terminal amino acid sequence of OCP3 with the homeodomain of different homeobox genes from Arabidopsis, including members of the KN and HD-Zip families. Asterisks above the alignments correspond to amino acid positions in the homeodomain that are highly conserved in all organisms and define the homeodomain signature. Black shading indicates amino acids conserved in all entries, and gray shading indicates amino acids with similar physicochemical characteristics.

(D) Leaves of transgenic Arabidopsis plants expressing a 35S:GFP or a 35:OCP3-GFP fusion were observed using confocal microscopy. Shown are projections of the fluorescent images of epidermal cells. A predominant nuclear localization of the OCP3-GFP fusion protein is observed when it is compared with the general cellular distribution of the GFP protein alone. 


\section{P. cucumerina}

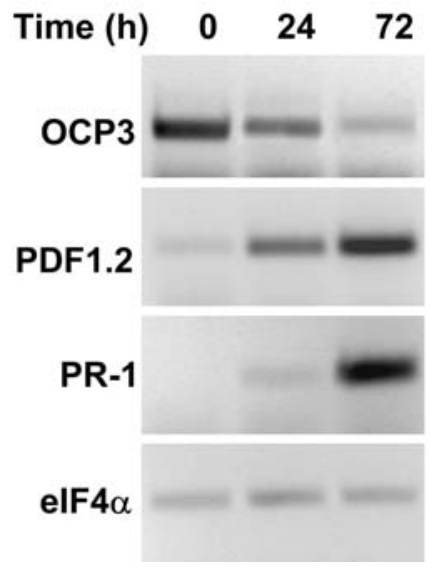

Figure 8. Expression of $O C P 3$ and Defense Response Marker Genes after $P$. cucumerina Infection.

RT-PCR analysis of OCP3, PDF1-2, and PR-1 expression in $P$. cucumerina-infected leaf tissues. Wild-type plants were inoculated by spraying with a suspension of $10^{5}$ spores $/ \mathrm{mL}$, and tissue was frozen for RNA extraction. Numbers indicate hours after inoculation. The bottom gels show RT-PCR for the housekeeping gene elF $4 \alpha$ here used as a loading control. The experiment was repeated two times with similar results.

Interestingly, the OCP3 gene is expressed at very low levels in healthy plants, and this constitutive expression is partially repressed during the course of infection by a fungal necrotroph. In addition, the resistance phenotype conferred by the ocp3 mutation is blocked when assayed in the coil mutant background, with the ocp3 coi1 double mutant plants retaining the increased sensitivity to necrotrophs attributable to coi1. These findings suggest that $O C P 3$ may play a role in the defense response regulated by JA. In fact, the recessive ocp3 mutation confers constitutive expression of the PDF1.2 gene, which encodes a defensin protein with a defined role in the JAmediated plant defense response (Thomma et al., 1998). Because PDF1.2 expression is fully dependent on COI1 (Turner et al., 2002) and is up in healthy ocp3 mutant plants, our finding reinforces the consideration that $O C P 3$ might be functioning in a COI1-dependent manner by acting as a negative regulator of the JA-mediated defense response to necrotrophic pathogens.

Another salient feature of ocp3 plants is the increased accumulation of $\mathrm{H}_{2} \mathrm{O}_{2}$ observed to occur under resting conditions that is accompanied by the constitutive expression of the $\mathrm{H}_{2} \mathrm{O}_{2}$ inducible marker gene GST1 (Levine et al., 1994; Alvarez et al., 1998) but not by symptoms indicative of cell death. $\mathrm{H}_{2} \mathrm{O}_{2}$ and other ROI molecules are normally produced to high levels during infection by both biotrophic and necrotrophic pathogens and have been implicated as regulatory signals for the basal disease resistance response to these pathogens (Tiedemann, 1997; Mengiste et al., 2003). However, of the pathogens tested on ocp3 plants, only enhanced resistance was observed toward necrotrophic pathogens, whereas the resistance to biotrophic pathogens remained invariant. This significant difference might indicate that the ocp3 mutation may affect specific functions related to ROls by regulating certain effector molecules directed toward the sensing and identification of a necrotroph. Alternatively, OCP3 may be functioning as a specific regulator of the redox homeostasis, and any alteration in this role, such as that anticipated to occur in the recessive ocp3 mutant, may result in increased accumulation of ROIs, and in particular of $\mathrm{H}_{2} \mathrm{O}_{2}$. This in turn may activate specific signal components that may predispose the plant to react more effectively to an infection by a necrotrophic pathogen. Interestingly, $\mathrm{SA}$ and $\mathrm{H}_{2} \mathrm{O}_{2}$ have been demonstrated to form a feedback loop circuit during the course of a plant-pathogen interaction (Draper, 1997; Shirasu et al., 1997), and there is evidence suggesting that SA may be required for a local response to a necrotroph such as Botrytis at the point of infection (Govrin and Levine, 2000; Ferrari et al., 2003). However, SA synthesis and accumulation are neither increased nor repressed in ocp3 plants (data not shown). Moreover, the analysis of double mutant plants for ocp3 and key regulators of SA accumulation and perception, such as the ocp3 pad4, ocp3 nahG, or ocp3 npr1 double mutants generated in this work, indicate that SA is not required for the observed ocp3-mediated resistance to necrotrophs. Likewise, the plant hormone ET neither seems to be required for the enhanced resistance of ocp3. Here, the lack of perception of this hormone, as studied with the ocp3 ein2 double mutant plants, does not suppress or reduce the characteristic resistance of ocp3 plants to $P$. cucumerina. Because JA and ET can work either in concert or independently for the activation of specific signaling pathways (Ellis and Turner, 2001; Thomma et al., 2001), the ET-independent resistance of ocp3 may indicate that OCP3 regulates a specific branch of the JA pathway. Moreover, this branch appears to be the same as that ascribed to the JA-regulated and ETindependent JIN1 transcription factor (Lorenzo et al., 2004), as deduced from the lack of additive effect observed in the ocp3 jin1 double mutant plants. All these observations point to a role of OCP3 in specifically regulating a COI1-dependent resistance to necrotrophic pathogens.

OCP3 is a member of the homeobox gene family. Homeobox proteins are ubiquitous in higher organisms and represent master control switches involved in developmental processes and cellular adaptation to changes in the environment. They function as transcriptional regulators that are characterized by the presence of an evolutionarily conserved homeodomain responsible for specific DNA binding (Gehring et al., 1994). In plants, two major classes of homeodomain-encoding genes have been identified: the homeodomain class represented by KNOTTED1 (Vollbrecht et al., 1991) and the family of HD-Zip proteins (Schena and Davis, 1992). The latter is characterized by an additional Leu zipper motif adjacent to the homeodomain that facilitates homodimerization and heterodimerization of the transcriptional regulators. Functional characterization of some members of the homeobox family supports a role for some of them as key regulators of hormone signaling (Himmelbach et al., 2002), adaptive responses to environmental cues (Steindler et al., 1999; Zhu et al., 2004), and pathogen-derived signaling processes (Mayda et al., 1999).

The single point mutation identified in the ocp3 allele results in abnormal splicing of the corresponding transcript that provokes 
an internal deletion of the first 36 nucleotides of exon III. This short deletion leads to a frame shift in the ocp3 open reading frame that results in the generation of a premature stop codon. This mutation thus leads to a truncated ocp3 protein consisting of 210 amino acid residues instead of the 354 amino acid residues predicted for OCP3. The predicted 60 -amino acid domain corresponding to the homeodomain is located within the 144-amino acid C-terminal domain that is missing in ocp3. This domain is required for homeobox proteins to function as transcriptional regulators because it is the place where contact with DNA is established, primarily through helix 3 of the homeodomain, which targets the major groove of the DNA helix present in the promoter region of downstream genes (Gehring et al., 1994). Therefore, it is conceivable that the mutated ocp3 protein no longer functions as a transcriptional regulator. It is thus our current working hypothesis that OCP3 functions as a specific transcription factor of a JA-mediated and COI1-dependent plant cell signal transduction pathway and modulates transcription of genes important for the defense response(s) to necrotrophic pathogens.

The identification of target genes of OCP3 and interacting protein partners is our challenge for the future. Furthermore, the possible interaction of OCP3 with other transcriptional regulators involved in the defense response to necrotrophic pathogens, such as the MYC-related JIN1 protein (Lorenzo et al., 2004), the AP2-like ERF1 protein (Lorenzo et al., 2003), the MYB-related BOS1 protein (Mengiste et al., 2003), or the WRKY70 transcription factor (Li et al., 2004), and how they operate in a concerted manner to regulate transcription are interesting challenges for the future. All these approaches should help understand the mechanistic basis of the regulatory function of OCP3 and how we can exploit this function to generate plants more resistant to fungal pathogens without affecting the defense responses to other types of pathogens.

\section{METHODS}

\section{Plants, Growth Conditions, and Treatments}

Arabidopsis thaliana plants were grown in soil or on plates containing MS media, as described previously (Mayda et al., 2000). The ocp3 mutant was isolated in a screen for constitutive expressers of the Ep5C-GUS reporter gene in transgenic Col-0 plants mutagenized with ethyl methanesulfonate, as described previously for another mutant (Mayda et al., 2000). The transgenic line used (line 5.2) was homozygous and contained a single insertion of the Ep5C-GUS transgene. The ocp3 mutant line used in these experiments has been backcrossed three times to the wild-type parental line. Plants were grown in a growth chamber $\left(19\right.$ to $23^{\circ} \mathrm{C}, 85 \%$ relative humidity, $100 \mu \mathrm{Em}^{-2} \mathrm{~s}^{-1}$ fluorescent illumination) in a 10-h-light and 14-h-dark cycle. Unless otherwise indicated, fully expanded leaves of 4-week-old plants were used for all experiments. Staining for the presence of $\mathrm{H}_{2} \mathrm{O}_{2}$ via the DAB uptake method was performed as described by Thordal-Christensen et al. (1997). Staining for the presence of GUS activity was performed as described previously (Mayda et al., 2000).

\section{Pathogen Infection}

Pseudomonas syringae pv tomato DC3000 was grown and prepared for inoculation as described previously (Mayda et al., 2000). The density of the bacterial populations was determined by plating serial dilutions on King's B medium supplemented with rifampicin $(50 \mu \mathrm{g} / \mathrm{mL})$ at $28^{\circ} \mathrm{C}$ and counting the colony-forming units at different times. Data are reported as means and standard deviations of the log (colony-forming units/fresh weight) of six to eight replicates. Hyaloperonospora parasitica resistance assays were done on 3-week-old plants that were sprayed with a conidial suspension of $H$. parasitica isolate NOCO $\left(10^{5}\right.$ conidiospores $\mathrm{mL}^{-1}$ tap water) as described previously (Mayda et al., 2000). On the seventh day, the density of the spores on the plantlets (seven pots per treatment, each pot treated separately) was assessed using a haemocytometer. Alternatively, leaf samples were stained with lactophenol-trypan blue at different days after inoculation and examined under the microscope as described previously (Mayda et al., 2000).

For resistance to Plectosphaerella and Botrytis, 3-week-old seedlings were transplanted to single pots and cultivated at a $22^{\circ} \mathrm{C}$ day $/ 18^{\circ} \mathrm{C}$ night temperature with $12 \mathrm{~h}$ of light per $24 \mathrm{~h}$. When plants were 6 weeks old, they were inoculated by applying $6-\mu \mathrm{L}$ droplets of spore suspension of either Plectosphaerella cucumerina $\left(5 \times 10^{6}\right.$ spores $\left.\mathrm{mL}^{-1}\right)$ or Botrytis cinerea $\left(2.5 \times 10^{4}\right.$ conidia $\left.\mathrm{mL}^{-1}\right)$ to three fully expanded leaves per plant. $P$. cucumerina was isolated from naturally infected Arabidopsis (accession Landsberg erecta) (Ton and Mauch-Mani, 2004) and grown on $19.5 \mathrm{~g} / \mathrm{L}$ of potato dextrose agar (Difco, Detroit, $\mathrm{Ml}$ ) at room temperature for 2 weeks before spores were collected and suspended in $10 \mathrm{mM}$ $\mathrm{MgSO}_{4}$. B. cinerea (strain BMM1, isolated from Pelargonium zonale; Zimmerli et al., 2001) was grown on $19.5 \mathrm{~g} / \mathrm{L}$ of potato dextrose agar (Difco) at $20^{\circ} \mathrm{C}$ for $10 \mathrm{~d}$. The conidia were collected and suspended in sterile PDS (12 $\mathrm{g} \mathrm{L}^{-1}$; Difco). The plants were maintained at $100 \% \mathrm{RH}$, and disease symptoms were evaluated 4 to $10 \mathrm{~d}$ after inoculation by determining the average lesion diameter on three leaves of five plants each.

\section{Genetic Analysis}

Crosses were performed by emasculating unopened buds and using the pistils as recipients for pollen. Backcrosses with the parental transgenic line were performed using Ep5C-GUS plants as the pollen donor. The reciprocal crosses were also performed. F1 and F2 plants were grown on MS plates and tested for GUS activity. Segregation of phenotype in the F2 generation was analyzed for goodness of fit with the $\chi^{2}$ test.

\section{PCR-Based Mapping}

An ocp3 plant (in the Col background) was crossed with Landsberg erecta, and amongst the segregating F2 progeny, homozygous ocp3 mutants were selected for mapping. Recombinant seedlings were identified using SSLP markers by the protocol described by Bell and Ecker (1994) and with new markers as reported on the Arabidopsis database Web site (www.arabidopsis.org).

\section{Generation of Double Mutants}

The mutant alleles used throughout this study were npr1-1 (Cao et al., 1997), pad4-1 (Zhou et al., 1998), coi1-1 (Xie et al., 1998), ein2-5 (Alonso et al., 1999), and jin1-1 (Lorenzo et al., 2004). All the mutants and transgenic plants used in these studies were in ecotype Col-0. The ocp3 npr1, ocp3 pad4, ocp3 coi1, ocp3 ein2, ocp3 jin1, and ocp3 nah G double mutants were generated using ocp3 as recipient for pollen. The homozygosity of the loci was confirmed using a molecular marker for each of the alleles in segregating populations. All the double mutants were confirmed in the F3 generation, except ocp3 coi1 plants that were sterile and could only be propagated as heterozygotes for coi1. For the double mutant containing ein2-5, F2 seed was plated on MS plates containing $20 \mu \mathrm{M}$ 1-amino-cyclopropane-1-carboxylic acid and placed in a growth 
chamber. After $3 \mathrm{~d}$ in the dark, the seedlings were scored for the presence or absence of the ET-induced triple response. The ein2 mutant, being ET insensitive, does not display the triple response. F2 plants that lacked the triple response were collected and transferred to soil to score for homozygosity for ocp3.

\section{Genomic and cDNA Cloning}

The genomic sequence was used as the basis for cloning of cDNAs and genomic clones. Poly $\left(\mathrm{A}^{+}\right) \mathrm{RNA}$ was isolated from different wild-type and ocp3 plants and was reverse-transcribed using oligo(dT) primers as described (Mayda et al., 1999). These were used as templates to amplify $O C P 3$ and ocp3 cDNAs using different combinations of the sense and antisense gene-specific primers: pfullD1 (5'-GAATTCATGATAAAAGCCATGG-3'), pfullR1 (5'-GTTAACTCTAGATCTTTCCGGAG-3'), pD1 (5'-GGTGATGTTGATGTTGATGTTG-3'), pR1 (5'-CTTAGGTTCGACCACAACATCTTCAG-3'), and pD2 (5'-ATCTGGCAGCTGAGGTTTGTCTTG-3').

\section{Reverse Complementation}

The OCP3 genomic region was amplified by PCR using gene-specific primers designed to include the $1.5-\mathrm{kb}$ region upstream of the start codon and a part of the $3^{\prime}$ region that follows the stop codon. The sequences of the OCP3 genomic forward and reverse primers used were $5^{\prime}$-GAGATTGGAACGTGGGTCGACTTTAG-3' and 5'-TTCCTGAATTCATACTTTATCATAG-3', respectively. A 3.2-kb genomic fragment containing the wild-type At5g11270 gene was obtained by PCR and cloned to pCAMBIA1300 to render clone PCAMBIAOCP3 that was transferred to Agrobacterium tumefaciens and used to transform ocp3 plants by the floral-dip method (Bechtold et al.,1993).

\section{Expression Analysis}

To analyze the level of gene expression by RT-PCR, total RNA samples were prepared from leaf tissues using the Total RNA kit from Ambion (Austin, TX). Reverse transcription was performed using the RT-for-PCR kit from Clontech (Palo Alto, CA). The oligonucleotide primer sets ( $50 \mathrm{pmol}$ each) used to amplify OCP3 were OCP3PCR1 (5'-GCTTAAAAGACTGGCTTATGCATTG-3')/OCP3PCR2 (5'-GCTTTGGAGCGGGTCACGAAG-3'). The primers used to amplify PDF1.2 were PDF1.2PCR1 (5'-ATGGCTAAGTTTGCTTCCAT-3')/PDF1.2PCR2(5'-ACATGGGACGTAACAGATAC- $3^{\prime}$ ). The primers used to amplify PR1 were PR1PCR1 (5'-ATGAATTTTACTGGCTATTC-3')/PR1PCR2 (5'-AACCCACATGTTCACGGCGGA-3'). For detecting OCP3 expression, PCR amplification was programmed for 30 cycles, with each cycle consisting of $95^{\circ} \mathrm{C}$ for $0.5 \mathrm{~min}, 55^{\circ} \mathrm{C}$ for $0.5 \mathrm{~min}$, and $72^{\circ} \mathrm{C}$ for $0.5 \mathrm{~min}$. For $P R-1$, PCR amplification was programmed for 17 cycles, with each cycle consisting of $95^{\circ} \mathrm{C}$ for $0.5 \mathrm{~min}, 55^{\circ} \mathrm{C}$ for $0.5 \mathrm{~min}$, and $72^{\circ} \mathrm{C}$ for $0.5 \mathrm{~min}$. For PDF1.2, PCR amplification was programmed for 23 cycles, with each cycle consisting of $95^{\circ} \mathrm{C}$ for $0.5 \mathrm{~min}, 65^{\circ} \mathrm{C}$ for $0.5 \mathrm{~min}$, and $72^{\circ} \mathrm{C}$ for $0.5 \mathrm{~min}$.

\section{Confocal Laser Microscopy}

A Leica TCS SL confocal microscope (Mannheim, Germany) was used in these studies. To detect GFP fluorescence, the excitation wavelength was $488 \mathrm{~nm}$, and a band-pass filter of 510 to $525 \mathrm{~nm}$ was used for emission. Confocal images were taken from leaves from 15-d-old transgenic plants expressing 35S-GFP or 35S-OCP3-GFP that were mounted on standard microscope slides in the presence of water.

\section{ACKNOWLEDGMENTS}

We thank B. Wulff and P. Tornero for comments on the manuscript and R. Solano for helpful discussion. We also thank A. Molina for providing fungi strains, Susi Sauri for her work with these strains, and Astrid Agorio for collaborating in the RT-PCR experiments. We acknowledge the support of the Spanish Ministry of Science and Technology (Grant BMC2003-00267 to P.V.) for financial support.

Received March 1, 2005; revised April 21, 2005; accepted April 22, 2005; published May 27, 2005.

\section{REFERENCES}

Alonso, J.M., Hirayama, T., Roman, G., Nourizadeh, S., and Ecker, J.R. (1999). EIN2, a bifunctional transducer of ethylene and stress responses in Arabidopsis. Science 284, 2148-2152.

Alvarez, M.E., Pennell, R.I., Meijer, P.J., Ishikawa, A., Dixon, R.A., and Lamb, C. (1998). Reactive oxygen intermediates mediate a systemic signal network in the establishment of plant immunity. Cell 92, 773-784.

Apostol, I., Heinstein, F.H., and Low, P.S. (1989). Rapid stimulation of an oxidative burst during elicitation of cultured plant cells. Role in defense and signal transduction. Plant Physiol. 90, 109-116.

Baker, C.J., and Orlandi, E.W. (1995). Active oxygen species in plant pathogenesis. Annu. Rev. Phytopathol. 33, 299-321.

Bechtold, N., Ellis, J., and And Pelletier, G. (1993). In planta Agrobacterium mediated gene transfer by infiltration of adult Arabidopsis thaliana plants. C. R. Acad. Sci. Paris Life Sci. 316, 11941199.

Bell, C.J., and Ecker, J.R. (1994). Assignment of 30 microsatellite loci to the linkage map of Arabidopsis. Genomics 19, 137-144.

Berger, S., Bell, E., and Mullet, J.E. (1996). Two methyl jasmonateinsensitive mutants show altered expression of AtVsp in response to methyl jasmonate and wounding. Plant Physiol. 111, 525-531.

Berrocal-Lobo, M., Molina, A., and Solano, R. (2002). Constitutive expression of ETHYLENE-RESPONSE-FACTOR1 in Arabidopsis confers resistance to several necrotrophic fungi. Plant J. 29, 23-32.

Cao, H., Glazebrook, J., Clarke, J.D., Volko, S., and Dong, X. (1997). The Arabidopsis NPR1 gene that controls systemic acquired resistance encodes a novel protein containing ankyrin repeats. Cell $\mathbf{8 8}$, 57-63.

Clarke, J.D., Liu, Y., Klessig, D.F., and Dong, X. (1998). Uncoupling $P R$ gene expression from NPR1 and bacterial resistance: Characterization of the dominant Arabidopsis cpr6-1 mutant. Plant Cell 10, 557-569.

Clarke, J.D., Volko, S.M., Ledford, H., Ausubel, F.M., and Dong, X. (2000). Roles of salicylic acid, jasmonic acid, and ethylene in cprinduced resistance in Arabidopsis. Plant Cell 12, 2175-2190.

Coego, A., Ramirez, V., Ellul, P., Mayda, E., and Vera, P. (2005). The $\mathrm{H}_{2} \mathrm{O}_{2}$-regulated Ep5C gene encodes a peroxidase required for bacterial speck susceptibility in tomato. Plant J. 42, 283-293.

Cress, W.D., and Triezenberg, S.J. (1991). Critical structural elements of the VP16 transcriptional activation domain. Science 251, 87-90.

Dangl, J.L., and Jones, J.D. (2001). Plant pathogens and integrated defence responses to infection. Nature 411, 826-833.

Delaney, T.P., Uknes, S., Vernooij, B., Friedrich, L., Weymann, K., Negrotto, D., Gaffney, T., Gutrella, M., Kessmann, H., Ward, E., and Ryals, J. (1994). A central role of salicylic acid in plant disease resistance. Science 266, 1247-1250.

Devoto, A., Nieto-Rostro, M., Xie, D., Ellis, C., Harmston, R., Patrick, E., Davis, J., Sherratt, L., Coleman, M., and Turner, J.G. (2002). 
COI1 links jasmonate signalling and fertility to the SCF ubiquitin-ligase complex in Arabidopsis. Plant J. 32, 457-466.

Dingwall, C., and Laskey, R.A. (1991). Nuclear targeting sequences-A consensus? Trends Biochem. Sci. 16, 478-481.

Draper, J. (1997). Salicylate, superoxide synthesis and cell suicide in plant defence. Trends Plant Sci. 2, 162-165.

Durrant, W.E., and Dong, X. (2004). Systemic acquired resistance. Annu. Rev. Phytopathol. 42, 185-209.

Ellis, C., and Turner, J.G. (2001). The Arabidopsis mutant cev1 has constitutively active jasmonate and ethylene signal pathways and enhanced resistance to pathogens. Plant Cell 13, 1025-1033.

Ferrari, S., Plotnikova, J.M., De Lorenzo, G., and Ausubel, F.M. (2003). Arabidopsis local resistance to Botrytis cinerea involves salicylic acid and camalexin and requires EDS4 and PAD2, but not SID2, EDS5 or PAD4. Plant J. 35, 193-205.

Gaffney, T., Friedrich, L., Vernooij, B., Negretto, D., Nye, G., Uknes, S., Ward, E., Kessmann, H., and Ryals, J. (1993). Requirement of salicylic acid for induction of systemic acquired resistance. Science 261, 754-756.

Gehring, W.J., Affolter, M., and Bürglin, T. (1994). Homeodomain proteins. Annu. Rev. Biochem. 63, 487-526.

Govrin, E.M., and Levine, A. (2000). The hypersensitive response facilitates plant infection by the necrotrophic pathogen Botrytis cinerea. Curr. Biol. 10, 751-757.

Grant, J.J., and Loake, G.J. (2000). Role of reactive oxygen intermediates and cognate redox signaling in disease resistance. Plant Physiol. 124, 21-29.

Gupta, V., Willits, M.G., and Glazebrook, J. (2000). Arabidopsis thaliana EDS4 contributes to salicylic acid (SA)-dependent expression of defense responses: Evidence for inhibition of jasmonic acid signaling by SA. Mol. Plant Microbe Interact. 13, 503-511.

Hammond-Kosack, K.E., and Parker, J.E. (2003). Deciphering plantpathogen communication: Fresh perspectives for molecular resistance breeding. Curr. Opin. Biotechnol. 14, 177-193.

Heery, D.M., Kalkhoven, E., Hoare, S., and Parker, M.G. (1997). A signature motif in transcriptional co-activators mediates binding to nuclear receptors. Nature 387, 733-736.

Himmelbach, A., Hoffmann, T., Leube, M., Hohener, B., and Grill, E. (2002). Homeodomain protein ATHB6 is a target of the protein phosphatase $\mathrm{ABI} 1$ and regulates hormone responses in Arabidopsis. EMBO J. 21, 3029-3038.

Kauss, H., and Jeblick, W. (1995). Pretreatment of parsley suspension cultures with salicylic acid enhances spontaneous and elicited production of $\mathrm{H}_{2} \mathrm{O}_{2}$. Plant Physiol. 108, 1171-1178.

Kunkel, B.N., and Brooks, D.N. (2002). Cross talk between signaling pathways in pathogen defense. Curr. Opin. Plant Biol. 5, 325-331.

Levine, A., Tenhaken, R., Dixon, R., and Lamb, C. (1994). $\mathrm{H}_{2} \mathrm{O}_{2}$ from the oxidative burst orchestrates the plant hypersensitive disease resistance response. Cell 79, 583-593.

Li, J., Brader, G., and Palva, E.T. (2004). The WRKY70 transcription factor: A node of convergence for jasmonate-mediated and salicylatemediated signals in plant defense. Plant Cell 16, 319-333.

Lorenzo, O., Chico, J.M., Sanchez-Serrano, J.J., and Solano, R. (2004). JASMONATE-INSENSITIVE1 encodes a MYC transcription factor essential to discriminate between different jasmonateregulated defense responses in Arabidopsis. Plant Cell 16, 1938-1950.

Lorenzo, O., Piqueras, R., Sanchez-Serrano, J.J., and Solano, R. (2003). ETHYLENE RESPONSE FACTOR1 integrates signals from ethylene and jasmonate pathways in plant defense. Plant Cell 15, 165-178.
Mayda, E., Mauch-Mani, B., and Vera, P. (2000). The Arabidopsis dth9 mutant is compromised in systemic acquired resistance without affecting SA-dependent responses. Plant Cell 12, 2119-2128.

Mayda, E., Tornero, P., Conejero, V., and Vera, P. (1999). A tomato homeobox gene (HD-Zip) is involved in limiting the spread of programmed cell death. Plant J. 20, 591-600.

Mengiste, T., Chen, X., Salmeron, J.M., and Dietrich, R.A. (2003). The BOS1 gene encodes an R2R3MYB transcription factor protein that is required for biotic and abiotic stress responses in Arabidopsis. Plant Cell 15, 2551-2565.

Mur, L.A., Brown, I.R., Darby, R.M., Bestwick, C.S., Bi, Y.M., Mansfield, J.W., and Draper, J. (2000). A loss of resistance to avirulent bacterial pathogens in tobacco is associated with the attenuation of a salicylic acid-potentiated oxidative burst. Plant $\mathrm{J}$. 23, 609-621.

Nigg, E.A. (1997). Nucleocytoplasmic transport: Signals, mechanism and regulation. Nature 386, 779-787.

Penninckx, I.A., Eggermont, K., Terras, F.R., Thomma, B.P., De Samblanx, G.W., Buchala, A., Metraux, J.P., Manners, J.M., and Broekaert, W.F. (1996). Pathogen-induced systemic activation of a plant defensin gene in Arabidopsis follows a salicylic acidindependent pathway. Plant Cell 8, 2309-2323.

Petersen, M., et al. (2000). Arabidopsis MAP kinase 4 negatively regulates systemic acquired resistance. Cell 103, 1111-1120.

Schena, M., and Davis, R.W. (1992). HD-Zip proteins: Members of an Arabidopsis homeodomain superfamily. Proc. Natl. Acad. Sci. USA 89, 3894-3898.

Shah, J., Kachroo, P., and Klessig, D.F. (1999). The Arabidopsis ss1 mutation restores pathogenesis-related gene expression in npr1 plants and renders defensin gene expression salicylic acid dependent. Plant Cell 11, 191-206.

Shirasu, K., Nakajima, H., Rajasekhar, V.K., Dixon, R.A., and Lamb, C. (1997). Salicylic acid potentiates an agonist-dependent gain control that amplifies pathogen signals in the activation of defense mechanisms. Plant Cell 9, 261-270.

Spoel, S.H., et al. (2003). NPR1 modulates cross-talk between salicylate- and jasmonate-dependent defense pathways through a novel function in the cytosol. Plant Cell 15, 760-770.

Staswick, P.E., Yuen, G.Y., and Lehman, C.C. (1998). Jasmonate signaling mutants of Arabidopsis are susceptible to the soil fungus Pythium irregulare. Plant J. 15, 747-754.

Steindler, C., Matteucci, A., Sessa, G., Weimar, T., Ohgishi, M., Aoyama, T., Morelli, G., and Ruberti, I. (1999). Shade avoidance responses are mediated by the ATHB-2 HD-Zip protein, a negative regulator of gene expression. Development 126, 42354245.

Thomma, B.P., Eggermont, K., Penninckx, I.A.M.A., Mauch-Mani, B., Vogelsang, R., Cammue, B.P.A., and Broekaert, W.F. (1998). Separate jasmonate-dependent and salicylate-dependent defenseresponse pathways in Arabidopsis are essential for resistance to distinct microbial pathogens. Proc. Natl. Acad. Sci. USA 95, 1510715111.

Thomma, B.P., Penninckx, I.A., Broekaert, W.F., and Cammue, B.P. (2001). The complexity of disease signaling in Arabidopsis. Curr. Opin. Immunol. 13, 63-68.

Thordal-Christensen, H., Zhang, Z., Wei, Y., and Collinge, D.B. (1997). Subcellular localization of $\mathrm{H}_{2} \mathrm{O}_{2}$ in plants. $\mathrm{H}_{2} \mathrm{O}_{2}$ accumulation in papillae and hypersensitive response during the barley-powdery mildew interaction. Plant J. 11, 1187-1194.

Tiedemann, A.V. (1997). Evidence for a primary role of active oxygen species in induction of host cell death during infection of bean leaves with Botrytis cinerea. Physiol. Mol. Plant Pathol. 50, 151-166. 
Tierens, K.F., Thomma, B.P., Bari, R.P., Garmier, M., Eggermont, K., Brouwer, M., Penninckx, I.A., Broekaert, W.F., and Cammue, B.P. (2002). Esa1, an Arabidopsis mutant with enhanced susceptibility to a range of necrotrophic fungal pathogens, shows a distorted induction of defense responses by reactive oxygen generating compounds. Plant J. 29, 131-140.

Ton, J., and Mauch-Mani, B. (2004). $\beta$-Amino-butyric acid-induced resistance against necrotrophic pathogens is based on ABAdependent priming for callose. Plant J. 38, 119-130.

Turner, J.G., Ellis, C., and Devoto, A. (2002). The jasmonate signal pathway. Plant Cell 14 (suppl.), S153-S164.

Vijayan, P., Shockey, J., Levesque, C.A., Cook, R.J., and Browse, J. (1998). A role for jasmonate in pathogen defense of Arabidopsis. Proc. Natl. Acad. Sci. USA 95, 7209-7214.

Vollbrecht, E., Veit, B., Sinha, N., and Hake, S. (1991). The develop- mental gene Knotted-1 is a member of a maize homeobox gene family. Nature 350, 241-243.

Xie, D.X., Feys, B.F., James, S., Nieto-Rostro, M., and Turner, J.G. (1998). COl1: An Arabidopsis gene required for jasmonate-regulated defense and fertility. Science 280, 1091-1094.

Zhou, N., Tootle, T.L., Tsui, F., Klessig, D.F., and Glazebrook, J. (1998). PAD4 functions upstream from salicylic acid to control defense responses in Arabidopsis. Plant Cell 10, 1021-1030.

Zhu, J., Shi, H., Lee, B.H., Damsz, B., Cheng, S., Stirm, V., Zhu J-K., Hasegawa, P., Bressan, R.A. (2004). An Arabidopsis homeodomain transcription factor gene, $\mathrm{HOS9}$, mediates cold tolerance through a CBFindependent pathway. Proc. Natl. Acad. Sci. USA 101, 9873-9878.

Zimmerli, L., Métraux, J.P., and Mauch-Mani, B. (2001). $\beta$-Aminobutyric acid-induced protection of Arabidopsis against the necrotrophic fungus Botrytis cinerea. Plant Physiol. 126, 517-523. 

IV. Discusión general. 



\section{Discusión general.}

En el presente trabajo hemos abordado la caracterización del gen Ep5C de tomate, así como el papel que desempeña dicho gen en los mecanismos de defensa de las plantas frente a patógenos.

Ep5C codifica una peroxidasa catiónica extracelular (Gadea et al., 1996; Hiraga et al., 2001).

De los análisis realizados a partir de la comparación de secuencia de dicho gen con otras peroxidasas de plantas podemos concluir que Ep5C muestra entre un 65 y un $80 \%$ de homología a nivel de secuencia aminoacídica con el resto de las peroxidasas analizadas.

En este trabajo demostramos que el gen Ep5C posee un patrón de expresión muy característico que demuestra que la señalización que activa selectivamente a este gen difiere, al menos en parte, de las que median en la activación de otros genes relacionados con la respuesta defensiva. Esta observación nos hace sugerir que estamos en presencia de un gen que, aún a pesar de responder a estímulos patogénicos, muestra un mecanismo de regulación transcripcional diferente.

Ep5C durante interacciones patogénicas muestra una inducción temprana, tanto en un contexto de naturaleza compatible como en uno de naturaleza incompatible. En ambos casos se alcanza un máximo de expresión a las dos horas después de la inoculación con la bacteria Pseudomonas syringae. Por el contrario, esta pronta inducción de Ep5C contrasta con lo observado para genes PRs (e.g. PR1), cuyos transcriptos comienzan a acumularse a las 12 horas después de la inoculación o incluso más tarde, alrededor de las 24 horas, en las plantas susceptibles. Estas diferencias cinéticas demuestran, una vez 


\section{$\underline{\text { Discusión }}$}

más, que $E p 5 C$ se comporta de manera diferente a lo observado para otros genes relacionados con la respuesta defensiva en plantas.

La rápida y temprana inducción de la expresión de Ep5C sólo se produjo en aquellos tejidos que fueron inoculados directamente con la bacteria. Por el contrario, en tejidos alejados del sitio de inoculación dicha inducción no acontece. Esto sugiere que la señal que genera la inducción de la expresión de Ep5C es común para ambos tipos de interacciones (compatibles e incompatibles), pero que el mecanismo opera sobre bases locales, algo distinto a lo que ocurre con el gen $P R$ 1 , el cual responde tanto a nivel local como distal, como se ha descrito anteriormente (Ryals et al.,1996).

Dentro de las señales que median el desarrollo de una HR en los primeros estadios de infección de una planta con un patógeno avirulento se encuentran las especies de oxígeno reactivas "ROS" (e.g. ión superóxido $\left(\mathrm{O}_{2}{ }^{-}\right)$, y el peróxido de hidrógeno $\left(\mathrm{H}_{2} \mathrm{O}_{2}\right)$; Sutherland, 1991; Baker et al., 1995; Jabs et al., 1996; Alvarez et al., 1998; Delldonne et al., 1998; Grant et al., 2000). Los tratamientos realizados con las mezclas de Xantina-Xantina oxidasa y Glucosa-Glucosa oxidasa, produjeron una pronta acumulación de transcriptos de Ep5C, con un pico máximo de acumulación del RNA mensajero correspondiente a las 2 horas después de infiltrar las hojas con los cócteles enzimáticos. Esta forma temprana de inducción se asemeja a lo observado tras la inoculación con la bacteria Pseudomonas syringae. Sin embargo, esta inducción mediada por las mezclas enzimáticas resultó ser transitoria, comenzando a decaer los niveles de transcritos a las 6 horas y desapareciendo definitivamente a las 12 horas.

Los ensayos realizados con posterioridad infiltrando los mismos cócteles de xantina-xantina oxidasa en presencia de superóxido 
dismutasa (SOD) y/o catalasa demuestran que esta última inhibe la capacidad inductora de la mezcla enzimática, lo cual confirma que efectivamente el $\mathrm{H}_{2} \mathrm{O}_{2}$ es la molécula o la señal que realmente participa como inductora de la expresión de Ep5C.

Hasta la fecha se conoce muy poco acerca de las bases moleculares que rigen los mecanismos de susceptibilidad de las plantas frente a patógenos virulentos, específicamente a Pseudomonas (Greenberg y Vinatzer, 2003). Sin embargo, se ha demostrado que aun en ausencia de una interacción gen a gen, las plantas pueden activar un sistema de defensa que de alguna manera limita el desarrollo de ciertos patógenos virulentos (Glazebrook et al., 1996).

La generación de plantas transgénicas de tomate, portadoras del gen Ep5C, en sentido y en antisentido, nos permitió profundizar en la posible función de esta peroxidasa en los mecanismos de defensa frente a patógenos virulentos. Así, las plantas antisentido mostraron una marcada resistencia frente a la inoculación con la bacteria Pseudomonas syringae pv .tomato. Ello no ocurre sin embargo en las plantas transgénicas portadoras del gen Ep5C en sentido.

Ep5C podría ser necesario para el crecimiento y desarrollo del patógeno, actuando como un factor provirulencia, o alternativamente, una pérdida de función de dicho gen provocaría una activación de las defensas en la planta, lo cual limitaría el crecimiento del patógeno. Sin embargo, esta segunda opción no parece ser la causa de la resistencia mostrada por las líneas antisentido, debido a que no existen diferencias significativas entre las plantas controles y las plantas portadoras de la construcción en antisentido, en cuanto a los niveles de expresión de algunos de los genes marcadores observados (P69 y PR1). Por tales razones, la correcta inducción y deposición de Ep5C en los espacios 


\section{$\underline{\text { Discusión }}$}

extracelulares podría ser esencial para la generación de alguna molécula señal desconocida, generada bien por parte de la bacteria o por parte de la planta, y que de alguna manera estuviera limitando el crecimiento y desarrollo del patógeno. Por ello nuestros resultados estarían reforzando la idea de que dicha peroxidasa podría actuar como un factor de provirulencia. Nuestros resultados coinciden con los obtenidos con el gen PMR6 de Arabidopsis, el cual codifica una pectato liasa extracelular (Vogel et al., 2002), que juega un papel importante en el crecimiento del hongo Eryshiphe cichoracearum. Así, Ep5C representa un nuevo elemento en la cascada de resistencia a patógenos virulentos, y su utilización ofrece nuevas oportunidades para la obtención de variedades de cultivos resistentes al ataque de patógenos.

Dada la similitud de inducción del gen Ep5C en tomate y en plantas transgénicas de Arabidopsis thaliana portadoras de la construcción Ep5C::GUS, y habida cuenta de que dicho gen supone un marcador exquisito para la señalización mediada de manera específica por $\mathrm{H}_{2} \mathrm{O}_{2}$, procedimos mediante genética directa a identificar mutantes alterados en la expresión de dicho gen aun en ausencia de estímulo patogénico. A estos mutantes les hemos denominado "ocp" (overexpressor of cationic peroxidase).

En el presente trabajo se abordó la identificación y la caracterización en profundidad de uno de esos mutantes, en concreto el mutante ocp3. Las plantas ocp3 se caracterizan por presentar una elevada resistencia a patógenos necrotrofos $(B$. cinerea y $P$. cucumerina), mientras que la susceptibilidad a patógenos biotrofos ( $P$. syringae y $H$. parasítica) permanece inalterada. La resistencia a patógenos necrotrofos esta correlacionada con la activación 
transcripcional del gen PDF1.2, el cual codifica una defensina (Thomma et al., 1997).

El gen OCP3 presenta unos niveles de expresión muy bajos en plantas sanas, y su expresión disminuye a medida que la infección por patógenos necrotofos avanza. Sin embargo, el fenotipo de resistencia conferido por la mutación ocp3 desaparece cuando esta se introduce en un fondo coi1. Este resultado refuerza el papel que juega el gen OCP3, en los mecanismos de defensa dependientes de JA. Por otra parte, se conoce que la expresión del gen PDF1.2 es dependiente de COI1 (Turner et al., 2002), lo cual sugiere que OCP3 funcionaría como un regulador negativo de la respuestas defensivas dependientes de JA.

La generación de $\mathrm{H}_{2} \mathrm{O}_{2}$ juega un papel importante en la defensa frente a patógenos biotrofos y necrotrofos, y su acumulación se ha propuesto como mensajero secundario implicado en los mecanismos de resistencia basal de las plantas frente a patógenos (Tiedermann, 1997; Mengiste et al., 2003). La presencia de ciertos niveles de $\mathrm{H}_{2} \mathrm{O}_{2}$ es otro de los aspectos característicos del mutante ocp3, y su acumulación parece estar correlacionada con los niveles constitutivos de GST1 observados en estas plantas (Levine et al., 1994; Alvarez et al., 1998). Sin embargo, las plantas ocp3 solo mostraron resistencia frente a patógenos necrotrofos, demostrando que posiblemente el gen OCP3 funcione como un regulador específico de los procesos redox implicados en la resistencia a este tipo de patógenos.

Tanto el $\mathrm{SA}$ como el $\mathrm{H}_{2} \mathrm{O}_{2}$ juegan un papel importante en los mecanismos de interacción planta-patógeno (Draper et al., 1997; Shirasu et al., 1997). Existen evidencias que demuestran que el SA resulta necesario para la activación de las respuestas locales de las plantas frente a hongos necrotrofos (Botrytis cinerea) en el sitio de 


\section{$\underline{\text { Discusión }}$}

infección (Govrin y Levine, 2000; Ferrari et al., 2003). Sin embargo, en el mutante ocp3 no aparecen alteradas ni la síntesis ni la acumulación de SA. El análisis de los dobles mutantes ocp3 pad4; ocp3 nahG y ocp3 npr1, revelaron que el SA no parece estar implicado en la resistencia observada en el mutante ocp3 a hongos necrotrofos. Tampoco el ET parece estar asociado a la resistencia observada en el mutante ocp3. El doble mutante ocp3 ein2 no suprime la resistencia de las plantas ocp3 a P. cucumerina. En Arabidopsis las rutas del ET y del JA parecen actuar en paralelo (Ellis et al., 2001; Thomma et al., 2001); sin embargo, los resultados obtenidos en este trabajo apuntan a que el gen OCP3 regula una parte específica de esta ruta, más bien la relacionada con el JA. Este resultado concuerda con lo descrito por Lorenzo et al., 2004 para el mutante jin1. El doble mutante ocp3 jin1 mostró un efecto aditivo en cuanto a la resistencia a Botrytis cinerea, reforzando la hipótesis de que el gen OCP3 participa específicamente en la resistencia a patógenos necrotrofos mediante una via dependiente de COI1.

OCP3 es un gen perteneciente a la familia de los "homeobox". Estos genes se encuentran ampliamente representados en todos los organismos superiores. Los homeobox están implicados en muchos procesos biológicos de desarrollo y de adaptación a diferentes factores ambientales. Su función como reguladores transcripcionales ha sido bien caracterizada, con la presencia de un dominio bien conservado (Homeodominio) responsable de la unión específica a ADN (Gehring et al., 1994). En plantas se han identificado dos familias mayoritarias: Ios KNOTTED1 (Vollbrecht et al., 1991) y la familia de los HD-Zip (Schena y Davis, 1992). La caracterización funcional de algunos de los miembros de estas familias ha revelado el papel que desempeñan en procesos tan importantes en las plantas como lo son la regulación y la señalización de ciertas hormonas (Himmelbach et al., 2002), la adaptación a 
diferentes condiciones ambientales (Steindler et al., 1999; Zhu et al., 2004) y últimamente la participación en los mecanismos de defensa de las plantas frente a patógenos (Mayda et al., 1999).

La mutación puntual identificada en el gen ocp3 produjo una delección de los primeros 36 nucleótidos del exon III, provocando una alteración en el marco abierto de lectura, originándose así una proteína truncada de 210 aminoácidos. Los 60 aminoácidos correspondientes al homeodominio se encuentran localizados en la posición 144 de la zona carboxilo terminal de la proteína. Dicha región resulta muy importante para la función de estos genes como reguladores de la transcripción, pues como bien se sabe es esta zona la que interacciona con el ADN. Así pues, la ausencia de este domino en la secuencia del mutante ocp3 y por tanto la pérdida de función inherente a dicha mutación confirma el papel que desempeña el gen OCP3 como un factor de transcripción específico de la ruta de JA, mediando la represión de diferentes genes implicados en los mecanismos de defensa frente a patógenos necrotrofos.

La búsqueda e identificación de posibles genes dianas de OCP3, podrían aportar nuevos elementos que facilitarían el entendimiento de la función del mismo en los mecanismos de defensa de las plantas frente a patógenos, y de esta manera estaríamos en condiciones de generar nuevas herramientas en la obtención cultivos más resistentes a plagas y enfermedades. 

V. Conclusiones. 



\section{Conclusiones.}

1. Ep5C es un gen de respuesta temprana cuyo patrón de inducción resulta algo peculiar por no responder a las típicas moléculas señalizadoras asociadas a los mecanismos de defensa en plantas (SA, ET, JA). De igual modo, tampoco muestra inducción por herida. Su expresión esta asociada a los niveles de $\mathrm{H}_{2} \mathrm{O}_{2}$ producidos durante el transcurso de una infección patogénica.

2. Las plantas transgénicas de tomate portadoras del gen Ep5C en antisentido muestran una elevada resistencia a $P$. syringae. pv tomato y hemos propuesto que Ep5C podría actuar como factor de provirulencia frente a dicha bacteria.

3. El mutante ocp3 de Arabidopsis thaliana se caracteriza por exhibir una elevada resistencia frente a patógenos necrotrofos (P.cucumerina y $B$. cinerea), mientras que la susceptibilidad frente a patógenos biotrofos permanece inalterada. Dicha resistencia se correlaciona con los niveles constitutivos de PDF1.2 observados en las plantas mutantes ocp3.

4. El gen OCP3 (At5g11270) ha sido identificado por clonaje posicional y complementa a la mutación ocp3. OCP3 es un miembro de la familia de los homeobox de plantas implicado en la respuesta defensiva frente a patógenos necrotrofos.

5. OCP3 constituye un regulador negativo de la resistencia dependiente de JA e independiente de SA. 

VI. Bibliografía. 



\section{Bibliografía.}

Aarts, N.; Metz, M.; Holub, E.; Staskawicz, B.J.; Daniels, M.J., y Parker; J.E. (1998). Different requeriments for EDS1 and NDR1 by disease resistance genes define at least two $R$ gene-mediated signalling pathways in Arabidopsis. Proc. Natl. Acad. Sci. USA 95: 10306-10311.

Abeles, F., Morgan, P., y Salveit, M. (1992). Ethylene in Plant Biology. (Academic Press, San Diego, CA) vol. 2.

Agrios, G.N. (1988). Plant Pathology. London: Academic Press.

Alamillo J.M., y García-Olmedo F. (2001). Effects of urate, a natural inhibitor of peroxynitrite-mediated toxicity, in the response of Arabidopsis thaliana to the bacterial pathogen Pseudomonas syringae. Plant J 25, 529-541.

Alborn, H.T., Turlings, T.C.J., Jones, T.H. Stenhagen, G., Loughrin, J.H., y Tumlinson, J.H. (1997). An elicitor of plant volatiles from beet armyworm oral secretions. Science 276, 945-949.

Aldridge. D.C., Galt, S., Giles, D., y Turner, W. (1971). Metabolites of Lasiodiplodia theobromae. J Chem Soc Commun, 1623-1627.

Alonso, J.M., Hirayama. T., Roman, G., Nourizadeh, S., y Ecker, J.R. (1999). EIN2, a bifunctional transducer of ethylene and stress responses in Arabidopsis. Science 284, 2148-2152.

Alonso, J.M., Stepanova, A.N., Leisse, T.J., Kim, C.J., Chen, H., Shinn, P., Stevenson, D. K., Zimmerman, J., Barajas, P., Cheuk, R., Gadrinab, C., Heller, C., Jeske, A., Koesema, E., Meyers, C.C., Parker, H., Prednis, L., Ansari, Y., Choy, N., Deen, H., Geralt, M., Hazari, N., Hom, E., Karnes, M., Mulholland, C., Ndubaku, R., Schmidt, I., Guzman, P., Aguilar-Henonin, L., Schmid, M., Weigel, D., Carter, D.E., Marchand, T., Risseeuw, E., Brogden, D., Zeko, A., Crosby, W.L., Berry, C.C. y Ecker, J.R. (2003). Genome-Wide Insertional Mutagenesis of Arabidopsis thaliana. Science 301, 653-657.

Alvarez, M.E., Pennell, R.I., Meijer, P.J., Ishikawa, A., Dixon, R.A., C. (1998). Reactive oxygen intermediates mediate a systemic signal network in the establishment of plant immunity. Cell 92, 773-784.

Anderson, M., Chen, Z., y Klessig, D.F. (1998). Possible involvement of lipid peroxidation in salicylic acid-mediated induction of PR-1 gene expression. Phytochemistry 47, 555-566.

Apostol, I., Heinstein, F.H., y Low, P.S. (1989). Rapid stimulation of an oxidative burst during elicitation of cultured plant cells. Role in defense and signal transduction. Plant Physiol. 90, 109-116.

Asai, T., Tena, G., Plotnikova, J., Willmann, M.R., Chiu, W.L., Gomez-Gomez, L., Boller, T., Ausubel, F.M., y Sheen, J. (2002). MAP kinase signalling cascade in Arabidopsis innate immunity. Nature 415, 977-983. 
Axtell, M.J., y Staskawicz, B.J. (2003). Initiation of RPS2-specified disease resistance in Arabidopsis is coupled to the AvrRpt2-directed elimination of RIN4. Cell 112, 369-377.

Azevedo, C., Sadanandom, A., Kitagawa, K., Freialdenhoven, A., Shirasu, K. y Schulze-Lefert, P. (2002). The RAR1 interactor SGT1, an essential component of $R$ gene-triggered disease resistance. Science 295, 2073-6.

Bai,C., Sen, P., Hofmann, K., Ma, L., Goebl. M., Harper, J.W., y Elledge, S.J (1996). SKP1 connects cell cycle regulators to the ubiquitin proteolysis machinery through a novel motif, the F-box. Cell 86, 263-274.

Baker C.J. y Orlandi, E.W. (1995). Active oxygen in plant pathogenesis. Annu Rev Phytopathol 33, 299-321.

Basse, C.W., Fath, A., y Boller, T. (1993). High affinity binding of a glycopeptide elicitor to tomato cells and microsomal membranes and displacement by specific glycan suppressors. J Biol Chem 268, 14724-14731.

Bauer, Z., Gomez-Gomez, L., Boller, T., y Felix, G. (2001). Sensitivity of different ecotypes and mutants of Arabidopsis thaliana toward the bacterial elicitor flagellin correlates with the presence of receptor-binding sites. J Biol Chem 276, 45669-45676.

Beaudoin, N., Serizet, C., Gosti, F., y Giraudat, J. (2000). Interactions between abscisic acid and ethylene signaling cascades. Plant Cell 12, 1103-1115.

Beligni, .V. y Lamattina, L. (2000). Nitric oxide stimulates seed germination and deetiolation, and inhibits hipocotyl elongation, three light-inducible responses in plants. Planta, 210 (2): 215-21.

Belkhadir, Y., Subramaniam, R., y Dangl, J.L. (2004). Plant disease resistance protein signalling: NBS-LRR proteins and their partners. Curr. Opin. Plant Biol. 7, 391-399.

Berger S, Bell E, Mullet JE. (1996). Two Methyl Jasmonate-Insensitive Mutants Show Altered Expression of AtVsp in Response to Methyl Jasmonate and Wounding. Plant Physiol. un;111(2):525-531.

Berger S. (2002) Jasmonate-related mutants of Arabidopsis as tools for studying stress signaling. Planta. Feb;214(4):497-504.

Bi, Y-M., Kenton, P., Mur, L., Darby, R. y Draper, J. (1995). Hydrogen peroxide does not function downstream of salicylic acid in the induction of PR protein expression. Plant J. 8, 235-245.

Bleecker, A.B., Estelle, A., Somerville, C., y Kende, H. (1988). Insensitivity to ethylene conferred by a dominant mutation in Arabidopsis thaliana. Science 241, 1086-1089.

Bleecker, A.B., y Kende, H. (2000). Ethylene: a gaseous signal molecule in plants. Annu Rev Cell Dev Biol 16, 1-18.

Blumwald, E., Aharon, G.S. y Lam, B.C-H. (1998). Early signal transduction pathways in plant-pathogen interactions. Trends in Plant Science. 3: 342-346. 
Boller, T. (1995). Chemoperception of microbial signals in plant cells. Annu Rev Plant Physiol Plant Mol Biol 46, 189-214.

Boller, T., y Kenn, N.T. (2001). Resistance genes and the perception and transduction of elicitors signals in host-pathogen interactions. In Mechanisms of resistance to plant diseases, A.J. Slusarenko, R.S.S. Fraser, and L.C. Van Loon, eds ( Kluwer Academic Publishers), pp. 189-229.

Bolwell G.P. (1999). Role of active oxygen species and NO in plant defence responses. Curr. Opin Plant Biol 2; 287-294.

Bolwell G.P., Butt VS, Davies DR y Zimmerlin A (1995). The origin of the oxidative burst in plants. Free Radical Res 23, 517-532.

Bonas, U.,y Lahaye, T. (2002). Plant disease resistance triggered by pathogen-derived molecules: refined models of specific recognition. Curr Opin Microbiol 5, 44-50.

Bowler C, Alliotte T, Van den Bulcke M, Bauw G, Vandekerckhove J, Van Montagu M, Inze D. (1989). A plant manganese superoxide dismutase is efficiently imported and correctly processed by yeast mitochondria. Proc Natl Acad Sci U S A. May;86(9):3237-41.

Bowles, D. (1990). Defense-related proteins in higher plants. Annu. Rev. Biochem., 59: 873-907.

Bowling, S.A., Guo, A., Cao, H., Gordon, A.S., Klessig, D.F., y Dong, X. (1994). A mutation in Arabidopsis that leads to constitutive expression of systemic acquired resistance. Plant Cell 6, 1845-1857.

Bradley DJ, Kjellbom P y Lamb CJ (1992). Elicitor- and wound-induced oxidative cross-linking of a proline-rich plant cell wall protein: a novel, rapid defense response. Cell 70, 21-30.

Brederode, F.T., Linthorst, H.J.M. y Bol, J.F. (1991). Differential induction of acquired resistance and PR gene expression in tobacco by virus infection, ethephon treatment, UV light and wounding. Plant Mol Biol. 17, 1117-1125.

Brisson, L.F.; Tenhaken, R. y Lamb, C. (1994). Function of oxidative cross-linking of cell wall structural proteins in plant disease resistance. Plant Cell, 6: 1703-1712.

Cartieaux F, Thibaud MC, Zimmerli L, Lessard P, Sarrobert C, David P, Gerbaud A, Robaglia C, Somerville S, Nussaume L. (2003). Transcriptome analysis of Arabidopsis colonized by a plant-growth promoting rhizobacterium reveals a general effect on disease resistance. Plant J. Oct;36(2):177-88.

Cao, H., Bowling, S.A., Gordon, A.S., y Dong, X. (1994). Characterization of an Arabidopsis Mutant That Is Nonresponsive to Inducers of Systemic Acquired Resistance. Plant Cell 6, 1583-1592.

Century, K.S., Shapiro, A.D., Repetti, P.P., Dahlbeck, D., Holub, E., y Staskawicz, B.J. (1997). NDR1, a pathogen-induced component required for Arabidopsis disease resistance. Science 278, 1963-1965.

Chamulitrat W, Hughes MF, Eling TE, Mason RP. (1991). Superoxide and peroxyl radical generation from the reduction of polyunsaturated fatty acid 


\section{$\underline{\text { Bibliografía }}$}

hydroperoxides by soybean lipoxygenase. Arch Biochem Biophys Oct;290(1):153-9.

Chao, Q., Rothenberg, M., Solano, R., Roman, G., Terzaghi, W., y Ecker, J.R. (1997). Activation of the ethylene gas response pathway in Arabidopsis by the nuclear protein ETHYLENE-INSENSITIVE3 and related proteins. Cell 89, 11331144.

Chen, Z.; Silva, H., y Klessig, D.F. (1993). Active oxygen species in the induction of plant systemic acquired resistance by salicylic acid. Science, 262: 1883-1886.

Chen, C., y Chen, Z. (2002). Potentiation of developmentally regulated plant defense response by AtWRKY18, a pathogen-induced Arabidopsis transcription factor. Plant Physiol. 129, 706-716.

Cheong, J.J., y Hahn, M.G. (1991). A specific, high-affinity binding site for the heptabeta-glucoside elicitor exists in soybean membranes. Plant Cell 3, 137-147.

Cheong, J.J. y Choi, Y.D. (2003). Methyl jasmonate as a vital substance in plants. Trends Genet 19, 409-413.

Chinnusamy, V., Schumaker, K., y Zhu, J.K. (2004). Molecular genetic perspectives on cross-talk and specificity in abiotic stress signalling in plants. J Exp Bot 55, 225-236.

Clark KL, Larsen PB, Wang X, Chang C. (1998). Association of the Arabidopsis CTR1 Raf-like kinase with the ETR1 and ERS ethylene receptors. Proc Natl Acad Sci U S A. Apr 28;95(9):5401-6.

Clarke, J.D., Aarts, N., Feys, B.J., Dong, X., y Parker, J.E. (2001). Constitutive disease resistance requires EDS1 in the Arabidopsis mutants cpr1 and cpr6 and is partially EDS1-dependent in cpr5. Plant J 26, 409-420.

Collinge, D.B., Kragh, K.M. Mikkelsen, J.D., Nielse, K.K., Rasmussen, U. Y Vad, K. (1993). Plant chitinases. Plant Journal. 3, 31-40.

Conrath, U., Chen, Z., Ricigliano, J.R., y Klessig, D.F. (1995). Two inducers of plant defense responses, 2,6-dichloroisonicotinic acid and salicylic acid, inhibit catalase activity in tobacco. Proc Natl Acad Sci U S A 92, 7143-7147.

Constabel CP, Bertrand C, Brisson N. (1993). Transgenic potato plants overexpressing the pathogenesis-related STH-2 gene show unaltered susceptibility to Phytophthora infestans and potato virus X. Plant Mol Biol. Aug;22(5):775-82.

Corpas FJ, Barroso JB y del Rio LA. (2001). Peroxisomes as a source of reactive oxygen especies and nitric oxide signal molecules in plant cell. Trends Plant Sci,6 145-150.

Cosio, E.G., Frey, T., Verduyn, R., Van Boom, J., y Ebel, J. (1990). High-affinity binding of a synthetic heptaglucoside and fungal glucan phytoalexin elicitors to soybean membranes. Plant Cell 3, 137-147.

Creelman RA, Mullet JE. (1997). Biosynthesis and action of jasmonates in plants. Annu Rev Plant Physiol Plant Mol Biol. Jun;48:355-381. 
Creelman, R.A., y Rao, M.V. (2002). The oxilipin pathway in Arabidopsis. In The Arabidopsis Book, S.C.a.M. Somerville, E.M., ed (American Society of Plant Biologists.

Cullimore, J.V., Ranjeva, R., y Bono, J.J. (2001). Perception of lipochitooligosaccharidic Nod factors in legumes. Trends Plant Sci 6, 24-30.

Czernic, P., Visser, B., Sun, W., Savoure, A., Deslandes, L., Marco, Y., Van Montagu, M., y Verbruggen, N. (1999). Characterization of an Arabidopsis thaliana receptor-like protein kinase gene activated by oxidative stress and pathogen attack. Plant J 18, 321-327.

Dangl, J.L., R.A. Dietrich, y M.H. Richherg. (1996). Death don't have no mercy: Cell death programs in plant-microbe interactions. Plant Cell 8: 1793-1807.

Dangl, J.L. (1998). Plants just say NO to pathogens. Nature, 394: 525-526.

Dat J, Vandenbeele S, Vranova E, Van Montagu M, Inze D y Van Breusegm F (2000). Dual action of the active oxygen species during plants stress responses. Cell Mol Life Sci 57, 779-795.

De Leon IP, Sanz A, Hamberg M, Castresana C. (2002). Involvement of the Arabidopsis alpha-DOX1 fatty acid dioxygenase in protection against oxidative stress and cell death. Plant J. Jan;29(1):61-2.

Del Rio LA, Pastori GM, Palma JM, Sandalio LM, Sevilla F, Corpas FJ, Jimenez A, Lopez-Huertas E, Hernandez JA. (1998). The activated oxygen role of peroxisomes in senescence Plant Physiol.:116(4):1195-200.

Delaney, T.P., Friedrich, L., y Ryals, J.A. (1995). Arabidopsis signal transduction mutant defective in chemically and biologically induced disease resistance. Proc. Natl. Acad. Sci. U.S.A. 92, 6602-6606.

Delaney, T.P. (2000). New mutants provide clues into regulation of systemic acquired resistance. Trends Plant Sci. 5, 49-51.

Delledone, M., Xia, Y., Dixon, R.A. y Lamb, C. (1998). Nitric oxide functions as a signal in plant disease resistance. Nature. 394, 585-588.

Demole, E., Lederer, E., y Mercier, D. (1962). Isolement et détérmination de la structure du jasmonate methyle, constituant odorant characteristique de l'éssence de jasmine. Helv. Chim. Acta 45, 675-685.

Dempsey, D.A., Shah, J., y Klessig, D.F. (1999). Salicylic acid and disease resistance in plants. Crit Rev Plant Sci 18, 547-575.

Desikan R, Hancock JT, Coffey MJ y Neill S (1996). Generation of active oxygen in elicited cells of Arabidopsis thaliana is mediated by a NADPH oxidase-like enzyme. FEBS Lett 382, 213-217.

Deslandes, L., Olivier, J., Theulieres, F., Hirsch, J., Feng, D.X., Bittner-Eddy, P., Beynon, J., y Marco, Y. (2002). Resistance to Ralstonia solanacearum in Arabidopsis thaliana is conferred by the recessive RRS1-R gene, a member of a novel family of resistance genes. Proc. Natl. Acad. Sci. U.S.A. 99, 24042409. 
Deslandes, L., Olivier, J., Peeters, N., Feng, D.X., Khounlotham, M., Boucher, C., Somssich, I., Genin, S., y Marco, Y. (2003). Physical interaction between RRS1-R, a protein conferring resistance to bacterial wilt, and PopP2, a type III effector targeted to the plant nucleus. Proc. Natl. Acad. Sci. U.S.A. 100. 80248029.

Despres C, DeLong C, Glaze S, Liu E, Fobert PR. (2000). The Arabidopsis NPR1/NIM1 protein enhances the DNA binding activity of a subgroup of the TGA family of bZIP transcription factors. Plant Cell. Feb;12(2):279-90.

Desveaux D, Despres C, Joyeux A, Subramaniam R, Brisson N. (2000). PBF-2 is a novel single-stranded DNA binding factor implicated in PR-10a gene activation in potato. Plant Cell. Aug;12(8):1477-89.

Desveaux D, Subramaniam R, Despres C, Mess JN, Levesque C, Fobert PR, Dangl JL, Brisson N. (2004). A "Whirly" transcription factor is required for salicylic acid-dependent disease resistance in Arabidopsis. Dev Cell. Feb;6(2):229-40.

Devoto, A.; Nieto-Rostro, M.; Xie, D.; Ellis, C.; Harmston, R.; Patrick, E.; Davis, J.; Sherrat, L.; Coleman, M., y Turner, J. G. (2002). COI1 links jasmonate signalling and fertility to the SCF ubiquitin-ligase complex in Arabidopsis. Plant J, 32: 457-466.

Devoto, A., y Turner, J.G. (2003). Regulation of jasmonate-mediated plant responses in arabidopsis. Ann Bot (Lond) 92, 329-337.

Devoto A, Ellis C, Magusin A, Chang HS, Chilcott C, Zhu T, Turner JG. (2005). Expression profiling reveals COI1 to be a key regulator of genes involved in wound- and methyl jasmonate-induced secondary metabolism, defence, and hormone interactions. Plant Mol Biol. Jul;58(4):497-513.

Dieterle M, Zhou YC, Schafer E, Funk M, Kretsch T. (2001). EID1, an F-box protein involved in phytochrome A-specific light signaling. Genes Dev. Apr 15;15(8):939-44.

Doke, N., Y, Miura, L.M. Sanchez, H-J. Park, T. Toritake, H, Yoshioka, y K. kawakita. (1996). The oxidative burst protects plants against pathogen attack: Mecanism and roles as an emergency signal for plant bio-defense-a review. Gene 179, 45-51.

Domingo, C., V. Conejero y P. Vera. (1994). Genes encoding acidic and basis class $111 \beta-1,3-g l u c a n a s a s$ are expressed in tomato plants upon viroid infection. Plant Mol Biol 24, 725-732.

Dong, X. (1998). SA, JA, ethylene, and disease resistance in plants. Curr. Opin. Plant. Biol. 1, 316-323.

Dong, X. (2001). Genetic dissection of systemic adquired resistance. Curr. Opin. Plant. Biol. 4, 309-314. 
Dong X, Li X, Zhang Y, Fan W, Kinkema M, Clarke J. (2001). Regulation of systemic acquired resistance by NPR1 and its partners. Novartis Found Symp.; 236:165-73; discussion 173-5.

Draper, J. (1997). Salicylate, superoxide synthesis and cell suicide in plant defence. Trends Plant Sci 2, 162-165.

Du, H., y Klessig, D.F. (1997). Identification of a Soluble, High-Affinity Salicylic Acid Binding Protein in Tobacco. Plant Physiol 113, 1319-1327.

Durner, J., y Klessig, D.F. (1995). Inhibition of ascorbate peroxidase by salicylic acid and 2,6-dichloroisonicotinic acid, two inducers of plant defense responses. Proc Natl Acad Sci U S A 92, 11312-11316.

Durner J, Klessig DF. (1996).Salicylic acid is a modulator of tobacco and mammalian catalases. J Biol Chem. Nov 8;271(45):28492-501.

Durner J, Wendehenne D y Klessig DF (1998). Defense gene induction in tobacco by nitric oxide, cyclic GMP and cyclic ADP-ribose. Proc. Natl. Acad. Sci. USA 95, 10328-10333.

Durner, J. y Klessing, D.F. (1999). Nitric oxide as a signal in plants. Current Opinion in Plant Biology, 2: 369-374.

Ebel, J., y Cosio, E.G. (1994). Elicitors of plant defense responses. Int Rev Cytol 148, $1-36$.

Ecker, J.R. (1995). The ethylene signal transduction pathway in plants. Science 268, 667-675.

Ellis C, Turner JG. (2001). The Arabidopsis mutant cev1 has constitutively active jasmonate and ethylene signal pathways and enhanced resistance to pathogens. Plant Cell. May;13(5):1025-33.

Ellis, C., Karafyllidis, I., Wasternack, C., y Turner, J.G. (2002). The Arabidopsis mutant cev1 links cell wall signaling to jasmonate and ethylene responses. Plant Cell 14, 1557-1566.

Endre, G., Kereszt, A., Kevei, Z., Mihacea, S., Kalo, P., y Kiss, G.B. (2002). A receptor kinase gene regulating symbiotic nodule development. Nature 417, 962-966.

Eulgem, T., Rushton, P.J., Robatzek, S., y Somssich, I.E. (2000). The WRKY superfamily of plant transcription factors. Trends Plant Sci. 5, 199-206.

Falk, A., Feys, B.J., Frost, L.N., Jones, J.D., Daniels, M.J., y Parker, J.E. (1999). EDS1, an essential component of $R$ gene-mediated disease resistance in Arabidopsis has homology to eukaryotic lipases. Proc. Natl. Acad. Sci. U.S.A. 96, 3292-3297.

Farmer, M.J., Czernic, P., Michael, A., y Negrel, J. (1999). Identification and characterization of cDNA clones encoding hydroxycinnamoyl-CoA:tyramine Nhydroxycinnamoyltransferase from tobacco. Eur J Biochem 263, 686-694. 
Felix, G., Duran, J.D., Volko, S., y Boller, T (1999). Plants have a sensitive perception system for the most conserved domain of bacterial flagellin. Plant $\mathrm{J}$. 18, 265-276.

Feng S, Ma L, Wang X, Xie D, Dinesh-Kumar SP, Wei N, Deng XW. (2003). The COP9 signalosome interacts physically with SCF COI1 and modulates jasmonate responses. Plant Cell. May;15(5):1083-94.

Ferrari, S.; Plotnikova, J. M.; De Lorenzo, G., y Ausubel, F. M. (2003). Arabidopsis local resistance to Botrytis cinerea involves salicylic acid and camalexin and requires EDS4 and PAD2, but not SID2, EDS5 or PAD4. Plant J. 35: 193-205.

Feuillet, C., Schachermayr, G., y Keller, B (1997). Molecular cloning of a new receptor like kinase gene encoded at the Lr10 disease resistance locus of wheat. Plant J. 11, 45-52.

Feys B, Benedetti CE, Penfold CN, Turner JG. (1994). Arabidopsis Mutants Selected for Resistance to the Phytotoxin Coronatine Are Male Sterile, Insensitive to Methyl Jasmonate, and Resistant to a Bacterial Pathogen. Plant Cell. May;6(5):751-759.

Feys, B.J., y Parker, J.E. (2000). Interplay of signaling pathways in plant disease resistance. Trends Gene 16, 449-455.

Feys, B.J., Moisan, L.J., Newman, M.A., y Parker, J.E. (2001). Direct interaction between the Arabidopsis disease resistance signaling proteins, EDS1 and PAD4. Embo J 20, 5400-5411.

Flor, H.H. (1971). Current status of the gene-for-gene concept. Annu. Rev. Phytopathol. 9: 275-296.

Forouhar, F.; Yang, Y.; Khmer, D.; Chen, Y.; Fridman, E.; Park, S.W.; Chiang, Y.; Acton, T.B.; Montelione, G.T.; Pichersky, E.; Klessig, D.F., y Tong, L. (2005). Structural and biochemical studies identify tobacco SABP2 as a methyl salicylate esterase and implicate it in plant innate immunity. Proc Natl Acad Sci USA, Feb 1, 102 (5): 1773-1778.

Fujita, H., y Syono, K. (1996). Genetic analysis of the effects of polar auxin transport inhibitors on root growth in Arabidopsis thaliana. Plant Cell Physiol. 1996 Dec;37(8):1094-101.

Gadea, J.; Mayda, M.E.; Conejero, V., y Vera P. (!996). Characterization of defenserelated genes ectopically expressed in viroid-infected tomato plants. Mol. PlantMicrobe Interact, 9: 409-415.

Gaffney, T., Friedrich, L., Vernooij, B., Negrotto, D., Nye, G., Uknes, S., Ward, E., Kessmann, H., y Ryals, J. (1993). Requirement of salicylic acid for the induction of systemic acquired resistance. Science 261, 754-756.

Gagne, J.M., Downes, B.P., Shiu, S. H., Durski, A.M., y Vierstra, R.D. (2002). The F box subunit of the SCF E3 complex is encoded by a diverse superfamily of genes in Arabidopsis. Proc Natl Acad Sci U S A 99, 11519-11524. 
Gao, Z., Chen, Y.F., Randlett, M.D., Zhao, X.C., Findell, J.L., Kieber, J.J., y Schaller, G.E. (2003). Localization of the Raf-like kinase CTR1 to the endoplasmic reticulum of Arabidopsis through participation in ethylene receptor signaling complexes. J Biol Chem 278, 34725-34732.

Garcia-Olmedo F, Carmona MJ, Lopez-Fando JJ, Fernandez JA, Castagnaro A, Molina A, Hernandez-Lucas C, Carbonero P (1992). Characterization and analysis of thionin genes. In T Boller, F Meins, eds, Genes envolved in plant defence Springer-Verlag,Wien 283-302.

Gehring, W. J.; Affolter, M., y Bürglin, T. (1994). Homeodomain proteins. Annu. Rev. Biochem, 63: 487-526.

Ghassemian, M., Nambara, E., Cutler, S., Kawaide, H., Kamiya, Y., y McCourt, P. (2000). Regulation of abscisic acid signaling by the ethylene response pathway in Arabidopsis. Plant Cell 12, 1117-1126.

Glazebrook, J., y Ausubel, F.M (1994). Isolation of phytoalexin-deficient mutants of Arabidopsis thaliana and characterization of their interaction with bacterial pathogens, Proc. Natl. Sci. U.S.A 91, 8955-8959.

Glazebrook J, Rogers EE, Ausubel FM. (1996). Isolation of Arabidopsis mutants with enhanced disease susceptibility by direct screening. Genetics. Jun;143(2):973-82.

Glazebrook J, Zook M, Mert F, Kagan I, Rogers EE, Crute IR, Holub EB, Hammerschmidt R, Ausubel FM (1997) Phytoalexin-deficient mutants of Arabidopsis reveal that Pad4 encodes a regulatory factor and that four PAD genes contribute to downy mildew resistance. Genetics 146: 381-392.

Glazebrook, J. (1999). Genes controlling expression of defense responses in Arabidopsis. Curr. Opin. Plant Biol. 2, 280-286.

Glazebrook, J. (2001). Genes controlling expression of defense responses in Arabidopsis--2001 status. Curr. Opin. Plant Biol. 4, 301-308.

Glickman, M.H., y Ciechanover, A. (2002). The ubiquitin-proteasome proteolytic pathway: destruction for the sake of construction. Physiol Rev. 82, 373-428.

Gomez-Gomez, L Felix, G., y Boller T. (1999). A single locus determines sensitivity to bacterial flagellin in Arabidopsis thaliana. Plant J 18, 277-284.

Gomez-Gomez, L., y Boller, T. (2000). FLS2: an LRR receptor-like kinase involved in the perception of the bacterial elicitor flagellin in Arabidopsis. Mol Cell 5, 10031011.

Gomez-Gomez, L., y Boller, T. (2002). Flagellin perception: a paradigm for innate immunity. Trends Plant Sci 7, 251-256.

Goodman, R.N. y Novacky, A.J. (1994). The hypersensitive reaction in plants to pathogen. A resistance phenomena. St. Paul, MN:APS Press.

Govrin, E. M., y Levine, A. (2000). The hypersensitive response facilitates plant infection by the necrotrophic pathogen Botrytis cinerea. Curr. Biol, 10: 751-757. 
Grant, M.; Brown, L; Adams, S.; Knight, M.; Ainslie, A. y Mansfield, J. (2000). The RPM1 plant disease resistance gene facilitates a rapid and sustained increase in cytosolic calcium that is necessary for the oxidative burst and hypersensitive cell death. Plant J., 23(4): 441-450.

Grant, J.J. y Loake, G.J. (2000). Role of reactive oxygen intermediates and cognates redox signalling in disease resistance. Plant Physiol. 124, 21-29.

Gray WM, del Pozo JC, Walker L, Hobbie L, Risseeuw E, Banks T, Crosby WL, Yang M, Ma H, Estelle M. (1999). Identification of an SCF ubiquitin-ligase complex required for auxin response in Arabidopsis thaliana. Genes Dev. Jul 1;13(13):1678-91.

Greenberg, J.T., y Vinatzer, B.A. (2003). Identifying type III effectors of plant pathogens and analysing their interaction with plant cells. Curr. Opin. Microbiol. 6: $20-28$.

Grignon, C. (1999). Recent avances onproteins of plants terminal membranes. Biochimie 81, 577-596.

Görlach, J.; Volrath, S.; Knauf-Beiter, G.; Hengy, G.; Beckhove, U.; Kogel, K. H.; Oostendorp, M.; Staub, T.; Ward, E.; Kessmann, H., y Ryals, J. (1996). Benzothiadiazole, a novel class of inducers of systemic adquired resistance, activates gene expression and disease resistance in wheat. Plant Cell, 8: 629643.

Guo, H., y Ecker, J.R. (2004). The ethylene signaling pathway: new insights. Curr Opin Plant Biol 7, 40-49.

Guzman, P., y Ecker, J.R. (1990). Exploiting the triple response of Arabidopsis to identify ethylene-related mutants. Plant Cell 2, 513-523.

Hahn, M.G. (1996). Microbial elicitors and their receptors in plants. Annu Rev Phytopathol 34, 387-412.

Hammond-Kosack KE y Jones JDG (1996). Resistance gene-dependent plant defense response. Plant Cell 8, 1773-1791.

Hammond-Kosack, K.E., y Parker, J.E. (2003). Deciphering plant-pathogen communication: fresh perspectives for molecular resistance breeding. Curr. Opin. Biotechnol. 14, 177-193.

Hassig, C.A., Tong, J.K., y Schreiber, S.L. (1997). Fiber-derived butyrate and the prevention of colon cancer. Chem Biol 4, 783-789.

He, Z.H., Cheeseman, I., He, D., y Kohorn, B.D. (1999). A cluster of five cell wallassociated receptor kinase genes, Wak1-5, are expressed in specific organs of Arabidopsis. Plant Mol Biol 39: 1189-1196.

Henderson, L.M.; Chappel, J.B. (1996). NADPH oxidase of neutrophils. Biochim Biophys Acta, Feb 15;1273(2):87-107.

Himmelbacj, A.; Hoffmann, T.; Leube, M.; Hohener, B., y Grill, E. (2002). Homeodomain protein ATHB6 is a target of the protein phosphatase ABI1 and regulates hormone response in Arabidopsis. EMBO J. 21: 3029-3038. 
Hiraga, S.; Sasaki, K.; Ito, H.; Ohashi, Y., y Matsui, H. (2001). A large family of class III plant peroxidases. Plant Cell Physiol. May;42(5):462-8.

Hunt, M. y Ryals, J. (1996). Systemic acquired resistance signal transduction. Crit. Rev. Plants Sci. 15, 583-606.

lavicoli A, Boutet E, Buchala A, Metraux JP. (2003). Induced systemic resistance in Arabidopsis thaliana in response to root inoculation with Pseudomonas fluorescens CHA0. Mol Plant Microbe Interact. Oct;16(10):851-8.

Innes, R.W. (1998). Genetic dissection of $R$ gene signal transduction pathways. Curr. Opin. Plant Biol. 1, 299-304.

Inoue, T., Higuchi, M., Hashimoto, Y., Seki, M., Kobayashi, M., Kato, T., Tabata, S., Shinozaki, K., y Kakimoto, T. (2001). Identification of CRE1 as a cytokinin receptor from Arabidopsis. Nature 409, 1060-1063.

Ishikawa A, Okamoto H, Iwasaki Y, Asahi T. (2001). A deficiency of coproporphyrinogen III oxidase causes lesion formation in Arabidopsis. Plant JJul;27(2):89-99.

Ito, Y., Kaku, H., y Shibuya, S. (1997). Identification of high-affinity binding protein for $\mathrm{N}$ - acetylchtoologosachsride elicitor in the plasma membrane of suspensioncultured rice cells by affinity labelling. Plant Journal 12, 347-356.

Jabs, T.; Dietrich, R.A., y Dangl, J.L. (1996). Initiation of runaway cell death in an Arabidopsis mutant by extracellular superoxide. Science. Sep27; 273(5283): 1853-1856.

Jabs, T.; Tschope, M.; Colling, C.; Hahlbrock, K. y Scheel, D. (1997). Elicitorstimulated ion fluxes and $\mathrm{O}_{2}$ - from the oxidative burst are essential components in triggering defense gene activation and phytoalexin synthesis in parsley. Proc. Nati. Acad. Sci. USA, 94: 4800-4805.

Jackson AO, Taylor DN (1996). Plant-Microbe Interactions: Life and Death at the interface. Plant Cell 8: 1651-1668.

Jia, Y., McAdams, S.A., Bryan, G.T., Hershey, H.P., y Valent, B. (2000). Direct interaction of resistance gene and avirulence gene products confers rice blast resistance. EMBO J. 19, 4004-4014.

Jirage, D., Tootle, T.L., Reuber, T.L., Frost, L.N., Feys, B.J., Parker, J.E., Ausubel, F.M., y Glazebrook, J. (1999). Arabidopsis thaliana PAD4 encodes a lipaselike gene that is important for salicylic acid signaling. Proc Natl Acad Sci U S A 96, 13583-13588.

Jirage, D., Zhou, N., Cooper, B., Clarke, J.D., Dong, X., y Glazebrook, J. (2001). Constitutive salicylic acid-dependent signaling in cpr1 and cpr6 mutants requires PAD4. Plant J 26, 395-407.

Johnson, P.R., y Ecker, J.R. (1998). The ethylene gas signal transduction pathway: a molecular perspective. Annu Rev Genet 32, 227-254.

Jones, O.T. (1994). The regulation of superoxide production by the NADPH oxidase of neutrophils and other mammalian cells. Bioessays, Dec;16(12):919-23. 
Jones, A. (2000). Does the plant mitochondrion integrate cellular stress and regulate programme cell death? Trends in Plant Science, 5: 225-230.

Kachroo P, Yoshioka K, Shah J, Dooner HK, Klessig DF. ( 2000). Resistance to turnip crinkle virus in Arabidopsis is regulated by two host genes and is salicylic acid dependent but NPR1, ethylene, and jasmonate independent. Plant CellMay;12(5):677-90.

Kachroo P, Shanklin J, Shah J, Whittle EJ, Klessig DF. (2001).A fatty acid desaturase modulates the activation of defense signaling pathways in plants. Proc Natl Acad Sci U S A. Jul 31;98(16):9448-53

Kariola, T., Palomaki, T.A., Brader, G., y Palva, E.T. (2003). Erwinia carotovora subsp. carotovora and Erwinia-derived elicitors HrpN and PehA trigger distinct but interacting defense responses and cell death in Arabidopsis. Mol Plant Microbe Interact 16, 179-187.

Kawano, T (2003). Roles of the reactive oxygen species-generating peroxidase reactions in plant defense and growth induction. Plant Cell Rep. 21, 829-837.

Kawasaki T, Henmi K, Ono E, Hatakeyama S, Iwano M, Satoh H, Shimamoto K. (1999). The small GTP-binding protein rac is a regulator of cell death in plants. Proc Natl Acad Sci U S A. Sep 14;96(19):10922-6.

Keen, NT. (1990). Gene-for-gene complementarity in plant-pathogen interactions. Annu. Rev. Genet. 24, 447-463.

Keller T, Damude HG, Werner D, Doerner P, Dixon RA y Lamb C (1998). A plant homolog of the neutrophil NADPH oxidase gp91 phox subunit gene encodes a plasma membrane protein with $\mathrm{Ca}^{2+}$ binding motifs. Plant Cell 10, 255-266.

Kessler, A., y Baldwin, I.T. (2002). Plant responses to insect herbivory: the emerging molecular analysis. Annu Rev. Plant Biol. 53, 299-328.

Kieber, J.J. Rothenberg, M., roman, G., Feldmann, K.A., y Ecker, J.R. (1993). CTR1, a negative regulator of the ethylene response pathway in Arabidopsis, encodes a member of the raf family of protein kinases. Cell 72, 427-441.

Kim, Y.S., Lee, J.H., Yoon, G.M., Cho, H.S., Park, S.W., Suh, M.C., Choi, D., Ha, H.J., Liu, J.R., y Pai, H.S. (2000). CHRK1, a chitinase-related receptor-like kinase in tobacco. Plant Physiol 123, 905-915.

Kloek AP, Verbsky ML, Sharma SB, Schoelz JE, Vogel J, Klessig DF, Kunkel BN. (2001). Resistance to Pseudomonas syringae conferred by an Arabidopsis thaliana coronatine-insensitive (coi1) mutation occurs through two distinct mechanisms. Plant J. Jun;26(5):509-22.

Kumar, D., y Klessig, D.F. (2003). High-affinity salicylic acid-binding protein 2 is required for plant innate immunity and has salicylic acid-stimulated lipase activity. Proc. Natl. Acad. Sci. U.S.A. 100, 16101-16106.

Kunkel, B.N., y Brooks, D.M. (2002). Cross talk between signalling pathways in pathogen defense. Curr Opin Plant Biol 5, 325-331. 
Lamb C y Dixon RA. (1997). The oxidative Burst in plant disease resistance. Annu. Rev. Plant Physiol. Plant Mol. Biol. 48, 251-275.

Lawton, K., S., Uknes, L. Friedrich, T. Gaffney, D. Alexander, R. Goodman, J. P. Métraux, H. Kessmann, P. Ahl-Goy, M. Gut-Rella, E. Ward, J. Ryals. (1993). The molecular biology of systemic acquired resistance. In Mechanisms of Defense Responses in Plants. B. Fritig and M. Legrand, eds (Dordrecht, The Netherlands:

Lee, S., Suh, S., Kim, S., Crain, R.C., Kwak, J.M., Nam, H.G., y Lee, Y. (1997). Systemic elevation of phosphatidic acid and lysophospholipid levels in wounded plants. Plant J 12.

Legendre L, Rueter S, Heinstein PF, Low PS. (1993). Characterization of the Oligogalacturonide-Induced Oxidative Burst in Cultured Soybean (Glycine max) Cells. Plant Physiol. May;102(1):233-240.

Levine A, Tenhaken R, Dixon $\mathbf{R}$ y Lamb $\mathbf{C}$ (1994). $\mathrm{H}_{2} \mathrm{O}_{2}$ from the oxidative burst orchestrates the plant hypersensitive disease resistance response. Cell 79, 583-593.

Li, X., Zhang, Y., Clarke, J.D., Li, Y., y Dong, X. (1999). Identification and cloning of a negative regulator of systemic acquired resistance, SNI1, through a screen for suppressors of npr1-1. Cell 98, 329-339.

Li, J., Brader, G., y Palva, E.T. (2004). The WRKY70 transcription factor: a node of convergence for jasmonate-mediated and salicylate-mediated signals in plant defense. Plant Cell 16, 319-331.

Ligterink W, Kroj T, zur Nieden U, Hirt H, Scheel D. (1997). Receptor-mediated activation of a MAP kinase in pathogen defense of plants. Science: 27;276(5321):2054-7.

Linthorst HJ, Danhash N, Brederode FT, Van Kan JA, De Wit PJ, Bol JF. (1991). Tobacco and tomato PR proteins homologous to win and pro-hevein lack the "hevein" domain. Mol Plant Microbe Interact. Nov-Dec;4(6):586-92.

Liu, Y., Schiff, M., Marathe, R., y Dinesh-Kumar, S.P. (2002). Tobacco Rar1, EDS1 and NPR1/NIM1 like genes are required for $N$-mediated resistance to tobacco mosaic virus. Plant J. 30, 415-429.

Lorenzo O, Piqueras R, Sanchez-Serrano JJ, Solano R. (2003). ETHYLENE RESPONSE FACTOR1 integrates signals from ethylene and jasmonate pathways in plant defense. Plant Cell. Jan;15(1):165-78.

Lorenzo O, Chico JM, Sanchez-Serrano JJ, Solano R. (2004). JASMONATEINSENSITIVE1 encodes a MYC transcription factor essential to discriminate between different jasmonate-regulated defense responses in Arabidopsis. Plant CellJul;16(7):1938-50.

Lusser, A., Kolle, D., y Loidl, P. (2001). Histone acetylation: lessons from the plant kingdom. Trends Plant Sci 6, 59-65. 
Mach JM, Castillo AR, Hoogstraten R, Greenberg JT. (2001). The Arabidopsisaccelerated cell death gene ACD2 encodes red chlorophyll catabolite reductase and suppresses the spread of disease symptoms. Proc Natl Acad Sci U S A. Jan 16;98(2):771-6. Epub 2001 Jan 9

Mackey, D., Holt, B.F., Wiig, A., y Dangl, J.L. (2002). RIN4 interacts with Pseudomonas syringae type III effector molecules and is required for RPM1mediated resistance in Arabidopsis. Cell 108, 743-754.

Mackey, D., Belkhadir, Y., Alonso, J.M., Ecker, J.R., y Dangl, J.L. (2003). Arabidopsis RIN4 is a target of the type III virulence effector AvrRpt2 and modulates RPS2-mediated resistance. Cell 112, 379-389.

Maldonado, A.M., Doerner, P., Dixon, R.A., Lamb, C.J., y Cameron, R.K. (2002). A putative lipid transfer protein involved in systemic resistance signalling in Arabidopsis. Nature 419, 399-403.

Maleck, K.; Levine, A.; Eugelm, T.; Morgan, A.; Schmid, J.; Lawton, K.A.; Dangl, J.L. y Dietrich, R.A. (2000). The transcriptome of Arabidopsis thaliana during systemic acquired resistance. Nat Genet, Dec 26 (4): 403-410.

Martin, G.B., Brommonschenkel, S.H., Chunwongse, J., Frary, A., Ganal, M.W., Spivey, R., Wu, T., Earle, E.D., y Tanksley, S.D. (1993). Map-based cloning of a protein kinase gene conferring disease resistance in tomato. Science 262, 1432-1436.

Martin, G.B. (1999). Fuctional analysis of plant disease resistance enes and their downstream effectors. Current opinion in Plant BIOLOGY, 2: 273-279.

Mathieu, Y., A. Kurkjian, H. Xia, J. Guern, M. Spiro, M. O‘Nelly, P. Albersheim, y A Darvill. (1991). Menbrane responses induced by oligogalacturonides in suspecion-culture tobacco cells. Plant J. 1: 333-343.

Mauch-Mani B, Slusarenko AJ. (1993). Arabidopsis as a model host for studying plant-pathogen interactions. Trends Microbiol. 7: 265-70.

Mayda, E.; Tornero, P.; Conejero, V., y Vera, P. (1999). A tomato homeobox gene (HD-Zip) is envolved in limiting the spread of programme cell death. Plant J. 20, 591-600.

Mayer, B. y Hemmens, B. (1997). Biosíntesis and action of nitric oxide in mammalian cells. TIBS, 22: 477-481.

McConn, M., Creelman, R.A., Bell, E., Mullet, J.E., y Browse, J. (1997). Jasmonate is essential for insect defense in Arabidopsis. Proc. Natl Acad Sci U S A 94, 5473-5477.

MeindI, T., Boller, T., y Felix, G. (2000). The bacterial elicitor flagellin activates its receptor in tomato cells according to the address-message concept. Plant Cell 12, $1783-1794$.

Memelink, J., Verpoorte, R., y Kijne, J.W. (2001). Organization of jasmonate responsive gene expression in alkaloid metabolism. Trends Plants Sci 6, 212219. 
Mengiste, T.; Chen, X.; Salmeron, J. M., y Dietrich, R. A. (2003). The BOS1 genes encodes an R2R3MYB transcription factor protein that is required for biotic and abiotic stress response in Arabidopsis. Plant Cell, 15: 2551-2565.

Menke, F.L., Champion, A., Kijne, J.W., y Memelink, J. (1999). A novel jasmonateand elicitor-responsive element in the periwinkle secondary metabolite biosynthetic gene Str interacts with a jasmonate- and elicitor-inducible AP2domain transcription factor, ORCA2. Embo J 18, 4455-4463.

Métraux, J.P., Ahl-Goy, P., Staub, T., Speich, J., Steinemann, A., Ryals, J., y Ward, E. (1991). Induced resistance in cucumber in response to 2,6.dichloroisonicotinic acid and pathogens. In Advances in Molecular Genetics of Plant-Microbe Interactions. 1,432-439. H. Hennecke and D.P.S. Verma, eds (Dordrecht, The Netherlands:Kluwer).

Mithöfer, A., Fliegmann, J., Neuhaus-Uri, G., Schwarz, H., y Ebel, J. (2000). The hepta- -glucoside elicitor-binding proteins from legumes represent a putative receptor family. Biol Chem 381, 705-713.

Mittler R, Zilinskas BA. (1994). Regulation of pea cytosolic ascorbate peroxidase and other antioxidant enzymes during the progression of drought stress and following recovery from drought. Plant J. Mar;5(3):397-405.

Moffett, P., Farnham, G., Peart, J., y Baulcombe, D.C. (2002). Interaction between domains of a plant NBS-LRR protein in disease resistance-related cell death. EMBO J. 21, 4511-4519.

Montesano, M., Koiv, V., Mäe, A., y Palva, E.T. (2001). Novel receptor-like protein kinases induced by Erwinia carotovora and short oligouronides in potato. Mol. Plant Pathol. 2, 339-346.

Muskett, P.R., Kahn, K., Austin, M.J., Moisan, L.J., Sadanyom, A., Tor, M., Gordon, P., Cuzick, A., Eulgem, T., Sinapidou, E., Mert-Turk, F., Can, C., Dangl, J.L., y Holub, E.B. (2002). Arabidopsis SGT1b is required for defense signaling conferred by several downy mildew resistance genes. Plant Cell 14, 993-1003.

Nandi A, Krothapalli K, Buseman CM, Li M, Welti R, Enyedi A, Shah J. (2003). Arabidopsis sfd mutants affect plastidic lipid composition and suppress dwarfing, cell death, and the enhanced disease resistance phenotypes resulting from the deficiency of a fatty acid desaturase. Plant Cell. Oct;15(10):2383-98.

Nardini, M., y Dijkstra, B.W. (1999). Alpha/beta hydrolase fold enzymes: the family keeps growing. Curr Opin Struct Biol 9, 732-737.

Narvaez-Vasquez J, Florin-Christensen J, Ryan CA. (1999). Positional specificity of a phospholipase A activity induced by wounding, systemin, and oligosaccharide elicitors in tomato leaves. Plant Cell. Nov;11(11):2249-60.

Navarre, D.A.; Wendehenne, D.; Durner, J.; Noad, R. y Klessig, D.F. (2000). Nitric oxide modulates the activity of tobacco aconitase. Plant Physiol., 122(2): 57382. 
Nawrath, C., and Metraux, J.P. (1999). Salicylic acid induction-deficient mutants of Arabidopsis express PR-2 and PR-5 and accumulate high levels of camalexin after pathogen inoculation. Plant Cell 11, 1393-1404.

Nawrath, C., Heck, S., Parinthawong, N., y Métraux, J.P. (2002). EDS5, an essential component of salicylic acid-dependent signalling for disease resistance in Arabidopsis, is a member of the MATE transporter family. Plant Cell 14, 275286.

Norman-Setterblad C, Vidal S, Palva ET. (2000). Interacting signal pathways control defense gene expression in Arabidopsis in response to cell wall-degrading enzymes from Erwinia carotovora. Mol Plant Microbe Interact. Apr;13(4):430-8.

Nürnberger, T., Nennstiel, D., Jabs, T., Sacks, W.R., Hahlbrock, K., and Scheel, D. (1994). High affinity binding of a fungal oligopsptide elicitor to parsley plasma membranes triggers multiple defense responses. Cell 78, 449-460.

Nürnberger, T. (1999). Signal perception in plant pathogen defense. Cell. Mol. Life Sci. $55,167-182$.

Nürnberger, T., y Scheel, D. (2001). Signal transmission in the plant immune response. Trends Plant Sci 6, 372-379.

Nürnberger, T., y Brunner, F. (2002). Innate immunity in plants and animals: emerging parallels between the recognition of general elicitors and pathogen-associated molecular patterns. Curr Opin Plant Biol 5, 318-324.

O’Donnell, P.J., Schmelz, E.A., Moussatche, P., Lund, S.T., Jones, J.B., y Klee, H.J. (2003a). Suscriptible to intolerance a range of hormonal actions in a susceptible Arabidopsis pathogen response. Plant J 33, 245-257.

O'Donnell, P.J., Schmelz, E., Block, A., Miersch, O., Wasternack, C., Jones, J.B., y Klee, H.J. (2003b). Multiple Hormones Act Sequentially to Mediate a Susceptible Tomato Pathogen Defense Response. Plant Physiol 133, 11811189.

Ogawa K, Kanematsu S, Asada K. (1997). Generation of superoxide anion and localization of CuZn-superoxide dismutase in the vascular tissue of spinach hypocotyls: their association with lignification. Plant Cell Physiol. :38(10):111826.

Ohme-Takagi, M., Suzuki, K., y Shinshi, H. (2000). Regulation of ethylene-induced transcription of defense genes. Plant Cell Physiol 41, 1187-1192.

Orozco-Cárdenas ML, Narváez-Vásquez J y Ryan CA (2001). Hydrogen peroxide acts as a second Messenger for the induction of defense genes in tomato plants in response to wounding, systemin and methyl jasmonate. Plant Cell 13: 179-191.

Osbourn AE (1999). Antimicrobial phytoprotectans and fungal pathogens: a commentary. Fungal Genet Biol 26, 163-168. 
Palva, T. K.; Hurtig, M.; Saindrenan, P., y Palva, E. T. (2000). Salicylic acid induced resistance to Erwinia carotovora subs. carotovora in Tobacco. Mol. PlantMicrobe Interact, 7: 356-363.

Parker, J.E., E.B. Houlb, L.M. Frost, A. Falk, N.D. Gunn, y M.J. Daniels. (1996). Characterization of eds1, a mutation in Arabidopsis suppressing resistance to phenosphora parasitica specified by several different RPP genes. Plant Cell 8 , 2033-2046.

Pastuglia, M., Robu, D., Dumas, C., y Cock, J. M (1997). Rapid induction by wounding and bacterial infection of an $\mathrm{S}$ gene family receptor-like kinase gen in Brassica oleracea. Plant Cell 9, 49-60.

Pazin, M.J., Hermann, J.W., y Kadonaga, J.T. (1998). Promoter structure and transcriptional activation with chromatin templates assembled in vitro. A single Gal4-VP16 dimer binds to chromatin or to DNA with comparable affinity. J Biol Chem 273, 34653-34660.

Pei ZM, Murata Y, Benning G, Thomine S, Klusener B, Allen GJ, Grill E, Schroeder JI. (2000). Calcium channels activated by hydrogen peroxide mediate abscisic acid signalling in guard cells. Nature. Aug 17;406(6797):731-4.

Peng M y Kuc J (1992). Peroxidase-generated hydrogen peroxide as a source of antifungal activity in vitro and on tobacco leaf disk. Phytopathology 82, 696-699.

Pennell RI y Lamb C (1997). Programmed cell death in plants. Plant Cell 9, 1157-1168.

Penninckx IA, Thomma BP, Buchala A, Metraux JP, Broekaert WF. (1998). Concomitant activation of jasmonate and ethylene response pathways is required for induction of a plant defensin gene in Arabidopsis. Plant Cell. Dec;10(12):2103-13.

Pieterse CM, van Wees SC, van Pelt JA, Knoester M, Laan R, Gerrits H, Weisbeek PJ, van Loon LC. (1998). A novel signaling pathway controlling induced systemic resistance in Arabidopsis. Plant Cell. Sep;10(9):1571-80.

Pieterse CM, van Loon LC. (1999). Salicylic acid-independent plant defence pathways. Trends Plant Sci. Feb;4(2):52-58.

Pieterse, C.M.J., Ton J., y Van Loon, L.C. (2001). Cross-Talk between plant defense signalling pathways: boost or burden?. AgBiotechNet 3, ABN 068.

Potikha TS, Collins CC, Johnson DI, Delmer DP, Levine A. (1999). The involvement of hydrogen peroxide in the differentiation of secondary walls in cotton fibers. Plant Physiol. Mar;119(3):849-58.

Prasad TK, Anderson MD, Stewart CR. (1994). Acclimation, Hydrogen Peroxide, and Abscisic Acid Protect Mitochondria against Irreversible Chilling Injury in Maize Seedlings. Plant Physiol. Jun;105(2):619-627.

Radi R, Beckman JS, Bush KM, Freeman BA. (1991). Peroxynitrite-induced membrane lipid peroxidation: the cytotoxic potential of superoxide and nitric oxide. Arch Biochem Biophys. Aug 1;288(2):481-7. 
Ramachandran, S., Hiratsuka, K., y Chua, N.H. (1994). Transcription factors in plant growth and development. Curr Opin Genet Dev 4, 642-646.

Rao MV, Paliyath G, Ormrod DP, Murr DP, Watkins CB. (1997). Influence of salicylic acid on $\mathrm{H} 2 \mathrm{O} 2$ production, oxidative stress, and $\mathrm{H} 2 \mathrm{O} 2$-metabolizing enzymes. Salicylic acid-mediated oxidative damage requires $\mathrm{H} 2 \mathrm{O} 2$. Plant Physiol. Sep;115(1):137-49

Rogers EE, Ausubel FM (1997), Arabidopsis enhanced disease susceptibility mutants exhibit enhanced susceptibility to several bacterial pathogens and alterations in PR-1 gene expression. Plant Cell 9, 305-316.

Roman, G., Lubarsky, B., Kieber, J.J., Rothenberg, M., y Ecker, J.R. (1995). Genetic analysis of ethylene signal transduction in Arabidopsis thaliana: five novel mutant loci integrated into a stress response pathway. Genetics 139, 13931409.

Romeis T, Piedras P, Zhang S, Klessig DF, Hirt H, Jones JD._ (1999). Rapid Avr9and Cf- 9 -dependent activation of MAP kinases in tobacco cell cultures and leaves: convergence of resistance gene, elicitor, wound, and salicylate responses. Plant Cell: 11(2):273-87.

Romero-Puertas, M.C., Perazzolli, M., Zago, E.D., y Delledonne, M. (2004). Nitric oxide signalling functions in plant-pathogen interactions. Cell Microbiol. 6, 795803.

Ross, A.F. (1961). Systemic acquired resistance induced by localized virus infections in plants. Virology $14,340-358$.

Ruffer, M., Steipe, B., y Zenk, M.H. (1995). Evidence against specific binding of salicylic acid to plant catalase. FEBS Lett 377, 175-180.

Ryals, J.A., Neuenschwander, U.H., Willits, M.G., Molina, A., Steiner, H.Y., y Hunt, M.D.(1996). Systemic Acquired Resistance. Plant Cell 8, 1809-1819.

Ryan, C. A. (1990). Proteinase inhibitors in plants: Genes for improving defensas against insects and pathogens. Ann Rev Phytopathol 28: 425-449.

Ryu, S.B., y Wang, X. (1998). Increase in free linolenic and linoleic acids associated with phospholipase D-mediated hydrolysis of phospholipids in wounded castor bean leaves. Biochim Biophys Acta 1393, 193-202.

Sakai, H., Hua, J., Chen, Q.G., Chang, C., Medrano, L.J., Bleecker, A.B., y Meyerowitz, E.M. (1998). ETR2 is an ETR1-like gene involved in ethylene signaling in Arabidopsis. Proc Natl Acad Sci U S A 95, 5812-5817.

Samach A, Klenz JE, Kohalmi SE, Risseeuw E, Haughn GW, Crosby WL. (1999). The UNUSUAL FLORAL ORGANS gene of Arabidopsis thaliana is an F-box protein required for normal patterning and growth in the floral meristem. Plant J. Nov;20(4):433-45.

Satterlee, J.S., y Sussman, M.R. (1998). Unusual membrane-associated protein kinases in higher plants. J Membr Biol 164, 205-213. 
Scandalios JG. (1992). Processing, targeting and import into the mitochondria and peroxisomes of proteins coded by nuclear genes. Ontogenez. NovDec;23(6):592-611

Schaller F. (2001).Enzymes of the biosynthesis of octadecanoid-derived signalling molecules. J Exp Bot. Jan;52(354):11-23.

Schaller, A. y Ryan, C.A. (1996). Molecular cloning of a tomato leaf cDNA encoding an aspartic protease, a systemic wound response protein. Plant Mol. Biol. 31: 1073-1077.

Scheel, D. (1998). Resistance response physiology and signal transduction. Curr. Opin. Plant Biol. 1, 305-310.

Schena, M., y Davis, R. W. (1992). HD-Zip proteins: Memmbers of an Arabidopsis homeodomain superfamily. Proc Natl. Acad. Sci. USA, 89: 3894-3898.

Schmit, H.H.H.W. (1994). NO at work. Cell, 78: 919-925.

Serino, L., Reimmann, C., Baur, H., Beyeler, M., Visca, P., y Haas, D (1995). Structural genes for salicylate biosynthesis from chorismate in Pseudomonas aeruginosa. Mol Gen Genet 249, 217-228.

Shah, J., Tsui, F., y Klessig, D.F. (1997). Characterization of a salicylic acidinsensitive mutant (sai1) of Arabidopsis thaliana, identified in a selective screen utilizing the SA-inducible expression of the tms2 gene. Mol. Plant Microbe Interact. 10, 69-78.

Shah, J., Kachroo, P., y Klessig, D.F. (1999). The Arabidopsis ssi1 mutation restores pathogenesis-related gene expression in npr1 plants and renders defensin gene expression salicylic acid dependent. Plant Cell 11, 191-206.

Shah, J., Kachroo, P., y Klessig, D.F. (1999). The Arabidopsis ssi1 mutation restores pathogenesis-related gene expression in npr1 plants and renders defensin gene expression salicylic acid dependent. Plant Cell 11, 191-206.

Shah, J. (2003). The salicylic acid loop in plant defense. Curr Opin Plant Biol, 6: 365371.

Shah MM, Fujiyama K, Flynn CR, Joshi L. (2003). Sialylated endogenous glycoconjugates in plant cells. Nat Biotechnol. Dec;21(12):1470-1. Epub 2003 Nov 9.

Shao, F., Golstein, C., Ade, J., Stoutemyer, M., Dixon, J.E., y Innes, R.W. (2003). Cleavage of Arabidopsis PBS1 by a bacterial type III effector. Science 301, 1230-1233.

Shibuya, N., y Minami, E. (2001). Oligosaccharide signalling for defense responses in plant. Physiol Mol Plant Pathol 59, 223-233.

Shirasu K, Nakajima H, Rajasekhar VK, Dixon RA, Lamb C. (1997). Salicylic acid potentiates an agonist-dependent gain control that amplifies pathogen signals in the activation of defense mechanisms. Plant Cell. Feb;9(2):261-70. 
Shiu, S.H., y Bleecker, A.B. (2001). Plant receptor-like kinase gene family: diversity, function, and signaling. Sci STKE 2001, RE22.

Showalter AM. (1993). Structure and function of plant cell wall proteins. Plant Cell. Jan;5(1):9-23.

Slaymaker DH, Navarre DA, Clark D, del Pozo O, Martin GB, Klessig DF. (2002). The tobacco salicylic acid-binding protein 3 (SABP3) is the chloroplast carbonic anhydrase, which exhibits antioxidant activity and plays a role in the hypersensitive defense response. Proc Natl Acad Sci USA, 99: 11640-11645.

Smith, C. J. (1996). Accumulation of phytoalexins: Defense mechanisms and stimulus response system. New Phytol., 132: 1-45.

Solano, R., Stepanova, A., Chao, Q., y Ecker, J.R. (1998). Nuclear events in ethylene signaling: a transcriptional cascade mediated by ETHYLENE-INSENSITIVE3 and ETHYLENE-RESPONSE-FACTOR1. Genes Dev 12, 3703-3714.

Song, W.Y., Wang, G.L., Chen, L.L., Kim, H.S., Pi, L.Y., Holsten, T., Gardner, J., Wang, B., Zhai, W.X., Zhu, L.H., y et al. (1995). A receptor kinase-like protein encoded by the rice disease resistance gene. Xa21. Science 270, 1804-1806.

Spoel SH, Koornneef A, Claessens SM, Korzelius JP, Van Pelt JA, Mueller MJ, Buchala AJ, Metraux JP, Brown R, Kazan K, Van Loon LC, Dong X, Pieterse CM. (2003). NPR1 modulates croos-talk between salicylate and jasmonate-dependent defense pathways through a novel function in the cytosol. Plant Cell, 15: 760-770.

Stamler JS, Singel DJ, Loscalzo J. (1992). Biochemistry of nitric oxide and its redoxactivated forms. Science. Dec 18;258(5090):1898-902.

Stamler JS. (1994). Redox signaling: nitrosylation and related target interactions of nitric oxide. Cell. Sep 23;78(6):931-6.

Staskawicz BJ, Ausubel FM, Baker BJ, Ellis JG, Jones JD. (1995). Molecular genetics of plant disease resistance. Science. $5 ;$ 268(5211):661-7.

Staswick PE, Su W, Howell SH. (1992). Methyl jasmonate inhibition of root growth and induction of a leaf protein are decreased in an Arabidopsis thaliana mutant. Proc Natl Acad Sci U S A. Aug 1;89(15):6837-40

Staswick PE, Yuen GY, Lehman CC. (1998). Jasmonate signaling mutants of Arabidopsis are susceptible to the soil fungus Pythium irregulare. Plant $\mathrm{J}$. Sep;15(6):747-54

Stepanova, A.N., y Ecker, J.R. (2000). Ethylene signaling: from mutants to molecules. Curr Opin Plant Biol 3, 353-360.

Steindler, C.; Matteucci, A. ; Sessa, G. ; Weimar, T. ; Ohgishi, M. ; Aoyama, T. ; Moreli, G., y Ruberti, I. (1999). Shade avoidance responses are mediated by the ATHB2 HD-Zip protein, a negative regulator of gene expression. Development, 126 : 4235-4245.

Sticher, L., Mauch-Mani, B., y Métraux, J.P. (1997). Systemic acquired resistance. Annu. Rev. Phytopathol. 35, 235-270. 
Stracke, S., Kistner, C., Yoshida, S., Mulder, L., Sato, S., Kaneko, T., Tabata, S., Sandal, N., Stougaard, J., Szczyglowski, K., y Parniske, M. (2002). A plant receptor-like kinase required for both bacterial and fungal symbiosis. Nature 417, 959-962.

Strassner, J., Schaller, F., Frick, U.B., Howe, G.A., Weiler, E.W., Amrhein, N., Macheroux, P., y Schaller, A. (2002). Charecterization and cDNA-microarray expression analysis of 12-oxophytodienoate reductases reveals differential roles for octadecanoid biosynthesis in the local versus the systemic wound response. Plant J 32, 585-601.

Su. W., y Howell, S.H. (1992). A single genetic locus, CKR1, defines Arabidopsis mutants in which root growth is resistant to low concentrations of cytokinin. Plant Physiol 99, 1569-1574.

Sutherland, M.W. (1991). The generation of oxygen radicals during host plant responses to infection. Physiol. Mol. Plant Pathol, 39, 79-93.

Tenhaken, R., A. Levine, L.F. Brisson, R.A. Dixon, y C. Lamb. (1995). Function of the oxidative burst in hipersensitive disease resistance. Proc. Natl. Acad. Sci. 92. 4058-4163.

Tenhaken, R., y Rubel C. (1997). Salicylic Acid Is Needed in Hypersensitive Cell Death in Soybean but Does Not Act as a Catalase Inhibitor. Plant Physiol 115, 291298.

Thaler, J.S., Fidantsef, A.L., Duffey, S.S. y Bostock, R.M. (1999). Trade-offs in plant defense against pathogens and herbivores: a field demonstration of chemical elicitors of induced resistance. J. of Chemical Ecology 25, 1597-1609.

Thomma BP, Eggermont K, Tierens KF y Broekaert WF (1999). Requirement of functional ethylene-insensitive 2 gene for efficient resistance of Arabidopsis to infection by Botrytis cinerea. Plant Physiol. 121, 1093-1102.

Thomma B.P.; Penninckx, I. A.; Broekaert, W. F., y Cammue, B. P. (2001). The complexity of disease signalling in Arabidopsis. Curr. Opin. Immunol. 13: 63-68.

Tiedremann, A. V. (1997). Evidence for a primary role of active oxygen species in induction of host cell death during infection of bean leaves with Botrytis cinerea. Physiol. Mol. Plant Pathol, 50: 151-166.

Tierens KF, Thomma BP, Brouwer M, Schmidt J, Kistner K, Porzel A, Mauch-Mani B, Cammue BP, Broekaert WF (2001). Study of the role of antimicrobial glucosinolate derived isothiocyanates in resistance of Arabidopsis to microbial pathogens. Plant Physiol 125, 1688-1699.

Tierens FM-J, Thomma BPHJ, Bari RP, Garnier M, Eggermont K, Brouwer M, Penninckx IAMA, Broekaer WF y Cammue BPA (2002). Esa 1, an Arabidopsis mutant with enhanced susceptibility to a range of necrotrophic fungal pathogens, shows a distorted induction of defense responses by reactive oxygen generated compounds. Plant J. 29, 131-140.

Timmusk S, Wagner EG. (1999). The plant-growth-promoting rhizobacterium Paenibacillus polymyxa induces changes in Arabidopsis thaliana gene 
expression: a possible connection between biotic and abiotic stress responses. Mol Plant Microbe Interact. Nov;12(11):951-9.

Ton J, Pieterse CM, Van Loon LC. (1999). Identification of a locus in arabidopsis controlling both the expression of rhizobacteria-mediated induced systemic resistance (ISR) and basal resistance against Pseudomonas syringae pv. tomato. Mol Plant Microbe Interact. Oct;12(10):911-8.

Ton J, De Vos M, Robben C, Buchala A, Metraux JP, Van Loon LC, Pieterse CM. (2002). Characterization of Arabidopsis enhanced disease susceptibility mutants that are affected in systemically induced resistance. Plant J.Jan;29(1):11-21.

Tsuji J, Jackson EP, Gage DA, Hammerschmidt R, Somerville SC (1992). Phytoalexin accumulation in Arabidopsis thaliana during the hypersensitive reaction to Pseudomonas syringae pv syringae. Plant Physiol 98, 1309.

Tor, M., Gordon, P., Cuzick, A., Eulgem, T., Sinapidou, E., Mert-Turk, F., Can, C., Dangl, J.L., y Holub, E.B. (2002). Arabidopsis SGT1b is required for defense signaling conferred by several downy mildew resistance genes. Plant Cell 14, 993-1003.

Tornero, P., Conejero, V., y Vera, P. (1996). Primary structure and expression of a pathogen-induced protease (PR-P69) in tomato plants: Similarity of functional domains to subtilisin-like endoproteases. Proc. Natl. Acad. Sci. U.S.A. 93, 6332-6337.

Tornero, P., Conejero, V., y Vera, P. (1997). Identification of a new pathogen-induced member of the subtilisin-like processing protease family from plants. J. Biol. Chem. 272, 14412-14419.

Torres, M.A.; Onouchi, H.; Hamada, S.; Machida, C.; Hammond-Kosack, K.E. y Jones, J.D.G. (1998). Six Arabidopsis thaliana homologues of the human respiratory Bursa oxidase (gp91phox). Plant J., 14(3): 365-70.

Turner, J.G.; Ellis, C., y Devoto, A. (2002). The jasmonate signal pathway. Plant Cell, 14 (suppl.), S153-S164.

Umemoto, N., Kakitani, M., Iwamatsu, A., Yoshikawa, M., Yamaoka, N., y Ishida, I. (1997) The structure and function of a soybean beta-glucan-elicitor-binding protein. Proc Nati Acad Sci USA 94, 1029-1034.

Van der Fits, L., y Memelink, J. (2000). ORCA3, a jasmonate-responsive transcriptional regulator of plant primary and secondary metabolism. Science 289, 295-297.

Van Kan, J.A., Joosten, M.H., Wagemakers, C.A., van den Berg-Velthuis, G.C., de Wit, P.J. (1992) Differential accumulation of mRNAs encoding extracellular and intracellular PR proteins in tomato induced by virulent and avirulent races of Cladosporium fulvum. Plant Mol. Biol. 20, 513-527.

Van Loon, L.C., y van Strien, E.A. (1999). The families of pathogenesis-related proteins, their activities, and comparative anlysis of PR-1 type proteins. Physiol. Mol. Plant Pathol. 55. 
Van Wees, S.C., de Swart, E.A., van Pelt, J.A., van Loon, L.C., y Pieterse, C.M. (2000). Enhancement of induced disease resistance by simultaneous activation of salicylate- and jasmonate-dependent defense pathways in Arabidopsis thaliana. Proc. Natl. Acad. Sci. U.S.A. 97, 8711-8716.

Vera P., y V. Conejero. (1989). The induction and accumulation of the patogénesisrelated P69 proteinase in tomato during citrus exocortis viroid infection and in response to chemical treatments. Physiol Mol Plant Pathol 34: 323-334.

Vera-Estrella, R., B.J. Barkla, V.J. Higgins, y E. Blumwald. (1994). Plant defense response to fangal pathogens: Activation of host plasma membrana $\mathrm{H}^{+}$ATPase by elicitor-induced enzyme dephosphorylation. Plant Phisiol. 104: 209215.

Verberne, M.C., Budi Muljono, A.B., y Verpoorte, R. (1999). Salicylic acid biosynthesis.

Verhagen BW, Glazebrook J, Zhu T, Chang HS, van Loon LC, Pieterse CM. (2004). The transcriptome of rhizobacteria-induced systemic resistance in arabidopsis. Mol Plant Microbe Interact. Aug;17(8):895-908.

Vernooij, B., Friedrich, L., Morse, A., Reist, R., Kolditz-Jawhar, R., Ward, E., Uknes, S., Kessmann, H., y Ryals, J. (1994). Salicylic Acid Is Not the Translocated Signal Responsible for Inducing Systemic Acquired Resistance but Is Required in Signal Transduction. Plant Cell 6, 959-965.

Vick, B.A., y Zimmerman, D.C. (1984). Biosynthesis of jasmonic acid by several plant species. Plant Physiol 75, 458-461.

Vijayan P, Shockey J, Levesque CA, Cook RJ, Browse J. (1998). A role for jasmonate in pathogen defense of Arabidopsis. Proc Natl Acad Sci U S A. Jun 9;95(12):7209-14

Vogel, J.; Raab, T. K.; Schiff, C., y Somerville, S. C. (2002). PMR6, a pectate lyaselike gene required for powdery mildew susceptibility in Arabidopsis. Plant Cell, 14: 2095-2106.

Vollbrecht, E.; Veit, B.; Sinha, N., y Hake, S. (1991). The developmental gene Knotted-1 is a member of a maize homeobox gene family. Nature, 350: 241243.

Walker, J.C. (1994). Structure and function of the receptor-like protein kinases of higher plants. Plant Mol Biol 26, 1599-1609.

Wang, X,. Zafian, P., Choudhary, M., y Lawton, M. (1996). The PR5K receptor protein kinase from Arabidopsis thaliana is structurally related to a family of plant defense proteins. Proc. Natl Acad Sci U S A 93, 2598-2602.

Ward, E.R., Uknes, S.J., Williams, S.C., Dincher, S.S., Wiederhold, D.L., Alexyer, D.C., Ahl-Goy, P., Métraux, J.P., y Ryals, J.A. (1991). Coordinate Gene Activity in Response to Agents That Induce Systemic Acquired Resistance. Plant Cell 3, 1085-1094. 
Wasternack, C., y Hause, B. (2002). Jasmonates and octadecanoids: signals in plant stress responses and development. Prog Nucleic Acid Res Mol Biol 72, 165221.

Wendehenne, D., Pugin, A.; Klessig, D.F. y Durner, J. (2001). Nitric oxide: comparative synthesis and signaling in animal and plant cell. TRENDS in plant Science, 6: 177-183.

Wesley, S.V., Helliwell, C.A., Smith, N.A., Wang, M.B., Rouse, D.T., Liu, Q., Gooding, P.S., Singh, S.P., Abbott, D., Stoutjesdijk, P.A., Robinson, S.P., Gleave, A.P., Green, A.G., y Waterhouse, P.M. (2001). Construct design for efficient, effective and high-throughput gene silencing in plants. Plant J 27, 581590.

Weymann K, Hunt M, Uknes S, Neuenschwander U, Lawton K, Steiner HY, Ryals J (1995). Suppression and restoration of lesion formation in Arabidopsis Isd mutants. Plant Cell 7, 2013-2022.

Wildermuth MC, Dewdney J, Wu G, Ausubel FM. (2001). Isochorismate synthase is required to synthesize salicylic acid for plant defence. Nature. Nov 29;414(6863):562-5.

Woo HR, Chung KM, Park JH, Oh SA, Ahn T, Hong SH, Jang SK, Nam HG. (2001). ORE9, an F-box protein that regulates leaf senescence in Arabidopsis. Plant Cell. Aug;13(8):1779-90.

Wu, G., B.J. Shortt, E.B. Lawrence, E.B. Levine, K.C. Fitzsimons, y D.M. Shah. (1995). Disease resistance conferred by expression of a gene encoding $\mathrm{H}_{2} \mathrm{O}_{2}$ generating glucose oxidase in transgenic potato plants. Plant Cell 7, 1357-1368.

Xie DX, Feys BF, James S, Nieto-Rostro M, Turner JG. (1998). COI1: an Arabidopsis gene required for jasmonate-regulated defense and fertility. ScienceMay 15;280(5366):1091-4.

Xing, T., Higgins, V.J. y Blumwald, E. (1997). Race-specific elicitors of Cladosporium fulvum promote translocation of cytosolic components of NADPH oxidase to the plasma membrane of tomato cells. Plant Cell. 9, 249-259.

Xu L, Liu F, Lechner E, Genschik P, Crosby WL, Ma H, Peng W, Huang D, Xie D. 2002). The SCF(COI1) ubiquitin-ligase complexes are required for jasmonate response in Arabidopsis. Plant CellAug;14(8):1919-35.

Yahraus T, Chandra S, Legendre L, Low PS. (1995). Evidence for a Mechanically Induced Oxidative Burst. Plant Physiol. Dec;109(4):1259-1266.

Yang, Y., Shah, J. y Klessig, D.F. (1997). Signal perception and transduction in plant defense responses. Gene and development. 11, 1621-1639.

Yoder MD, Keen F NT, Jurnak F (1993). New domain motif: the structure of pectate Izase C, a secreted plant virulence factor, Science 206: 1503-1507.

Yoder OC, Turgeon BG, 't Westende YA (2001). Fungal genomics and pathogenicity. Curr Opin Plant Biol 4: 315-321. 
Zehnder, G.W., Murphy, J.F., Sikora, E.J. y Kloepper, J.W. (2001). Application of rhizobacteria for induced resistance. European Journal of Plant Pathology 107, 39-50.

Zeier, J., Delledonne, M., Mishina, T., Severi, E., Sonoda, M., y Lamb, C. (2004). Genetic elucidation of nitric oxide signaling in incompatible plant-pathogen interactions. Plant Physiol. 136, 2875-86.

Zhang S y Klessig DF (1998). The tobacco wounding-activated MAP kinase is encoded by SIPK. Proc. Natl. Acad. Sci. USA 95: 7225-7230.

Zhang, B., W. Chen, R.C. Foley, M Büttenr, y K.B. Singh. (1995). Interaction between distinct types of DNA-binding proteins enhance binding to ocs element promoter sequences. Plant Cell 7, 2241-2252.

Zhang, S., y Klessig, D.F. (2001). MAPK cascades in plant defense signaling. Trends Plant Sci 6, 520-527.

Zhang, Z,. D.B. Collinge, y H. Thordal-Christensen. (1995). Germin-like oxalate oxidase, a $\mathrm{H}_{2} \mathrm{O}_{2}$-producing enzime, accumulates in barley attacked by the powdery mildew fungus. Plant J.8, 139.145.

Zhou N, Tootle TL, Tsui F, Klessig DF, Glazebrook J. (1998).PAD4 functions upstream from salicylic acid to control defense responses in Arabidopsis. Plant Cell. Jun;10(6):1021-30.

Zhou N, Tootle TL, Glazebrook J. (1999). Arabidopsis PAD3, a gene required for camalexin biosynthesis, encodes a putative cytochrome P450 monooxygenase. Plant Cell.Dec;11(12):2419-28.

Zhu Q, Lamb CJ. (1991). Isolation and characterization of a rice gene encoding a basic chitinase. Mol Gen Genet. Apr;226(1-2):289-96.

Zhu, Q.; Maher, E. A.; Masoud, S.; Dixon, R. A., y Lamb, C. J. (1994). Enhanced protection against fangal attack by constitutive coexpression of chitinase and glucanase genes in transgenic tobacco. Bio/Technology, 12: 807-812.

Zhu, J.; Shi, H.; Lee, B. H.; Damsz, B.; Cheng, S.; Stirm, V.; Zhu, J-K.; Hasegawa, P., y Bressan, R.A. (2004). An Arabidopsis homeodomain transcriptional factor gene, HOS9, mediates cold tolerance through a CBF-independent pathway. Proc. Natl. Acad. Sci. USA, 101: 9873-9878. 

